\title{
The Art of Social Connection \\ Exploring Former Refugee and Host Society Integration via a Collaborative, Participatory Painting Project in Wellington City
}

\section{Amber Kale}

\begin{abstract}
A thesis submitted to Victoria University of Wellington in partial fulfilment of requirements for the degree of
\end{abstract}

\section{Master of Science in Geography}

School of Geography, Environment and Earth Sciences

Victoria University of Wellington 


\section{Abstract}

In light of the global humanitarian crisis, a climate of fear has arisen around refugees which is often exacerbated by the media perpetuating misinformation and negative stereotypes. Such misrepresentation is problematic as a skewed perspective of refugees, compounded with ethnic and cultural barriers to belonging, is leading to discriminatory practices in New Zealand. Thus, there exists an incongruence between New Zealand's non-discriminatory equal citizenship rights in law; and refugee and ethnic discrimination and marginalisation in processes of social integration. To begin to bridge this incongruence, this research explores how theories of social connection may be practically applied to enable more equitable social outcomes. A scholar activist orientation was employed, informed by a participatory action research epistemology. These philosophical foundations influenced a qualitative multi-method methodology consisting of painting workshops, semi-structured interviews, participant observation, and public feedback. Within the workshops, former refugee and host society participants explored how concepts of home, belonging, and visibility within public space are imagined, normalised, and contested within everyday practices of inclusion and exclusion in Wellington. These themes were significant in enhancing understanding of participants' unique experiences of displacement and place-attachment, and theorising how host societies might extend a more sincere welcome to newcomers. Applying a sociospatial relational framework to centralise participant interactions, I analysed how processes of social connection can begin to deconstruct negative refugee stereotypes, challenge normative conceptualisations of belonging, and enhance former refugees' access to citizenship rights. As New Zealand prepares to raise the annual refugee quota, such democratic explorations and representations of place are crucial in informing a multicultural social policy framework to guide equitable integration praxis and critical political debate.

\section{Keywords}

Former refugee, Host society, Painting, Participatory action research, Scholar activism, Social integration, Wellington 


\section{Acknowledgements}

As a community-based research project, this thesis could not have been written without the generosity, curiosity, knowledge, dedication, inspiration, and support of the Wellington, and wider New Zealand community. Many individuals, organisations, and institutions contributed to the funding, design, facilitation, and dissemination of this research, and all contributors deserve to be acknowledged and thanked for making this thesis possible.

The Kate Sheppard Memorial Trust helped to fund my research costs and Victoria University of Wellington supported my Masters' study through a Masters by Thesis Fees Scholarship. The trust and the university also provided website and media coverage to raise the profile of my project. The School of Geography, Environment and Earth Sciences provided me with a venue in which to hold the participant meetings and painting workshops, the audio-equipment to record data, and a quiet office space for me to read, reflect, and write.

My Masters' supervisor, Associate Professor Sara Kindon, and co-supervisor Dr. Polly Stupples, provided ongoing support and guidance throughout the research design, facilitation, writing, and dissemination. Perhaps more significantly, they encouraged me to pursue a topic I am passionate about, and their enthusiasm for my project matched my own.

Nick Tapper volunteered as my research assistant, helping to facilitate and record the painting workshops. Nick's contribution enabled the workshops to run smoothly and helped to prompt discussion, producing rich data for analysis.

ChangeMakers Refugee Forum, Red Cross, Make Foundation, Inverlochy Art School, Gordon Harris, the French Art Shop, the Friends of Timor community group, the Victoria Plus programme, ELT English Language School, my neighbours and friends, and many other individuals from Victoria University and the wider Wellington region assisted with participant recruitment through networking. 
Research participants each contributed roughly twelve hours over two months to attend meetings, interviews, painting workshops, and the exhibition presentation. The time, energy, knowledge, and inspiration participants have shared has given life to this project, making it vibrant, unique, and meaningful on both a personal and social level. Thanks are also due to the Preservatorium Café and Cannery for hosting the exhibition, and to all who came to view the mural and leave comments. Finally, thank-you to everyone who offered to help with the research, to my panel team members who presented with me at the Social Movements Conference, and to my friends, partner, and family who support and encourage me always.

I dedicate this thesis to Wellington city, in the hope that it may inspire other collaborative projects to strengthen our community, and that it may enable greater social justice and support for former refugees and for all those who come here seeking asylum and chasing dreams in the future. 


\section{Table of Contents}

$\begin{array}{ll}\text { Abstract and Keywords } & \mathbf{3}\end{array}$

$\begin{array}{ll}\text { Acknowledgements } & 4\end{array}$

Table of Contents 6

$\begin{array}{lr}\text { List of Figures } & \mathbf{8}\end{array}$

Chapter 1: Introduction 9

1:1 Context and aims

1:2 Research approach

1:3 Thesis structure

Chapter 2: Former Refugee and Host Society Integration

2:1 Citizenship rights

2:2 Visibility, agency, and social capital

2:3 Home and belonging

2:4 Chapter summary

Chapter 3: The Participatory Painting Project

3:1 Exploring a participatory action research (PAR) epistemology

3:2 A scholar activist orientation

3:3 A multi-method methodology

3:4 Participant recruitment

3:5 Data generation, collation, and dissemination

3:6 Applying a sociospatial relational framework of analysis

3:7 Chapter summary 
Chapter 4: Everyday Negotiations of Belonging

4:1 National identity and the right to belong

4:2 Symbolism, elicitation, and the creation of multilayered narratives

4:3 Change and displacement

4:4 Challenging hegemonic discourse

4:5 The role of humour in social interaction

4:6 Chapter summary

Chapter 5: A More Inclusive Citizenship

88

5:1 Hospitality and welcome

5:2 Emotional citizenship

5:3 Social citizenship

5:4 Chapter summary

Chapter 6: The Art of Social Connection

6:1 Methodological evaluation and recommendations

6:2 Key learnings

6:3 Informing social policy

Reference List

Appendices

1. Appendix One: Pilot painting workshop

2. Appendix Two: Participant recruitment

3. Appendix Three: Information, consent, and confidentiality forms

4. Appendix Four: Pre-workshop interview questions

5. Appendix Five: Workshop discussion questions

6. Appendix Six: Post-workshop interview questions

7. Appendix Seven: Exhibition flyer

8. Appendix Eight: Media dissemination 


\section{List of Figures}

Figure 1: New Zealand regional refugee resettlement locations...................11

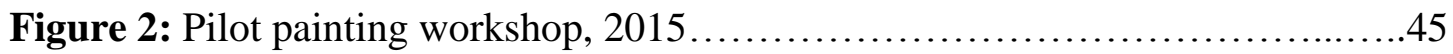

Figure 3: Sketching ideas.............................................54-55

Figure 4: Painting the mural............................................ 55

Figure 5: The exhibition presentation...................................57

Figure 6: A sociospatial relational framework............................66

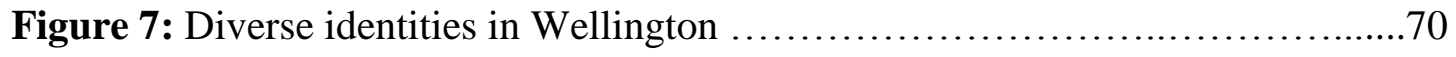

Figure 8: A link between home and a new life............................. 72

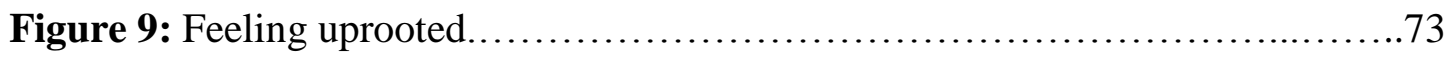

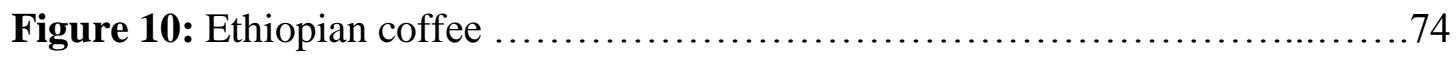

Figure 11: The 'family home' .......................................... 75

Figure 12: Our representation of the bucket fountain.......................... 76

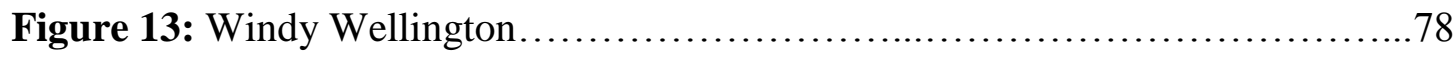

Figure 14: Yordanos' apple............................................... 84

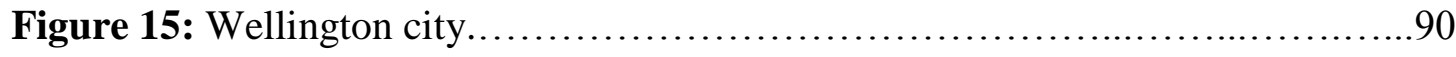

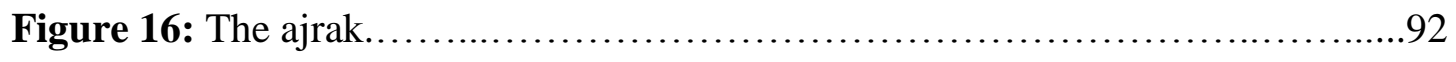

Figure 17: Carrying displacement and war................................ 93

Figure 18: Sharing music............................................. 96

Figure 19: Global citizens...........................................107 


\section{Chapter 1: Introduction}

\section{1:1 Context and aims}

\section{Research background}

In 2013, for the first time since the second world war, the number of displaced people worldwide exceeded fifty million (UNHCR, 2014). In 2017 asylum seekers and refugees fleeing from conflict are still inundating the borders of neighbouring countries in unprecedented numbers, risking their lives to traverse the seas in search of a safe place to raise their families. Through government, media, and social rhetoric, this rise in global displacement has become known as either the 'refugee crisis' or the 'European migrant crisis' (BBC News, 2017).

The United Nations (UN) 1951 Refugee Convention defines a refugee as someone who,

Owing to wellfounded fear of being persecuted for reasons of race, religion, nationality, membership of a particular social group or political opinion, is outside the country of his [sic] nationality and is unable or, owing to such fear, is unwilling to avail himself [sic] of the protection of that country; or who, not having a nationality and being outside the country of his [sic] former habitual residence as a result of such events, is unable or, owing to such fear, is unwilling to return to it (UNHCR, 1996).

Despite the masculine pronouns, this statement applies to all genders. Individuals who meet this definition are eligible to be selected by the UN to be resettled in a country which is signatory to the convention. The term 'asylum seekers' refers to people fleeing persecution who have not yet been granted refugee status, and refugees and asylum seekers are further distinguished from 'migrants' as they do not choose to move, but are forced to flee to ensure their safety (See UNHCR, 2016 and 2017).

Whilst the term 'crisis' does well to depict the magnitude of global forced migration and the urgency in which the world needs to address diverse causes of and solutions to displacement, it also lends itself to an air of overwhelming panic, which is problematic when linked solely to refugees or to Europe, and misleading when linked to migrants. Refugees are not the problem. They are the consequence of far deeper sociopolitical crises which remain unaddressed. Instead of working together to address these root 
causes, and in the meantime trying to accommodate refugees, many countries are fueling conflict, engaging in warfare, closing borders, building walls, and excluding those who have nowhere else to turn (Aljazeera, 2017; BBC News, 2017). Thus, what we are experiencing is not a refugee crisis but rather a humanitarian crisis.

Amidst this humanitarian crisis, a global climate of fear has arisen as the world discusses the possibility that terrorists may be strategically mobilised within emigration movements (Tsoukala, 2016). There is also a common perception that many refugees are bogus economic migrants, taking advantage of the current exodus from conflict areas to pursue a more prosperous life elsewhere (Kirkwood, McKinlay, \& McVittie, 2013). KhosraviNik (2010), McKay, Thomas, and Blood (2011), and O'Doherty and Lecouteur (2007) claim that the media has played a role in exacerbating these fears by perpetuating misinformation and negative refugee stereotypes, resulting in refugees being homogeneously labelled as illegitimate, illegal, and a threat to national security. These labels are problematic as members of resettlement nations, including many New Zealanders, are building a skewed perspective of refugees, which is leading to discriminatory practices within processes of social integration (Beaglehole, 2013, Ford, 2012).

Despite the increasing number of asylum seekers and refugees globally, New Zealand's annual UN refugee quota has stagnated at 750 places for the past 29 years. In response to a Wellington-based campaign to raise the quota (which I have been actively involved in since 2013), and growing pressure from human rights groups and the international community, the government recently announced that the new annual intake will be raised to 1000 places in the year 2018 (DoingOurBit, 2017). Whilst this figure is still embarrassingly low compared to the intake per capita of many other nations, there is also a need to match this new intake with adequate funding and support services.

Quota refugees granted asylum in New Zealand initially obtain the legal status of 'permanent residency'. Permanent residency confers the majority of citizenship rights, allowing residents to live, work, or study in New Zealand indefinitely (Immigration New Zealand, 2016). The terms 'former refugee' and 'refugee-background' are used within this thesis to acknowledge this change in legal status from being a refugee to a New Zealand resident (Immigration New Zealand, 2016). Those individuals who are 
accepted under the annual New Zealand quota have a six week orientation at the Mangere Refugee Resettlement Centre in Auckland before being resettled in either Auckland, Waikato, Manawatu, Wellington, Nelson, or Dunedin (Figure 1). Qualified social workers, case workers, cross-cultural workers, and trained volunteers then assist former refugees to understand New Zealand culture, navigate local systems, and find work (New Zealand Red Cross, 2017).

In addition to the UN quota, a further 300 places are set aside annually for refugees immigrating under New Zealand's 'family reunification' programme (which relies on a system of family sponsorship), and asylum seekers can apply for refugee status from within New Zealand. However, these resettlement categories do not necessarily guarantee permanent residency and access to full citizenship rights in New Zealand (New Zealand Immigration, 2017). Due to asylum seekers' unknown legal status and the possibility of expatriation - which could make processes of social integration far more complex - my research focuses only on those individuals who have formerly obtained refugee status.

\section{Figure 1: New Zealand regional refugee resettlement locations}

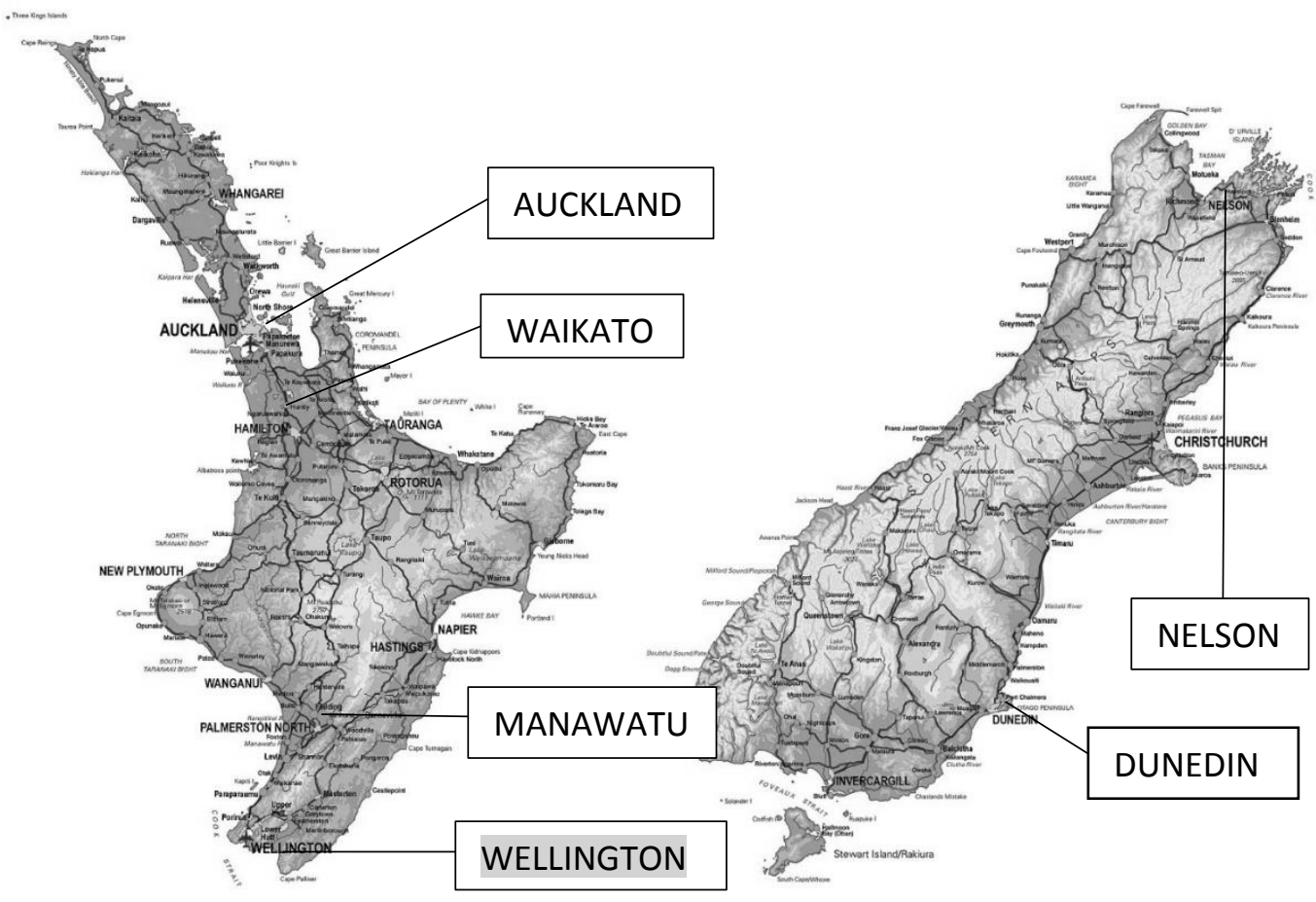

(Source: www.nztourmaps.com) 
Despite having citizenship rights and a brief introduction to life in New Zealand, resettling refugees often face a myriad of barriers to belonging (Kibreab, 2003). In Sibley and Liu's (2007) research on identity in New Zealand, participants from the dominant Pākehā (New Zealanders of European descent) and Māori (indigenous New Zealanders) ethnic groups claimed that New Zealand is a bicultural nation as stipulated in the Treaty of Waitangi, and that other ethnic groups do not have the same claim to belonging as themselves. This ethnic exclusion compounded with the stigma associated with refugee status, often contributes to former refugees feeling isolated from the wider host society. Thus, there exists an incongruence between New Zealand's nondiscriminatory citizenship rights in law, and refugee and ethnic marginalisation in processes of integration. This incongruence is problematic as a lack of support from dominant ethnic groups may isolate ethnic minorities, which could restrict former refugees' access to citizenship rights and lead to social inequalities (Beaglehole, 2013; Strang \& Ager, 2010).

\section{Research aims}

A key theory that aims to enhance cross-cultural relations is highlighted by Evans (2005), who claims that the world could be more 'homely' through processes of connection rather than otherness. Whilst Strang and Ager (2010) state that "the centrality of social connection in understanding refugee integration is well established in both policy and academic literature" (p. 596), more insight is needed into how theories of connection may be practically applied within an ethical framework, to ensure that citizenship rights do not remain an abstract ideology, but produce tangible equitable outcomes.

In light of this need, I decided to facilitate a community painting project in Wellington for my Masters. I selected Wellington as the research location as it is one of New Zealand's major refugee resettlement regions (highlighted in Figure 1). Due to my past refugee resettlement research, volunteering, and activism, I also had existing relationships with various refugee-background communities and local resettlement organisations in the city who were invaluable in providing support and local knowledge to enhance research rigour and ethical conduct. 
The project was informed by three broad sociopolitical objectives: to bridge academia, activism, and community development; to understand and enhance processes of former refugee and host society connection and social integration; and to improve access to rights for refugee-background New Zealanders. These goals far exceeded the capacity of the project; however, they are important to acknowledge as areas of academic and social development to which my research can contribute.

Through the project, this thesis aims to critically discuss the following question: How can collaborative, participatory painting processes enhance social connections between former refugees and Wellington host society members; advocate social justice for former refugees; and begin to bridge the incongruence between New Zealand's nondiscriminatory citizenship rights and exclusionary practices within processes of social integration?

I use the term 'host society members' to describe more settled, long-term residents. The popular use of the word 'host' in New Zealand refers to a temporary position whereby an individual, group, city, or nation might accommodate others as guests in a particular locale and accept responsibility to ensure that guests feel welcome and comfortable for the duration of their stay. To 'accommodate' is generally defined as an act of an individual or group making space for others, in terms of physical living space, psychological acceptance, and a tolerance or appreciation of diverse beliefs and needs.

This common understanding raises several contentions in the context of refugee integration. Firstly, there exists a power imbalance between hosts and guests - with hosts acting in leadership positions with control over the distribution of space and resources and the power to enforce certain etiquette (Thomas, Chiarelli-Helminiak, Ferraj, \& Barrette, 2015; Wilson, 2016). Thus, inequalities exist which could enhance processes of assimilation. Secondly, former refugees are legal residents or citizens they are not here as temporary visitors but are part of the host society themselves (Immigration New Zealand, 2016).

However, if we reconsider the notion of hospitality to be fluid, the term 'host society' aptly describes the temporary position of an existing society welcoming newcomers. Over time these 'guests' may themselves become 'hosts' and welcome others to the 
city. They may also become hosts through inviting others into their own homes or communities, or through entertaining others with various events and ideas (Wilson, 2010). Thus, the term host society is used to refer to settled Wellington residents who, upon the arrival of newcomers, have the responsibility of making space for them and enabling them to also become good hosts.

\section{Defining social integration}

Before proceeding, it is also important that I clarify the difference between social integration and assimilation. Assimilation is a process of newcomers replacing their prior traditions, cultures, and ways of life with the culture and etiquette of their new home. In short it is blending in, letting go, and becoming one of 'them' (Blunt \& Dowling, 2006). Such a process is not what I am advocating. Social integration on the other hand is about newcomers and long-term residents coming together to share their cultures and ideas, to learn from one another, and to acknowledge how diversity can enhance our communities and inspire future innovation and development (Strang \& Ager, 2010).

The term 'social integration' was first used by French sociologist Emile Durkheim in his explorations of the social causes of suicide (Durkheim, 1951). Durkheim perceived social integration to be a key process in the prevention of suicidal tendencies. Theorists researching happiness have also linked subjective wellbeing to the quality of social relationships, as further discussed in Chapter Two (Bruni, Comim, \& Pugno, 2008; Waldinger, 2016). Building on the perceived health benefits of social integration, the UN has developed a social integration branch within their Social Policy and Development Division. They state that,

An inclusive society is equipped with mechanisms which accommodate diversity, and facilitate/enable people's active participation in their political, economic and social lives. As such, it over-rides differences of race, gender, class, generation, and geography, and ensures equal opportunities for all to achieve full potential in life, regardless of origin. Such a society fosters, at the same time, emanates from well-being of each individual, mutual trust, sense of belonging and inter-connectedness (United Nations, 2017). 
Whilst 'inter-connectedness' is important in enabling effective social integration, the process of connecting need not 'over-ride' difference. Rather, differences need to be acknowledged to understand existing power imbalances and inequalities and the value of unique abilities, experiences, and knowledges. Difference is also downplayed through the common perception of integration as a 'two-way' process which acknowledges equal responsibility and requires equal contribution. Strang and Ager (2010) point out that, "The notion of a 'two-way' process, however, does bring with it the inherent danger of an implicit assumption that integration concerns the relationship between two distinct, but homogenous groups: the established population and the incomers" (p. 601). Such a distinction is problematic as former refugees do not constitute a homogeneous group, but maintain unique identities, as do members of the host society.

Due to the interplay of various unique identities, social integration is more than a reciprocal 'exchange' relationship; it involves multiple dynamic interactions and the (re)construction of society. Therefore, in tune with other human geographers and social scientists researching integration, I avoid the term 'two-way' and instead focus on collaboration to define diverse individuals or groups working together (Kindon, Pain, \& Kesby, 2007; mrs kinpaisby, 2008; Pulitano, 2012).

\section{1:2 Research approach}

\section{Epistemology and methodology}

To explore how collaborative, community-based research might contribute to more equitable social outcomes for former refugees, a scholar activist orientation was employed. This orientation was informed by a participatory action research epistemology (PAR), in which participants were actively engaged in the research process to enable more insightful participant representation and to ensure that the research has value to those whom it affects (Choudry, 2014; mrs kinpaisby, 2008). These philosophical foundations influenced a qualitative multi-method research methodology, consisting of painting workshops, semi-structured interviews, participant observation, and public feedback. 
Through workshop discussions, sketches, and the process of designing, painting, and exhibiting a large group mural, participants explored how ideas of home, belonging, and visibility within public space are imagined, normalised, and contested within everyday practices of inclusion and exclusion in Wellington. These themes were significant in enhancing understanding of participants' unique experiences of displacement and place-attachment, and theorising how host societies might extend a more sincere welcome to newcomers.

\section{Researcher positionality}

This creative project evolved through the intersection of my ongoing refugee resettlement research, my activism for refugee rights, and my professional work as a portrait artist. I spent four years on the road before starting university; working in Britain, travelling Europe, volunteering in Africa, and exploring Asia. I lived with local families, learnt different cultures, ate traditional foods, shared stories, painted these experiences, and connected with diverse people and places. Reflecting back, this stage of my life had far greater individual and social impact than my following years of undergraduate study, where I often felt disconnected from the world which I was studying. Yet, despite being eager to resume my travels, activism, and painting upon the completion of my degree, I realised that I could no longer do these activities justice without a deeper, more critical understanding of why I was doing them, and how they were impacting myself and others. I reasoned that if I could no longer study simply for the sake of building knowledge, and no longer travel, paint and protest uncritically, then I needed to find a way to interweave these once seemingly contrary identities to ensure that my artistic, activist, and academic pursuits had some purpose, some tangible outcome that could benefit the people and places who inspired such activities to begin with.

It is important to acknowledge that I am not a former refugee. I do not know how it feels to be persecuted or threatened, or what former refugees may need to comfortably resettle in different locations in New Zealand. As a fifth generation Pākehā and New Zealand citizen currently living in Wellington, I identify as a member of the Wellington host society. In this manner I am priviledged in that I associate with New Zealand's dominant ethnic and cultural group and am familiar with Wellington as a city. However, 
being part of the host society does not intuitively enable me to know how other host society members feel about living in Wellington, or how they feel about refugees and other newcomers resettling in this city. Therefore, for my research to benefit the diverse Wellingtonians on whom it focused, it was imperative that I drew upon the knowledge and experiences of individual participants, to avoid assuming the homogeneity of beliefs, experiences, and needs in any given research category, and to guide ethical research conduct and fair representation in dissemination (Choudry, 2014; mrs kinpaisby, 2008). Hence the significance of adopting a PAR epistemology.

\section{Ethics of representation}

In terms of the analysis of data, post-workshop interviews provided an opportunity for participants to evaluate the project in their own words. Their feedback and recommendations are interwoven with my own in the discussion, analysis, and conclusion chapters, to highlight multiple perceptions of the project and to represent diverse needs and unique knowledges and ideas.

Participants had the option of having their own name used within research dissemination to take credit for their contribution, or to remain anonymous for personal reasons (Appendix Three). Only one participant asked for a pseudonym to be used, supporting Evans (2004) claim that the imposition of confidentiality by standardised ethics regulations could be disempowering in participatory research where all contributions ought to be recognised and duly credited. For future reference, the pseudonym 'Sarah' is marked with an asterisk (*) to acknowledge that this is not the participant's real name.

Participants also consented to their artwork and photographs being represented in this thesis and any journal articles and news stories. During the workshops, individuals tended to adopt different roles in the creation of the mural. Whilst some were more involved in the conceptual and planning stages, others were more engaged in sketching or painting - depending on attendance, skills, strengths, and levels of comfort

participating in various stages. Due to this collaborative approach of drawing on different strengths and abilities, I've often credited images of different parts of the mural to the group - recorded by our project title of Inter-Mural Wellington. This group 
accreditation was especially significant for those times when three or four people worked together on one area. However, other images are credited to individual participants due to the very personal experiences they symbolise, or to recognise the time spent on this section, such as Ken discussing, researching, sketching and painting Wellington city (Figure 15).

\section{1:3 Thesis structure}

Chapter Two explores social, political, and geographical theories of citizenship rights, identity, visibility, home, and belonging. The purpose of this chapter is to contextualise my study within a broader field of academic research, and to gain insight into how these key theoretical concepts might shape processes of former refugee and host society integration.

Chapter Three then discusses the epistemological and methodological foundations of this research to acknowledge the ethical implications of particular approaches and methods. I outline the project methods in detail, working step by step through the interviewing, painting, exhibition, coding, and dissemination process, before mapping out a sociospatial relational analytical framework which centralises the study of relationships between former refugee and host society participants. This framework provides a lens through which inductive research findings can be critically examined, taking into account both the proximate social interrelations and the wider national and global connections that are shaping Wellington as a unique multicultural home and city.

In Chapter Four I discuss the thematic content emerging from the project explorations of home, belonging, and public visibility, as well as the relationship building techniques participants used to enhance workshop cooperation and enjoyment. I examine how the Treaty of Waitangi and New Zealand's postcolonial bicultural identity includes or excludes different groups and individuals, as well as other identity tensions which were raised when negotiating who to represent in our mural. I then explore how the use of symbolism, and the creation of multilayered narratives can enhance understanding of the multiple nuanced values and meanings of place and belonging. I also discuss how the development of people and city systems and structures can lead to a sense of 
displacement from or attachment to place, and how participants' changing perceptions of what it meant to be a 'refugee' or a 'New Zealander' shaped their integration experiences. Following on from these discussions, I aim to highlight how participants' use of humour throughout the workshops empowered individuals and enhanced social connections.

Chapter Five draws on theories of hospitality, welcome, and emotional and social citizenship to explore the interplay of citizenship rights, responsibilities, and everyday practice. In particular I focus on the way in which social dynamics and power imbalances change over time and place and due to different resources, and how such fluid, relational positionalities shape processes of home-making and sentiments of belonging.

Chapter Six concludes the research by evaluating the qualitative multi-method methodology and making recommendations for future participatory painting projects. Through revisiting the research question, I then distil the key findings from the previous chapters, before discussing the value of this research in informing a multicultural social policy framework to shape future integration praxis and political debate. 


\section{Chapter 2: Former Refugee and Host Society Integration}

This chapter focuses on social, political, and geographical theories of citizenship rights, identity, visibility, home, and belonging. These themes are significant in enhancing understanding of processes of social integration, as they shape everyday practices of inclusion or exclusion for resettling refugees through the restriction and negotiation of legal, physical, social, and psychological barriers. The aim of this chapter is to theoretically inform a participatory painting project which explores the development of social connections between former refugee and host society participants in Wellington, and which analyses how such connections may enhance social integration and enable more equitable outcomes for marginalised groups within New Zealand.

\section{2:1 Citizenship Rights}

\section{Civil citizenship configurations}

Around the world, civil citizenship (concerning the legal status of a nations' constituents) is configured in unique ways, conferring or denying rights to individuals depending on their nationality, race, ethnicity, gender, sexuality, age, religion, or ability. In the majority of 'developing' countries, (identified as relatively underdeveloped in terms of global socioeconomic opportunity) the citizenship rights conferred on an individual depend upon their nationality - the legal status of 'belonging' to a particular nation, rather than taking into consideration residency - the place where they currently reside (Kibreab, 2003). In these contexts, people who are citizens have full rights within 'their' country, whereas non-nationals (asylum seekers, refugees, or other immigrants) are not granted the same security, freedoms, or opportunities. In comparison, New Zealand, Australia, North America, and European Union member states provide non-nationals with almost the same rights as citizens (Kibreab, 2003). As mentioned in Chapter One, UN quota refugees resettling in New Zealand are legally considered New Zealanders and are entitled to full residency or citizenship rights (Immigration New Zealand, 2016). 
Kibreab (2003) argues that conditions in resettlement countries shape former refugees' choices to remain in that country or to return to their former country once it is 'safe' to do so. In countries where former refugees enjoy a decent standard of living and have the opportunity to one day become citizens, they tend to stay residing in the resettlement country even when it may be considered safe for them to return 'home'.

In the case of New Zealand, Kibreab's argument is supported by Searle, Prouse, L'Ami, Gray, and Grunner (2012), who claimed that 97 per cent of former refugees had applied for or been granted citizenship in New Zealand after ten years of entering the country as permanent residents. When asked why they chose to stay, "most replied that they felt New Zealand was their home, they wanted to feel part of New Zealand society or because they had lived in New Zealand for a long time" (p. 108). Yet, despite citizenship conditions in New Zealand being relatively favourable, many former refugees report experiences of discrimination, exclusion, and inequality (Beaglehole, 2013).

As well as discrimination based upon nationality, citizenship rights can differ depending on an individual's gender. In many countries men have more rights than women. Even in countries where equal gender rights are present, male-dominated systems do not always ensure that womens', or other gendered identities', rights are upheld in practice (Burn, 2011). The New Zealand Ministry for Women claims that, "New Zealand women enjoy the protection afforded through a strong statutory framework giving them full and equal rights" (Ministry for Women, 2016). However, New Zealand women have higher rates of unemployment and underemployment than men, there are far fewer women in leadership roles, and women are generally paid less for their work (Human Rights Commission, 2016b).

Racial, ethnic, religious, and sexual orientation-based inequalities also persist in New Zealand. The New Zealand Human Rights Commission states on their website that, "Pay differences are accumulative for some groups. Gender and ethnic pay gaps for example compound so that Pacific and Māori women are paid less per hour than European women” (Human Rights Commission, 2016b). People of other genders also face employment discrimination, and inequalities within the workforce are only one aspect of discrimination which prevents ethnic minority groups from accessing their rights as New Zealand residents and citizens. In terms of religion, there remain unequal 
privileges for Christians based on a British colonial legacy of Evangelism, despite New Zealand being considered a secular nation (Morris, 2009). Rights do differ by age in New Zealand, with laws generally implemented to protect children from exploitation and abuse; however, they too may be ineffective in practice (Community Law, 2016).

Therefore, whilst Kibreab (2003) claims that New Zealand has an ethically commendable citizenship framework for former refugees in legal terms, and Searle et al. (2012) claim that the majority of resettled refugees are content to make New Zealand home, there remains a need to ensure that the rights residency and citizenship confer are fair, practically accessible, and upheld so that all former refugees (and other New Zealanders) can integrate and fully participate in and contribute to society.

\section{Identity, performance, and market-based citizenship}

Sibley and Liu (2007) and Mortensen's (2008) research shows that whilst certain ethnic groups are growing within New Zealand, particularly the Asian community, these groups remain marginalised as both Pākehā and Māori participants considered New Zealand to be 'our' place where 'we' belong and others do not. Sibley and Liu (2007) claim that, rather than ethnic-national relations being based on power or economic imbalances, their research highlighted "primarily symbolic associations between national identity and ethnicity" (p. 1240). These symbolic associations of Māori and Pākehā inheriting the right to call New Zealand home have historic basis in the bilateral Treaty of Waitangi, which was signed in 1840 by Captain William Hobson and several other English settlers, and between 43 and 46 Māori chiefs (Waitangi Tribunal, 2016). The treaty is considered a legal foundation for New Zealand sovereignty and provides an emotional foundation for 'nationhood' (defined as a collective sovereign identity) (Sibley \& Liu, 2007).

It is important to note here that the Treaty is constantly being renegotiated to make sense of its contested translation and multiple interpretations. The Waitangi Tribunal operates to explore colonial injustices perpetrated by the British Crown against Māori, and to set right past wrongs and return stolen land (Waitangi Tribunal, 2016). Yet, despite the tribunal, inequalities still persist between Māori and Pākehā. Māori are underrepresented in New Zealand leadership positions, higher education, and positive health indicators, and overrepresented in New Zealand's prisons and poverty indicators 
(Marriott \& Sim, 2015; Te Ara, 2016). Thus, a bicultural national identity does not necessarily signify a cohesive or equitable nation in practice. Rather, it represents an ideological perspective of New Zealand, and the right to belong in this nation has long been contested and may be a sensitive topic for long-term New Zealanders and newcomers alike.

The significance of exploring ideas of 'belonging' within citizenship, is that citizenship is more than just a legal status for the sake of governance. Like the Treaty, citizenship provides an emotional foundation for nationhood, as well as shaping the conduct of citizens. In this manner, it is also an ideology and a practice - shaping worldviews and being performed through everyday actions. This lived aspect of citizenship is evident in Humpage's (2008) empirical literature review on citizenship in New Zealand, which shows that despite a strong ethnic-national link, "the most frequently mentioned characteristic of a good citizen was "community participation" (volunteer work, neighbourliness, actively caring for others, contributing to society)" (p. 123). Combining Sibley and Liu (2007) and Humpage's (2008) findings, there is the implication that belonging in New Zealand depends primarily on being Pākehā or Māori; yet people of other ethnicities can still be good citizens if they 'perform' as such by participating in and contributing to society.

The New Zealand government adopts a performative-based approach to citizenship, in particular focusing on market citizenship. According to Nawyn (2011), market citizenship “defines state membership based on a person's economic productivity” (p. 679). As an 'investment' into economic productivity, the New Zealand government provides short-term, minimalistic social welfare for resettling refugees (as well as other eligible New Zealanders) with the long-term goal of securing financial independence through work (New Zealand Immigration, 2016). This emphasis on employability is also reflected in the New Zealand Refugee Resettlement Strategy. The strategy focuses on five integration outcomes for former refugees consisting of: employment, education and training, English language, inclusion, and health and wellbeing. New Zealand Immigration claims on their website that,

Of the five, the employment and education and training goals are considered the two most important because they have the greatest impact on the government's plans for 
business growth. The Strategy outcomes are aligned with the government's Business

Growth Agenda which focuses on building a more productive and competitive economy (New Zealand Immigration, 2016).

Whilst employment is important for individuals, families, communities, and for national development, a focus on market citizenship fundamentally overlooks the humanitarian issue of refugee resettlement and New Zealand's obligations under international law. By aligning welfare and employability tactics with New Zealand's Business Growth Agenda, the New Zealand government prioritises forms of assistance which yield a higher economic return, rather than prioritising the wellbeing of those who most require our protection (ChangeMakers Refugee Forum et al., 2011; Human Rights Commission, 2016a).

Furthermore, a lack of English language proficiency, local knowledge, physical mobility, insufficient childcare options, and limited social connections, as well as the stigma of being a refugee, may prevent individuals from gaining education and employment, being welcomed to social events, and engaging in politics. These barriers have been recognised as hindering integration for refugee-background women in particular (Bose, 2014; Kale \& Kindon, 2016; Martin, 2008; Swe, 2013; Urry, 2012). Thus, the ability of many former refugees to meet expectations that may be perceived to constitute the right to belong as citizens, such as participating in and contributing to society, can be severely compromised.

\section{Social and emotional citizenship}

To address this gap between expected and realistically achievable citizenship performance, social citizenship is needed. Marshall (2006) defines social citizenship as "the right to defend and assert all one's rights on terms of equality with others and by due process of law" (p. 30). This involves the state, non-governmental organisations (NGOs), and wider host society working together to provide the appropriate welfare, services, networks and relationships to support individuals, families, and groups in meeting their basic needs and being able to participate in society free from discrimination.

NGO 'ChangeMakers Refugee Forum' in Wellington exemplifies social citizenship through their driving programme for refugee-background women. A lack of transport 
has been linked with decreased opportunities for study, work, and social participation, and can provide challenges for accomplishing basic tasks such as dropping children off at school and doing the shopping, or taking family members to the doctors (Bose, 2014; Kale \& Kindon, 2016; Martin, 2008; Swe, 2013; Urry, 2012). Throughout the process of refugee-background women obtaining a license, host society members and former refugee women work together to strengthen community relations and offer a holistic support system which involves interaction between police, driving instructors, community road safety organisations, English language services, and local community members (Kale \& Kindon, 2016). This collaborative process constitutes social citizenship as support from the host society is enabling a marginalised group to access the rights and opportunities they are entitled to and to participate fully in society as equal and valued New Zealanders.

To enhance social citizenship practice, Askins (2016) and Wood (2013) argue that understandings of citizenship need to be more inclusive, focusing on individuals' diverse experiences of being a citizen, and to what extent people feel like they belong. Through her empirical research which explores a befriending scheme between refugees, asylum seekers, and more settled residents in Newcastle, England, Askins (2016) claims that, "It is precisely the emotional that opens up the potential of/for making connections, and through which nuanced relationships develop, dualisms are destabilised, and meaningful encounters emerge in fragile yet hopeful ways" (p. 515).

Wood's (2013) research explores citizenship narratives of New Zealand secondary school students, drawing on empirical data generated through her wider 2008-2010 citizenship study. She also claimed that social participation and contribution was found to be strongly correlated to an individual's emotions and feelings, which were impacted significantly through their encounters with other students. Thus, there is a need for social citizenship to be understood in relation to emotional citizenship.

By building upon ChangeMakers, Marshall (2006), Askins (2016), and Wood's (2013) approaches of centralising individual emotions and social interactions within citizenship theory and praxis, scholars and resettlement practitioners can avoid simplifying social integration as a 'two-way' dialectical process which homogenises groups. Avoiding these binary categories can create more equitable, inclusive spaces 
for new social connections to be formed and greater senses of belonging to develop (Kindon et al., 2007; mrs kinpaisby, 2008; Pulitano, 2012; Strang \& Ager, 2010).

\section{2:2 Visibility, agency, and social capital}

\section{(Mis)Representation in the media}

Social constructions of place and identity within mainstream media and other forms of political discourse are often used to justify the inclusion or exclusion of asylum seekers and refugees in countries of resettlement. Through Kirkwood, Mckinlay, and McVittie's (2013) discursive analysis in Scotland they found that, "constructions of asylum seekers' and refugees' countries of origin as dangerous, and the host society as relatively problem-free, function to constitute their identities as legitimate and to justify their presence in the host society" (p. 453). When people perceived that refugees were economic migrants, simply in search of a more prosperous life, then they tended to view their claim for asylum as 'bogus' and 'greedy'. Whereas, when they became aware of the harsh conditions refugees were facing, they often accepted that asylum was justified as a humanitarian response. One local Scottish participant claimed that,

That was the way I portrayed them ... they were just selfish people just running for where they get the best ... but once I've come here and listened to a few stories ... I realised these countries have got problems, they've been splitting up families they're war-torn ... they're actually in fear of their ... lives (Kirkwood et al., 2013, p. 456).

O’Doherty and Lecouteur (2007) highlight how specific terms and categories used within the media shape public misperceptions of asylum seekers and refugees as 'unlawful'. In response to an article in the Australian newspaper, The Advertiser, they claim that, the use of the term "illegal immigrant" has legitimised the idea that asylum seekers don't have the right to be there and ought to be sent home. Global media has also played a role in the common misperception of refugees as terrorists - through selective and exaggerated reporting of 'risks' which remain unsubstantiated and contribute to public fear, panic, and prejudice amongst people who may have limited experience or contact with refugees (KhosraviNik, 2010; McKay et al., 2011). This fear is problematic as people around the world are building a skewed perspective of 
refugees, which allows stereotypes and discriminatory views to fester (Ford, 2012; Happer \& Philo, 2013).

However, whilst media often perpetuates negative refugee stereotypes and misinformation, KhosraviNik (2010) also points out that, "The role of discourse and mass media is paramount in not only disseminating potentially prejudiced ideologies but in re/constructing and re/creating the attitudes and "knowledges"' (p. 3). Thus, discourse could be utilised to share alternative narratives, as exemplified via The Dominion Post (2016), and The Press (2016) in New Zealand, which over the past few months have been running articles sharing local refugees' stories and accomplishments.

Yet, Nawyn (2011) highlights how even some positive representations, such as the depiction of refugees as 'model' citizens, require careful consideration.

By framing refugees as hard-working future contributors deserving of assistance, NGO staff engage with and ultimately submit to the requirements of market citizenship by using refugees' future economic productivity as the justification providing them welfare assistance (Nawyn, 2011, p. 680).

Such representations are problematic as they reserve the social status of 'belonging' for the rich or most-likely-to-succeed-economically over those most in need or with other valuable contributions to make. This is illustrated in the article by The Press (2016), where the main resettlement focus is on the education and occupations of those interviewed, rather than the social relationships they are forming, their general wellbeing, and their personal goals and achievements.

Social media and online blogs or comments can also perpetuate negative stereotypes and misinformation; however, Fozdar and Pedersen (2013) claim that due to their democratic nature, "Blogs are potentially useful sites for the development of communicative consciousness in relation to race issues, particularly the challenging of racism" (p. 321). Thus, viewers are gaining a more comprehensive understanding of the different perspectives and politics at play and can generate the dialogue and debate which is absent in many sources of mainstream media. 


\section{Visibility and agency}

Whilst former refugees are currently very visible in international and national media, social media, and political rhetoric, they remain underrepresented in social, political, and media decision-making processes (Bifulco, 2013). Thus, the majority of refugee representation oppresses refugee voices and lived experiences and can be unfair and often misleading. In response, Lollar (2015) notes that invisibility may become a shortterm strategic move for resettling refugees to avoid unwanted attention and as a form of protection.

Immigrants, now labeled as criminals and illegals, are increasingly highly visible in the news and the political realm putting them at increased risk of action against their presence. They slip below the radar to minimize their vulnerability, not an unreasonable choice for one thrown into criminal status (Lollar, 2015, p. 309).

In a way, strategic invisibility can be viewed as expressing agency - making a rational choice to disengage from public life to protect oneself. Invisibility appears to be a rational response when considering New Zealand's historical immigration policy biases which have favoured racial or ethnic groups who are considered 'similar' to New Zealanders. In this context, the New Zealand government has encouraged former refugees to assimilate - to cut ties with their former communities and identify with the host society (Beaglehole, 2013).

Yet, whilst invisibility involves choice, it is a very limited choice. In his 1968 book Le Droit à la ville, Lefebvre introduced the concept of the 'right to the city', arguing for more equal access to urban life. He argued that the opportunity to participate in social and political life ought not to be reserved for an elite population, but to be available to all residents. Building on this idea, Harvey (2003) claims that rather than simply enhancing access to resources, equal access to urban life involves increasing agency enhancing one's ability to change the city and society. Thus, whilst exposure may not always be appropriate, and at times could be disempowering, Lollar (2015) reiterates the need for public visibility to enhance refugees' opportunities for agency and to challenge the threats or oppression that leads to becoming invisible. She also claims that the opportunity to participate in social life relies on involvement from other 
members of society to open doors for new settlers - in other words, to practice social citizenship.

\section{Enhancing social connections}

A key concept that could enhance social citizenship is social capital, which refers to the human relational networks that enable effective social cooperation and trust in others. Social capital generally consists of social bonds, bridges, and links. Social bonds include non-governmental partnerships, such as family, friends, or close community groups, who provide support to individuals to improve social outcomes (Putnam, 2007; Strang and Ager, 2010). Social bridges aim to create spaces for diverse 'bonded' communities to interact and connect with one another and the government, in an environment that encourages reciprocity and aims to build mutual trust (Colson, 2003; Strang \& Ager, 2010; Thomas et al., 2015). Thus, social bridging enables social links through the establishment of networks and the provision of opportunities for marginalised groups to participate in wider social and political life, and access their full residency or citizenship rights (Kale \& Kindon, 2016; O’Neill \& Hubbard, 2010; Strang \& Ager, 2010; Tolia-Kelly, 2008).

Within refugee resettlement discourse, there are critiques that a focus on social bonding assimilates newcomers into ethnic subcultures, which can segregate ethnic groups into isolated enclaves rather than integrate them with the wider society (Beaglehole, 2013; Strang \& Ager, 2010). Whilst some former refugees may fare better by distancing themselves from their ethnic communities, there is a risk of individual isolation for individuals with no ethnic group support. This individual isolation arises in part due to former refugees' lack of local knowledge, as well as mutual cultural and language barriers between former refugees and host society members hindering cross-cultural relationships. Thus, Strang and Ager (2010) claim that bonding is important to provide support to former refugees in situations where the host society may not be resourced or able to do so.

Putnam (2007) also argues that bonding social capital preludes bridging social capital. In his nationwide survey analysis of diversity and social capital in the United States of America, he claimed that people find it easier to trust others and cooperate when they are in close social proximity and have a shared sense of identity. In more ethnically 
diverse neighbourhoods where shared identity was lacking, residents reported feeling more socially isolated from those of different ethnicity and from their own ethnic group. Therefore, Putnam (2007) argued that there is a need for more meaningful social interactions to strengthen relations within and across ethnic groups to enhance shared identities and a sense of belonging. He claims that, "The challenge is best met not by making 'them' like 'us', but rather by creating a new, more capacious sense of 'we' ( $p$. 163-164). This broader sense of shared identity creates a space for multiple identities to be interwoven (Cresswell, 2004).

Research on happiness and subjective wellbeing also tends to support the social capital model discussed by Putnam (2007) and Strang and Ager (2010), though happiness has been largely overlooked in macro level analyses of integration. Bruni, Comim, and Pugno (2008) claim that, "A robust finding of happiness research has been the strong association between good social relationships and subjective well-being" (p. 72). In his TEDx talk The Good Life, Robert Waldinger, the fourth director of the longitudinal Harvard Study of Adult Development, states that, "People who are more socially connected to family, to friends, to community, are happier. They are physically healthier, and they live longer than people who are less well connected". He also says "it's the quality of your close relationships that matters" (Waldinger, 2016).

The significance of this is that happier people are 'better' people - more likely to volunteer and contribute to society, and more trusting of others (Bruni et al., 2008). Such qualities directly align with the qualities which New Zealanders claimed make a 'good citizen' (Humpage, 2008). These theories together depict a positive feedback loop, whereby a focus on building strong community relations enhances an individual's happiness and subjective wellbeing, which in turn makes individuals more likely to participate and contribute to society, strengthening relations and enhancing the wellbeing of others (Lyubomirsky, 2008). Applying this feedback loop to Strang and Ager's (2010) integration model, social bonding enhances subjective wellbeing, leading to wider community participation and social bridging, which increases trust and reciprocity and enables greater support networks to develop for marginalised communities. This link between subjective wellbeing and enhanced social participation 
and contribution reiterates Askins (2016) and Wood's (2013) calls for a more inclusive emotional citizenship which focuses on individuals' experiences of being a citizen.

\section{2:3 Home and belonging}

\section{More than just a 'dwelling'}

Many former refugees who have applied for or been granted citizenship in New Zealand chose to stay because they felt as though New Zealand was their home and they wanted to feel part of New Zealand society (Searle et al., 2012). This emotional attachment to people and place through a sense of being 'at home' is significant to explore within

citizenship and social integration discourses, as the concept of 'home' has become increasingly important in regards to theorising and implementing solutions to the global humanitarian crisis and enhancing a sense of belonging for resettling refugees (Kibreab, 2003). Yet, academics have acknowledged the complexity of defining home, especially for people who lead mobile lives or who are navigating unfamiliar territory.

Some of the key questions within existing literature on home, inquire as to what home means to individuals and where home is (Blunt \& Dowling, 2006). Fitzpatrick (2002) claims that home is,

Something many of us take for granted. We come home to loved ones, safety, special spaces, and important memories. These elements are crucial to our sense of security, meaningfulness, and identity in the world. To find home - a feeling of belonging in a known social and geographic space - is fundamental to our sense of who we are. For refugees, many of whom have experienced war, oppression, and poverty, the need to seek an experience of home is a primary yearning (p. 151).

Whilst Fitzpatrick highlights how significant home is to an individual's sense of identity, belonging, and security, there are two key problems that arise from her statement. The first is that home is described as safe, special, and important. Such an understanding tends to represent an ideology of what home should be, and is exclusive to any contrary or negative experiences. As Blunt and Dowling (2006) claim, home may also be a place of insecurity, violence, and terror, and therefore, it ought to be recognised as subjective, contextual, and complex. Experiences should not be discredited if they 
do not represent the positive experiences of home that people typically yearn for. Rather, diverse and sometimes contradictory understandings of home are important in comprehending the significance of what refugees may have lost, and the value of what they are (re)creating.

The second problem with this statement is that Fitzpatrick defines home as a known social and geographic space. However, this does not account for homes made in unknown territory - in unfamiliar regions, refugee camps, detention centres, and foreign countries. It also does not account for temporary residence or nomadic lifestyles. Cresswell (2004) characterises such a 'fixed' or 'rooted' worldview as sedentary metaphysics. He claims that the problem with a sedentary perspective is that "people who lead mobile lives, either through choice or compulsion are seen as necessarily threatening" (p. 8). Thus, there are many challenges for refugees who are mobile and generally perceived as homeless or stateless.

Other theorists, such as Warner (1996), argue that rather than home necessarily being fixed or rooted to a specific location, it is often social relationships which connect people to different places. Al-Ali and Koser (2002) agree, claiming that, "Concepts of home are not static but dynamic processes, involving the acts of imagining, creating, unmaking, changing, losing and moving 'homes"' (p. 6). Taylor (2013) explains that, "This allows for the possibility that refugees might maintain a deep, emotional attachment to the lost home, while at the same time making a new home in the country of exile, or indeed in another country altogether" (p. 132). These authors do not argue that a dwelling (house or other place of residence) or geographic locale is unimportant in conceptualising home, but rather that home is primarily created through meaningful relationships, and can exist as a sentiment detached from a particular place as something imagined and shared (Anderson, 2006), or as multiple places which are linked in various ways over time and space.

\section{The nation as home}

Home can also be viewed at diverse scales, as a house, neighbourhood, community, city, country, continent, or even the world. Thus, the concept of home is not only important to individuals and groups, but has great social and political significance for nationhood and matters of national security. Nationhood refers to the uniting of people 
with shared politics or culture as a sovereign group (George, 1996). In this manner, a distinction is made between those who are members of the nation and those who are not, and national identity is constructed upon in-group similarities contrasted with outgroup differences.

Blunt and Dowling (2006) claim that in today's climate of fear surrounding global, national and local acts of terrorism, it has become more difficult to feel at home in the world and safe with strangers. Thus, matters of national security are closely linked with constructions of the nation as home. Walters (2004), has termed the intersection of home, land, and security 'Domopolitics'. He presents two key understandings of this term, whereby domo refers to "home as our place, where we belong naturally, and where, by definition, others do not" (p. 170), as well as referring to conquest, "a will to domesticate the forces which threaten the sanctity of home" (p. 242). In this manner, the nation-as-home is exclusive to new residents unless immigrants are prepared to acquiesce to assimilation and replace their old home with the new.

Some refugees may prefer this type of resettlement. As a Somali participant in Elliot and Yusuf's (2014) research in New Zealand claimed, "We need to move on or move away from the back-home politics and just focus on here. Simply to say, 'Here's our country, here's our home' - how can we be part of this?" (p. 109). Yet, as McNeill (1994) and Blunt and Dowling (2006) highlighted above, others cannot let go of their past home so easily and may retain diverse cultural traditions or create new hybrid identities. Whilst a nationalist sentiment serves to unite citizens through shared or imagined camaraderie and a sense of mutual belonging, it also homogenises citizens, overlooking diversity within a nation (Anderson, 2006; Gellner, 1983). This is problematic as mainstream politics and culture within different nations are not necessarily representative of the diverse populations living within their borders, and thus, minority groups who do not 'fit' with the dominant nationalist sentiment are often marginalised.

To include resettling refugees in society in a manner that feels more 'homely', Evans (2005) argues for a focus on processes of social connection rather than otherness. Prioritising social connections is significant as Fitzpatrick (2002) and Warner (1996) 
argued that relationships are central to creating home. Many local refugee resettlement organisations are building such connections via their own explorations of 'home'.

Through a Canadian church-group project titled There's No Place Like Home, locals are finding innovative ways to strengthen community relations by fundraising together for new housing for refugees (Saanich News, 2016). The Refugee Art Project (2016) in the Australian Villawood Detention Centre has a gallery exhibition called Memories of Home, through which asylum seekers' paintings are shared with the wider host society, and the Make Foundation (2016) in New Zealand recently facilitated a collaborative painting project between former refugees and schoolchildren in Wellington titled What Is Home? These projects all aimed to enhance social capital by bridging diverse social groups. Through creative and collaborative community development, the projects challenge normative assumptions of home and co-construct spaces for former refugees to make new homes.

\section{Diasporic home-making}

Concepts of multiple homes have inspired theorists to question whether the existence of transnational communities requires the notion of home to be reconsidered, and to explore how homes are made in the context of migration and through processes of integration (Blunt \& Dowling, 2006; Smyth, Stewart, \& Da Lomba, 2010). McNeill (1994) claimed that technological advances in transport and communication make it easier for immigrants to maintain their cultural identity in foreign places as they can "inhabit two different worlds simultaneously, dealing part of the time with aliens and part of the time with familiars, even if some of their familiars happen to live in another country, many miles away" (p. 304). With further technological advances in social media communications in the past couple of decades since this article was published, this point has accrued even greater significance.

Whilst time/space compression through enhanced communication may offer security through multiple support networks and diverse opportunities, it can also create confusion and tension through contradictory cultural messages, which can lead to alienation when refugees feel as though they belong neither 'here' nor 'there' (Blunt \& Dowling, 2006). Cresswell (2004) claims that, "The mapping of particular meanings, 
practices, and identities on to place ... leads to the construction of normative places where it is possible to be either 'in place' or 'out of place"' (p. 5).

In O’Neill and Hubbard's (2010) participatory arts project in the English East Midlands, refugees and new arrivals guided residents in a walking event through the city, "tracing an imaginary and real journey that linked the here and now with the then and there" (p. 46). In another participatory arts-based project, in which British Muslim immigrants recorded their affective experiences of being in the Lake District, Tolia-Kelly (2008) claims that, "The Lake District calls upon translocal memories of other landscapes and mobilities to construct a different sense of the 'national' landscape of England, striated by difference" (p. 134). In both of these studies, former refugees were acknowledged as social actors who contribute to the creation of home and a sense of belonging through attributing various values and meanings and cultural and personal nuances to local landscapes. Thus, diasporic home-making involves a dynamic, transformative process through which hybrid places, traditions and cultures emerge (Blunt \& Dowling, 2006). Due to such an interactive process, it is important to not only focus on former refugees in theories of social integration, but rather to centralise the relationships between former refugees and members of the host society, and to acknowledge the role of place in bringing these groups together or distancing them, geographically, socially, or emotionally.

\section{2:4 Chapter summary}

Strang and Ager (2010) claim that there is still much to be explored between frameworks of citizenship rights and processes of integration. This is evident in the incongruence between New Zealand's legal framework which confers equal rights regardless of nationality, race, ethnicity, gender, religion and sexuality; and the country's bicultural national identity which portrays an unequal legitimisation of Māori and Pākehā belonging. Citizens and residents of other ethnicities are generally welcome in New Zealand, though often remain marginalised due to a variety of social, political, linguistic, cultural, and mobility barriers. For former refugees, ethnic discrimination can compound the existing challenges that come with refugee status. 
To create a more inclusive society in practice, I agree with Evans (2005) that processes of social connection need to be prioritised. Greater host society support is needed for resettling refugees, in particular from the dominant Māori and Pākehā ethnic groups. Such support would constitute social citizenship, as it could improve access to civil citizenship rights and enhance social justice for marginalised groups. However, to enhance host society support, a shift is needed from social services prioritising physical integration needs such as employability, economic capital, and market citizenship, to prioritising emotional and social integration needs such as enhancing social connections, challenging exclusionary practices, and deconstructing harmful stereotypes. Enhancing social capital and subjective wellbeing can then assist former refugees in confidently applying for work, in a society which is confident employing people with diverse ethnic and cultural identities.

Therefore, my research aims to provide insight into how theories of connection may be practically applied within an ethical framework, to ensure that citizenship rights do not remain an abstract ideology, but produce tangible equitable outcomes. Exploring the complex challenges of conceptualising visibility, home, and belonging in this chapter helped me to shape my workshop discussion questions in a manner that aimed to elicit more nuanced, multilayered responses (Appendix Five). By focusing on individual lived experiences I hoped to avoid participants' assumptions of what citizenship in New Zealand should be, and learn the everyday realities involved in home-making, identity negotiations and representations, and belonging for diverse Wellingtonians (Cresswell, 2004). 


\section{Chapter 3: The Participatory Painting Project}

This chapter begins by discussing the research epistemological and methodological foundations to acknowledge the ethical implications of particular approaches and methods. I then outline the project methods in detail, working step by step through the interviewing, painting, exhibition, coding, and dissemination process, before mapping out a sociospatial relational analytical framework which centralises the study of relationships between former refugee and host society participants. This framework provides a lens through which inductive research findings can be critically examined, taking into account both the proximate social interrelations and the wider national and global connections that are shaping Wellington as a unique multicultural home and city.

\section{3:1 Exploring a participatory action research (PAR) epistemology}

\section{Challenging a 'certain type' of socially-legitimated intellect}

Activists interviewed in Choudry's (2014) study of social movement research in the global south, make reference to the wealth of knowledge that exists outside of academia, but which is often overlooked in favour of a certain type of socially-legitimated intellect. One activist claims that, "We are coming up with our own approaches in terms of framework-setting. So we are not actually confined or limiting ourselves to what is readily available in the literature in terms of framework" (p. 79). This statement implies that scholars are limiting themselves by only drawing upon published academic literature to design research projects, meanwhile some of society's key thinkers may be those who are not confined to the boundaries of academic institutions and standards. For instance, Wellington poet Lauris Edmond is quoted on a plaque on the Wellington waterfront saying:

It's true you can 't live here by chance,

you have to do and be, not simply watch

or even describe. This is the city of action,

the world headquarters of the verb. 
Edmond's poem showcases sociological understandings of social participation that exist beyond academia, which have arisen through inside social observation and interactions. In tune with the activists represented in Choudry's (2014) research, advocates of participatory research also acknowledge that research participants hold unique knowledge and experience. Thus, 'participatory geographies' are defined as,

A set of values and practices that supports the joint construction and conduct of geographical research, teaching and other activities with all of those involved, with the goal of pursuing social change leading to greater social justice and equality (mrs kinpaisby, 2008, p. 292).

One of the key participatory approaches in geography is 'participatory action research' (PAR). PAR places emphasis on the relational processes and sociospatial outcomes of participation, focusing on the interactions between people, places, and resources; the power dynamics which shape and are shaped through these interactions; and the ways in which applied theory is embodied, practised, challenged, and re-modelled (Kindon et al., 2007; Pain \& Francis, 2003). PAR also strives to create a space where researchers and their fellow community members can learn from one another, create new knowledge together, and work towards common or mutually beneficial goals (Kindon et al., 2007; mrs kinpaisby, 2008).

In O'Neill and Hubbard's (2010) PAR article, discussed in Chapter Two, one of the authors mentions how time invested in walking around the city with former refugees, mapping locations, and then depicting these journeys via painting "made her see Derby anew, registering the significance of sites that for her had previously held little resonance", and enhancing knowledge of the "other"' (p. 52). In another PAR project in New Zealand, community group 'Evolve' collaborated with Victoria University students and local African refugee-background youth to develop strategies aimed at enhancing the wellbeing of African youth in Wellington. In their project report they claimed that,

Emphasising and utilising an iterative cycle of action and reflection, the process took into account the multiple perspectives of the participants. This generated rich, diverse and appropriate knowledge, resulting in collaborative decision-making that was highly 
informed, and outcomes and actions that, we believe, are equitable and sustainable (Evolve \& Victoria University of Wellington, 2005, p. 4).

These empirical studies highlight PAR's pedagogical value through enhancing crosscultural and local knowledge and skills, its emotional value through providing a space for individuals to share their experiences, and its social value through practical community development that aims to achieve equitable and sustainable outcomes.

\section{Power negotiations}

Due to the investment of numerous stakeholders who constantly negotiate ethical praxis and research validity in PAR, this participatory methodology can be extremely rigorous - challenging Frideres' (1992) claim that PAR is 'non-scientific' (Dowling, 2016). Researchers can be held morally and scientifically accountable as their position, ideas, methods, and analysis are constantly being questioned by participants to ensure that research processes and outcomes are justifiable, contextually appropriate, ethical, trustworthy, and transformative. As one activist claimed in an interview with Choudry (2014),

When the research came, there were massive fights and debates about 'no, now you're asking the wrong question, why aren't you doing this...', and that is participatory, it's constant feedback, constant shifting of the research project and the way you're doing [it] as a result of the participation of those in that organisation (p. 83).

Yet, despite PAR often being credited for creating a more equal platform for dialogue and negotiation between researcher and participants, power imbalances are always present as the researcher initiates, facilitates, and analyses the 'participatory' process. In this manner, PAR may showcase involvement whilst actually enhancing and legitimising powerful research, political and business agendas instead of empowering marginalised communities (Baldwin, 2012; Kindon, 2010; Pain \& Francis, 2003).

Whilst these concerns are important and should not be taken lightly, they do not negate PAR as a valid research approach, but rather caution researchers to remain vigilant in reflecting upon their reasons for doing research, their own positionality and epistemology, and their interactions with participants throughout the research process (Cahill, Sultana, \& Pain, 2007; Kindon, 2012; Sultana, 2007). PAR does not aim to eradicate inevitable social imbalances, but to make them transparent and challenge 
them, to minimise inequity. Thus, as Cahill, Sultana, and Pain (2007) argue, ethical questions are engaged rather than circumvented, as power imbalances are being acknowledged and negotiated. In this respect PAR comes closer to challenging hegemonic Anglo-American narratives than many other forms of research which often neglect to consult or engage marginalised groups (Kesby, 2007; mrs kinpaisby, 2008; Pain \& Kindon, 2007).

\section{Participatory praxis}

In 2003 Pain and Francis claimed that scholars often theorised participatory approaches rather than engaged with practical solutions. In the following decade or so, more research emerged which practically applied the philosophical foundations of PAR as a transformative methodology (Wynne-Jones, North, \& Routledge, 2015). Whilst these empirical participatory studies have enabled spaces for social connections to be strengthened, new knowledges to be shared, and lives to be changed, there remain many questions in regards to the impact that such PAR methodologies might have beyond controlled research spaces (Kesby, 2007). Do research participants maintain new relationships beyond workshops, meetings, and group activities? Do they change the way they behave on account of the new knowledge they have processed? Can they transfer any new feelings of empowerment or agency to other aspects of their lives? Following up on these wider-reaching benefits of participatory research is significant, particularly in light of an increasing focus on assessing research by its social impact, as discussed in the following section (Rogers, Bear, Hunt, Mills, \& Sandover, 2014).

\section{3:2 A scholar activist orientation}

\section{Academic responsibility and accountability}

In 2010 the United Kingdom (UK) Autonomous Geographies Collective claimed that,

In the last few years a new generation of human geographers have returned to issues of political relevance with an outpouring of special collections, disciplinary networks and conference panels debating how to make geography more 'public', 'activist', 'moral', 'radical', and 'participatory', and less dominated by the current Anglo-American hegemony (p. 246). 
In 2016, six years after the collective acknowledged this focus on scholar activism, I presented my research through an interdisciplinary panel discussion at the third annual Social Movements Conference in Wellington, New Zealand. The conference, which focused on the academic/activist interface, had increased from 200 attendees the previous year to accommodate 400 people, with another 100 being turned away. Following the UK trend, these numbers reflected increasing interest in scholar activism in New Zealand, both within and beyond the social sciences.

A key driving force behind scholar activism is the desire to affect constructive change through research. Such sociopolitical agendas have been expressed through a historical trajectory of grassroots social movements; critical race, Marxist, feminist and PAR theories; and social justice activism which challenge dominant hegemonic voices and unequal postcolonial power structures (Cahill et al., 2007). In these sociopolitical understandings, scholars are not simply distant observers of society who think and act in an isolated academic vacuum - rather they are inextricably a part of society, interacting with other individuals and groups on a daily basis, drawing upon shared ideologies and cultural norms to shape their perspectives of the world, and producing research which could have a profound impact upon the people and places being studied (Dowling, 2016).

Therefore, students who participated in Alexander and Jarratt's (2014) research Rhetorical Education and Student Activism argued that academic institutions ought not to dissociate themselves from the society of which their affiliates and ideologies are a part, but to question their role within the community - "What is an academy for?" (p. 539).

Other members of society outside of academia are also exploring concepts of scholar activism and challenging the limitations and boundaries of dominant research methods and institutions. The activists in Choudry's (2014) study critiqued dominant academic and NGO research approaches "which they believed to be dissociated from, and of questionable relevance and utility to, the communities and sectors of society most impacted by the issues investigated" (p. 77). Research participant McKinley claimed that activists were trying to bridge the gap between academic theories and the communities being studied, by producing their own local participatory research: 
A research product, so to speak, that was accessible and understandable to ordinary people - it wasn't in 'academ-ese', it wasn't in journals, it wasn't about those publications. It was about getting it around and having policy impact, partially, but also fundamentally being able to have a sense that people are our goal in this (Choudry, 2014, p. 81).

I agree with McKinley that research 'success' ought to be measured by the social value of the research, not only by academic publications or citations. Researchers need to acknowledge their role as social actors, understand their relationships with research participants and the wider community, and accept accountability for their actions (Alexander \& Jarratt, 2014; Choudry, 2014; Pussetti, 2013; Rogers et al., 2014). This entails questioning why a specific study is of value and to whom, as well as identifying the social impact (both positive and negative) the research process and findings might have. It also involves reaching out beyond academic circles to include local people in all stages of the research, to inform local communities of research outcomes, and to adopt the wider epistemological orientation of 'studying the world to change it'.

\section{Placing impact on the agenda}

In light of such critiques and considerations, the UK Research Excellence Framework (REF) has recently begun assessing the quality of academic research by evaluating the impact that research is making - with 'impact' being defined as "an effect on, change or benefit to the economy, society, culture, public policy or services, health, the environment or quality of life, beyond academia" (Rogers et al., 2014, p. 3). This approach is known as the 'Impact Agenda'. The UK Impact Agenda is significant to my New Zealand based research as many of the challenges identified in response to this agenda present significant ethical considerations, which require attention from any scholar wishing to affect social change through research.

Whilst the Impact Agenda aims to address academic and public calls for scholars and academies to question the social significance of their work, it has also been heavily critiqued for making social change competitive as scholars try to develop their careers and compete for funding. Rogers, Bear, Hunt, Mills, and Sandover (2014) claim that "through such a competitive basis, research could become more marketised as academics build relationships with different kinds of users to find ways of making their 
work count" (p. 2). This could have negative implications for scholars - who risk losing their academic autonomy, and for research participants or local communities - whose needs may be overlooked in favour of higher-impacting studies, or for whom forced impact may be maladaptive. Thus, critical geographers are concerned that "impact may simply reinforce bureaucratic ideologies and government agendas rather than challenge them by attending to dissenting or marginal voices" (Rogers et al., 2014, p. 4).

Rogers et al. (2014) also claim that,

Although impact is currently traced from research outcomes, it is increasingly being built into research design and expectations. Such an approach risks trying to secondguess or calculate impact in a potentially deterministic manner, one that lessens room for the variety and surprise that inevitably accompanies research (p. 6).

They argue that the assumption that impact can be predicted is problematic, as it can be unexpected. To avoid calculating impact within social science research, and instead provide a platform where transformative processes can develop in unique ways, the activists in Choudry's (2014) study argue that research ought to start with groups or organisations identifying a need and asking for assistance through a pre-established relationship, rather than beginning with a theory to be tested and proven. This grassroots approach could also prevent impact research from becoming too 'marketised' or aligned with government agendas, as it would be driven by community groups or NGOs to meet the self-identified needs of local people. Such community-based research paves the way for scholars and participants to collaborate to generate more insightful knowledge and diverse ways of thinking in research, which is along the lines of PAR (Kesby, 2007; mrs kinpaisby, 2008).

\section{3:3 A multi-method methodology}

\section{The visual method of painting}

The philosophical foundations of PAR and scholar activism influenced a qualitative multi-method methodology within my research. Human Geographers and other social scientists using participatory epistemological and methodological approaches have recently focused on incorporating visual methods such as photography, drawing, video, 
hypermedia, and social media into their research, to explore the diverse beliefs and realities of individuals, groups and communities (Berg, 2008; Pink, 2007; Rose, 2012; Wilson \& Milne, 2015). For participants who speak little or none of the official language in their country of residence, or who have suffered trauma and therefore cannot find the words or the will to verbally or textually convey their stories, visual methods offer alternative methods of communication which can be both expressive and therapeutic (Afonso \& Ramos, 2004; Heusch, 2002; Pugh, 2003; Ramos, 2004). Yet, whilst there are many benefits to these innovative research approaches, Stafford (2010) claims that it is important that researchers question what they aim to achieve through using visual methods, and how images can enhance written discourse, to ensure that images will add value to the research.

Photography is currently the dominant visual method for documenting everyday life experiences in research, as a camera can capture an instant realistic image and can easily be used with minimal training, making it an effective tool for participatory research (Oh, 2012; Pink, 2007; Rose, 2012). However, there are limits as to what can be photographed. For example, people may not consent to having their photo taken, distant places and times may not be accessible, and ideological, supernatural, and metaphysical concepts are not directly visible. Afonso and Ramos (2004), and Canal (2004) argue that, whilst hand drawn or painted images take longer to create and, without a high degree of technical accuracy cannot capture the realistic representation that a photo can, sketching and painting can symbolically represent the people, places, times and phenomena that evade the camera.

In Afonso and Ramos' (2004) study which used an 'elicitation' technique, researchers sketched a scene which an informant described. When other informants viewed the image they also begin to share their memories, building up a collective representation of a certain event, time, or place. Ramos (2004) claims that in this way, "drawing is not merely a documenting activity but also an important and creative tool for interacting with and relating to human beings of different cultures and languages" (p. 149). Ferguson (2011) agrees, claiming that, "music or the visual arts are both means to express your own culture to others, and to participate in a shared experience with people who may speak different languages" (p. 29). 
Yet, painting may not suit all participants due to their varying needs and abilities. In a pilot painting workshop for former refugees that I conducted as part of my 2015 honours study (Figure 2, See Appendix One for details), one participant claimed that, "Even though it was fun ... it was also challenging because it's something I've never done and I'm not passionate about. I do think it's good, but just not for me. For me I'd rather write". In response to this comment, other participants claimed that people should only be involved in painting if they feel comfortable expressing themselves this way.

\section{Figure 2: Pilot painting workshop, 2015}

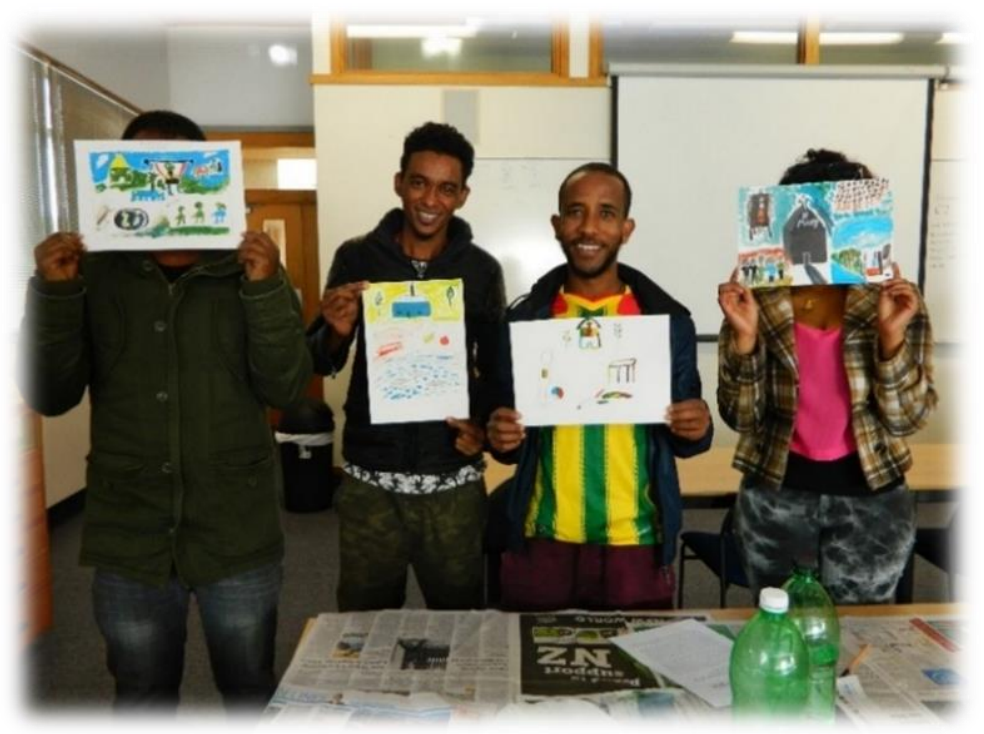

(Source: The author, 2015)

For those who do feel comfortable painting, the pilot workshop participants made statements claiming that the painting workshop was a "good opportunity to express how you feel". One participant said that,

One of the negative aspects that New Zealanders have towards refugees is, for them refugee is like dependent. They just come to depend on the government and suck the government's welfare benefit, which is not true. A lot of refugees they want to be positive citizens and they want to contribute to the economy. They want to support themselves and support the country, but sometimes they struggle to get a job, they don't have enough qualifications, they don't have the language to communicate with employers. So I think this kind of paintings can reflect what the refugees go through ... Those who really feel for refugees, if they see these paintings, I think it will help them understand more what is going on in the refugee people's minds. 


\section{Social context theory}

Whilst visual representations can enable unique explorations of everyday life, transcend language barriers, foster social connections, and inspire social change, an image on its own only shows a partial depiction and neglects the sequence of events prior to or post image, and the social dynamics at play in the creation, distribution, and interpretation of imagery (Chappell, Chappell, \& Margolis, 2011; Crang, 2010; Oldrup \& Carstensen, 2012; Pink, 2007). Theorists such as Oh (2012), Oldrup and Carstensen (2012), and Rose (2012) claim that oral and textual discourses are thus necessary to contextualise imagery in a particular time, place, and culture to enable greater insight into the social significance of the visual content. Therefore, dominant visual methodology frameworks build upon 'social context' theory, whereby the term visual is not exclusive to seeing, but includes imagery as part of a multi-method approach.

Social context theory challenges researchers to adopt a reflexive approach to visual processes, and to question how, where, when, and why an image is produced, and by whom (Constantino, Guyotte, Kellam, \& Walther, 2014; Oh, 2012; Rose, 2012). Such a contextualised approach is well aligned with PAR, as it enables a deeper exploration of the social, cultural, and political meaning that shapes and is shaped by human interaction and relative power struggles. Askins and Pain's (2011) project with African refugee children and British children painting together in England compared two methods - one where the children painted, and one where professional artists were employed to paint their stories for them. They found that the approach with professional artists reinforced 'otherness' and neglected to engage participants, and the children become bored and detached from the project. In this particular case, actively engaging the children in painting proved to be a more beneficial method as the children could participate more and have more control over how they expressed themselves.

Askins and Pain (2011) also explored what materials were being used within the project, and how these 'objects' shaped the painting process. They claimed that, "dominant social groupings and power relations were played out through the use/control of objects" (p. 813). Thomas, et al. (2015) claim that power relations are also shaped by where the artwork is created, and argue that a shared non-hierarchical locale is important to enable a more equal production and distribution of knowledge. Therefore, 
research techniques such as participant observation, interviews, and focus groups remain important within visual methodologies, to enhance understanding of the individual and social context and meaning of an artwork.

\section{Audiencing}

Images, particularly those which depict pain, suffering, and violence can be important in provoking empathic and political public responses whereby spectators become actively engaged with distant or 'unfortunate' others (Pussetti, 2013). Such engagement was evident in the international response to the widely circulated media image of drowned Syrian asylum seeker toddler Alan Kurdi. Alan Kurdi's image was powerful in generating global sympathy and demanding global action to develop safer passage for fleeing refugees. However, empathic responses are often founded upon a 'politics of pity' which reinforces negative stereotypes of refugees as powerless and traumatised (Pussetti, 2013).

This politics of pity is problematic as pre-arrival trauma is often over-stated for resettling refugees, due to the assumption that all refugees have experienced the unimaginable violence and terror that people associate with images such as Alan Kurdi's. In fact, rates of Post-Traumatic Stress Disorder (PTSD) in New Zealand are almost the same for former refugees entering the country (7 per cent) as they are for the wider population (6.1 per cent) (Javidi \& Yadollahie, 2012; McLeod \& Reeve, 2005). Mistakenly assuming that all former refugees are fragile and helpless only serves to differentiate 'them' from 'us', whilst overlooking the tremendous resilience and strength individuals may possess and their ability to contribute to society and be regarded as equals (Collie, Kindon, Liu, \& Podsiadlowski, 2010; Lenette, Brough, \& Cox, 2013; Munt, 2012).

Thus, there is a need to carefully consider not only the response that an image is designed to elicit, but also the consequences of this response. Pink (2007) argues that questioning who will view and interpret images is equally as important as questioning who will create them, as an audience will bring their own knowledges, preconceptions, and expectations with them, and will interpret each image in unique ways, resulting in multiple understandings and reactions. 
Art-therapist Heusch (2002) also highlights the need for vigilance and sensitivity to avoid countertransference, whereby the traumatic stories that may emerge through painting not only risk re-traumatising participants, but also risk traumatising the therapist (or in this case the researcher or other research participants). This concept of countertransference highlights the significance of art-making as an intersubjective process and reiterates the need to focus on the responses that stories and actions generate and how this shapes further narratives.

The epistemological and methodological foundations discussed throughout this section were instrumental in guiding ethical, engaging, and creative research praxis. From participant recruitment through to dissemination I aimed to include the local Wellington community in the research and to encourage participants to share their knowledge, so that together, we could create a space to educate one another, to learn, and to produce an artwork that built upon and expressed our unique identities whilst also enabling us to connect with and support one another as a group.

\section{3:4 Participant recruitment}

\section{The community networking process}

Participants for the painting project were recruited via a process of community networking. Reaching out to individuals through pre-established networks of trust enabled me to invite potential participants in a manner that did not homogenise people as a group, and it provided a sense of security in that the project was often recommended by a mutual acquaintance who could vouch for its integrity. I produced a flyer which was widely distributed by ChangeMakers Refugee Forum, Red Cross Refugee Services, Make Foundation, Inverlochy Art School, art supply store Gordon Harris, The French Art Shop, the Friends of Timor community group, the residents in my apartment building, the Victoria Plus programme, ETC English Language School, and various friends and Victoria University staff from both refugee and non-refugee backgrounds (Appendix Two). Individuals who met the criteria and were interested in participating then contacted me via e-mail and I invited them to participate in the project. 
The greatest challenge of this networking approach was the time it took to speak with people about the project and wait for the chain of connection to reach eligible and willing participants. It also took much longer to confirm former refugee participants than host society participants. There are the obvious reasons why people may not volunteer, due to being busy, disinterested, ineligible, and due to a lack of reimbursement for their time or a lack of perceived benefits from the project. Yet, in the case of former refugee residents in particular, other physical language, mobility, and childcare barriers may have existed (Bose, 2014; Kale \& Kindon, 2016; Martin, 2008; Swe, 2013; Urry, 2012). Non-participation may also be a short-term strategic move to avoid stigma or perceived 'unsafe' environments; to avoid being stereotyped, gossiped about, and misunderstood (DeSouza, 2011; Lenette et al., 2013; Lollar, 2015; Munt, 2012).

Other refugee resettlement practitioners and researchers also reported having difficulties with participant recruitment. One Assyrian cross-cultural worker said that many former refugees from backgrounds of poverty were not used to volunteering and engaging in community projects, as previously all time and resources were invested in basic survival needs. However, time spent networking did eventually pay off, as the project gained huge community support from the process of talking through my ideas with various community members and organisations.

\section{Key criterion}

Selected participants had to be either New Zealand residents or citizens living in Wellington, as the focus was on Wellington as a place of residence as opposed to a holiday destination or site of transition. Whilst individuals 'passing through' Wellington can shape and change, and be shaped and changed by the city in various ways, it is those who identify as New Zealanders whose access to civil rights will be most impacted by Wellington's changing sociopolitical and geographical landscapes. Regrettably, the criteria of residency or citizenship did rule out the participation of asylum seekers in this particular study, as mentioned in Chapter One.

Participants from the 2015 pilot painting workshop claimed that painting may be stressful for those who do not consider themselves to be 'creative'. Acknowledging this feedback, another key criterion for participant selection was an interest in painting; 
however, no formal painting skills were required. Whilst the idea was to use painting as a platform for self-expression and cross-cultural communication, a basic level of English language comprehension was requested to enable participation in group discussions and interviews. Interpreters were available, though all participants felt that they had sufficient English to engage with the group without the use of an interpreter.

\section{Research participants}

A purposive sample of eight participants were selected to be involved in the painting project: Five from the Wellington host society and three whom identified as former refugees. This number was strategically limited (I had been aiming for a maximum of ten participants) due to the depth of information I hoped to generate through individual interviews and group workshop interactions, and the limited time available to rigorously analyse such rich, relational data. Nick Tapper, an undergraduate student at Victoria, volunteered as my research assistant throughout the workshops, contributing to the setup of paints and food, facilitation of discussion, and photographic documentation of the painting process (Due to one of the participants having the same name, Nick Tapper will henceforth be referred to as Nick T).

The participants who volunteered were from diverse ethnic and cultural backgrounds. Former refugee participant Binyam had moved to New Zealand from Sudan (though his family is Eritrean) over a decade ago. Yordanos had also moved from Sudan (though her family is originally from Ethiopia), fifteen years ago when she was seven, and Sarah* had arrived in New Zealand four months ago from Iran. Host society participants were all born in New Zealand; except for Tayyaba who emigrated from Pakistan and lived in various countries as a child. However, Nic and Ken both came from recent immigrant backgrounds, with their parents moving to New Zealand from Canada and Japan respectively, whilst Hilary, Jamie, Nick T. and I identified as Pākehā from much earlier European immigrant families.

Participants were mostly in their twenties and thirties, with Hilary being slightly older in her early fifties. Hilary was the only participant who has children with her partner, though Nic also lived with his wife and Sarah* is currently in the process of trying to bring her husband from Iran to live with her in New Zealand. Other participants generally lived in flatting situations with friends, partners, or family members. 
Yordanos and Nick T. were both completing their undergraduate degree at Victoria University at the time of this project, whilst Sarah* had just begun English classes also held at the University. Ken, Nic, and Jamie had artistic backgrounds, with Ken working for a local architecture firm, Nic working with an arts and theatre group, and Jamie working at art supply store Gordon Harris whilst doing her own painting in a studio she rented nearby. Sarah* also has a background as an art teacher (and a diploma in mathematics), and was enquiring about opportunities to study or teach once her English classes finish. Binyam studied business management and now owns an Eritrean / Ethiopian restaurant in Wellington (which several of us celebrated at after the mural exhibition), whilst Hilary is a mum with a law degree who volunteers on the Aro Valley Community Council and works part time. At the time of the project, Tayyaba was the CEO of ChangeMakers Refugee Forum - whom I have worked collaboratively with in the past.

Tayyaba was the only host society participant who reported being in contact with former refugees, and Yordanos was the only former refugee who reported having host society friends. For the other participants, such interaction was not a part of their everyday lives, though meeting new people and learning about new cultures was something that participants were all interested in, hence their involvement in the project.

\section{3:5 Data generation, collation, and dissemination}

\section{Project objectives}

Running from the start of October until the start of December, 2016, research was coordinated as a Wellington-based community painting project titled: Inter-Mural Wellington. The term 'intermural' translates to 'between the walls of', highlighting the negotiation of proximate sociospatial boundaries within Wellington. It also refers to intercity interactions, illustrating processes of New Zealand national and global connectivity (Dictionary.com, 2016). With the inclusion of a hyphen, 'inter-mural' depicts the interactive process of creating a collaborative mural - one of the applied objectives of the painting project. This multilayered project title reflected the 
ambiguous nature of the research, whereby multiple dynamic perspectives were continuously at play.

Due to the small-scale nature and limited time frame available for this project, I did not expect any extreme social transformations. I considered the project to be a success if it:

- Prompted dialogue on processes of refugee integration

- Taught participants something new in terms of what it means to be a refugee or someone from a different culture

- Challenged normative assumptions of home, belonging and visibility in Wellington

- Fostered social connections between research participants

\section{Initial participant meeting}

At the beginning of the project a half-hour long participant meeting was held at Victoria University's Kelburn campus. The meeting aimed to introduce participants to one another and the researchers, build trust and rapport, and inform participants about the project to ensure understanding of the research and participants' rights and responsibilities. Time was set aside for individuals to voice any ideas or concerns, and to negotiate methods that were culturally sensitive and respectful of the diverse beliefs, needs, and interests at play (Dowling, 2016; Howitt \& Stevens, 2016; Kindon, 2016). Only three participants attended this meeting, yet absentees had valid reasons for not being present, such as illness, work, and pre-arranged travel plans.

\section{Semi-structured pre-workshop interviews}

The following week, individual interviews were conducted in pre-agreed-upon locations around Wellington city. Each interview took place in an environment where the participant and myself both felt comfortable, and which was appropriate in terms of accessibility (taking into consideration transport and childcare). Chosen locations consisted of participants' homes, the university, cafés, an art studio, and an art school. Consent and confidentiality forms were signed at the beginning of the pre-workshop individual interviews (Appendix Three), to give participants time to consider what they 
were agreeing to before signing, and to decrease a feeling of peer pressure that might have impacted personal decision-making processes whilst in the earlier group meeting. Interviews were semi-structured, with pre-written questions aiming to elicit relevant information, and impromptu follow-up questions eliciting and encouraging narratives and interpretive dialogue (Dunn, 2016) (Appendix Four). In this manner, interviews flowed more like a conversation. I prompted further discussion when participants raised interesting experiences, spent time greeting Hilary's neighbours as they called over the fence mid-interview, looked at photos of Jamie's new kittens, and answered participants' questions as to my personal views on refugee resettlement. These (sometimes seemingly irrelevant) digressions enabled participants to discuss things that were important to them, and sharing my own experiences and opinions with participants helped to build trust and rapport. Each interview lasted approximately half an hour, and participants had the option of using the audio recorder, which most did, or having their answers hand-written, which only one person preferred (Dunn, 2016).

\section{Painting workshops}

I then facilitated five painting workshops over five consecutive weeks, for two hours each Sunday, in a private seminar room at Victoria University. I had originally planned to have four workshops and a follow-up meeting. However, due to needing more painting time, the group opted for an extra workshop instead. Due to this change, there is some inconsistency between my flyers and information and consent forms listed in the Appendices section, and the steps reported in this Chapter. The workshop venue was selected for its size, ventilation (due to the use of paints), access to bathroom facilities, and accessibility via private and public transport. It was also located near my office which provided a safe space to store the wet mural between workshops. Participants had the opportunity to suggest other venues for these workshops during the initial meeting, though storing the mural someplace safe to dry made appropriate venues difficult to find, and we agreed that the university would suffice. We also negotiated a workshop time that would suit all participants.

All participation was voluntary, meaning that individuals chose to participate through their own free will. This voluntary approach was important in enabling community members to make their own (informed) decisions as to how, when, and where they felt 
comfortable participating in community research, sharing knowledge and experiences, and representing themselves in public. However, it was also problematic in encouraging ongoing attendance. Leading up to each workshop I e-mailed participants a reminder of the next workshop time and date, and participants often e-mailed back confirming their attendance or apologising for their absence. On Sundays, prior to each workshop, I purchased food then Nick T. and I set up the paints, mural and food and arranged the tables so that the group could sit facing one another for discussions. Participants often helped to tidy up with us after the workshops and carry the mural back to my office.

In the first workshop we (the researchers and participants) started by each introducing ourselves. We then took turns speaking about individual experiences and ideas relating to themes of home, belonging, and visibility in public space. I had already discussed these ideas with participants during their interviews, and thus, they had time to consider different experiences and ideas prior to sharing with the group. I had also prepared a PowerPoint presentation with several questions chosen to elicit relevant dialogue (Appendix Four). The participants, Nick T., and I then took time to reflect upon the group discussion and consider how to symbolically represent our experiences and ideas. We conversed and shared the food during this individual sketching time (Figure 3). Once we had ideas on paper we went around in a circle each sharing our images and negotiated how our unique images and symbols could connect together as a unified work. The workshop ended with us agreeing on the next steps to be taken.

\section{Figure 3: Sketching ideas}
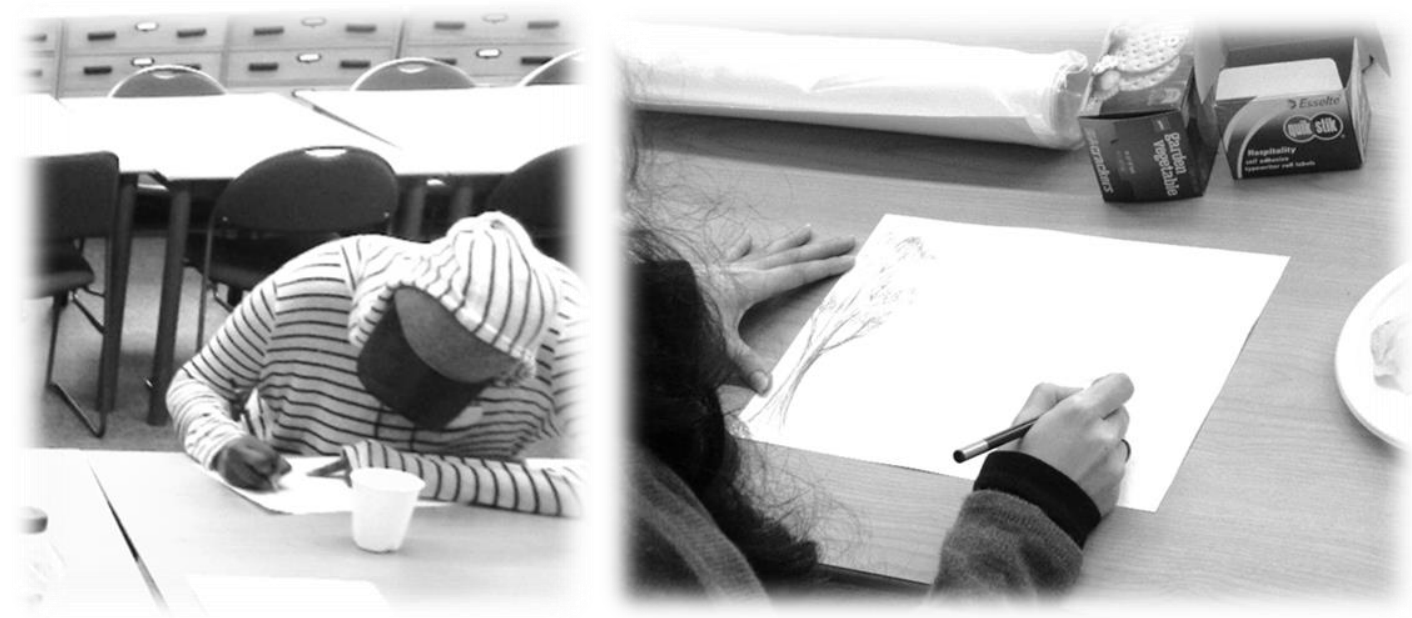


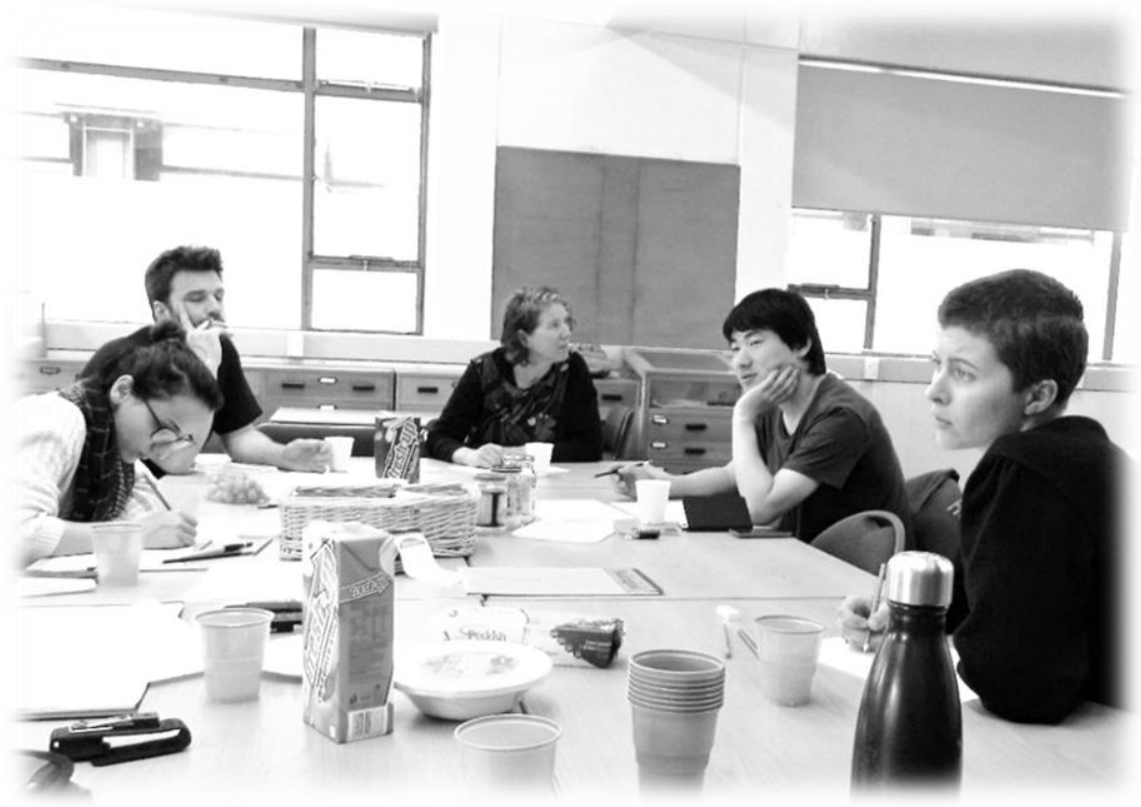

(Source: Nick Tapper, 2016)

The second workshop then built on the first, with more sketches and collaborative mural designs. Both of these workshops were audio-recorded and photographed (by Nick T.) with the consent of participants. Once the group had a blueprint of how ideas would flow together, we sketched up the mural on a sheet of canvas measuring $100 \mathrm{x} 140 \mathrm{~cm}$.

\section{Figure 4: Painting the mural}

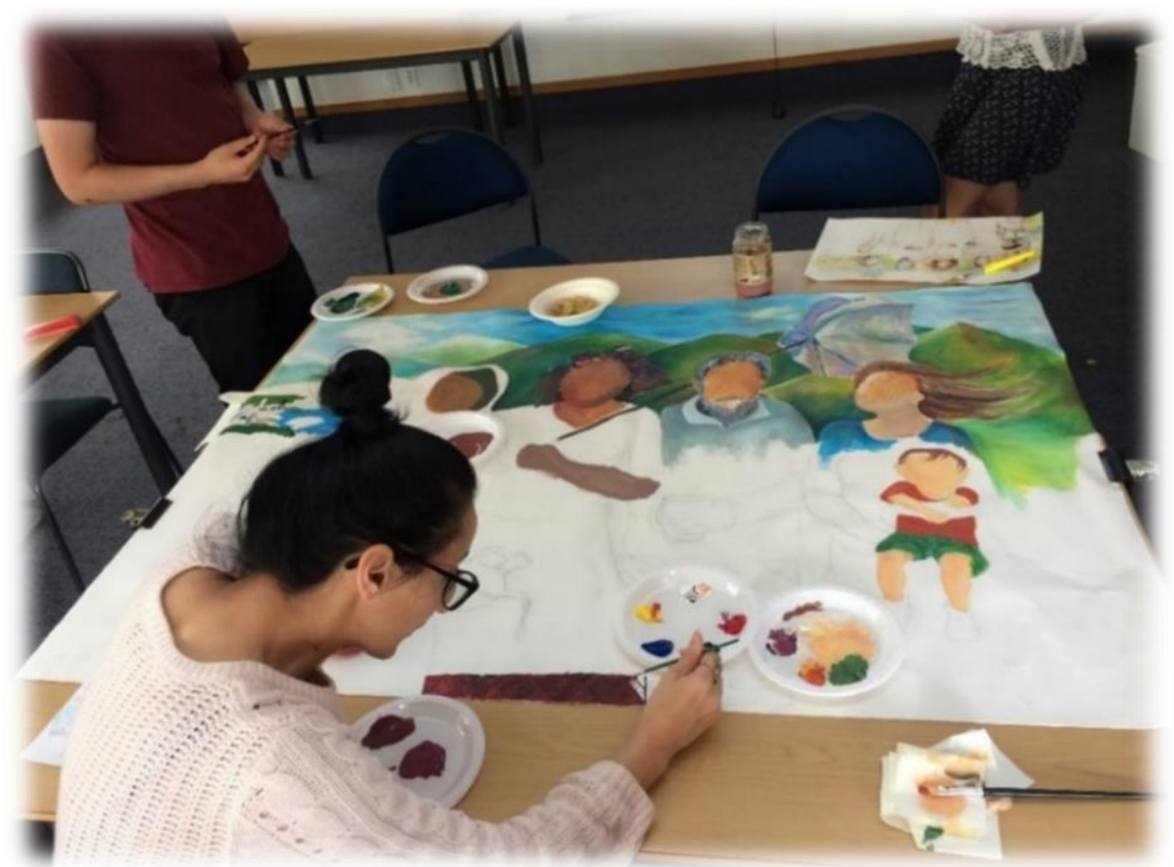

(Source: Nick Tapper, 2016) 
The following three workshops focused on painting the canvas (Figure 4). Acrylic paint was used due to this medium being easy to mix and apply in a wide variety of ways, fast-drying, and cost-effective. I demonstrated how to mix and apply paint throughout the workshops, to provide some basic skill training; however, a creative and innovative approach was encouraged where participants worked in their own styles and experimented with their own techniques. After the workshops I would spend an extra half hour or so writing notes from observations and planning for the following week.

\section{Post-workshop interviews}

Post-workshop interviews (following the same format as the pre-workshop interviews) were conducted to explore whether participants had gained new knowledge about each other throughout the painting process; whether their understandings of home, belonging, and visibility within public space had changed; and whether they felt more 'connected' to the other participants and Wellington city (Appendix Six). The purpose of inquiring about any changes was to understand how this collaborative, participatory painting project might have enhanced social connections between former refugee and Wellington host society participants.

\section{The exhibition presentation}

The canvas mural was designed to be portable so that the exhibition site could change and more diverse audiences could be reached. Wider dissemination is important in making social integration research more accessible to counteract negative refugee representations perpetuated by the media. Only one location was chosen to record the public response for the writing of this thesis, due to the time it took to arrange venues, display the work, and collate feedback. The exhibition opening night involved me presenting our mural to the public at a local café in Wellington city (Figure 5). I invited participants to speak if they wished to publically identify themselves and share their experience of the painting process; however most chose to remain anonymous or did not feel comfortable speaking in public, and the couple of people who initially offered to present were unable to do so on the night due to work and family obligations outside of Wellington. Therefore, I did a short presentation that drew upon participant quotes, and left plenty of time for participants to interact with audience members and talk about 
the mural in their own way. Time was available at the end to observe the mural in detail, network, and share food and drinks.

The mural and a comment book I had prepared earlier (Figure 5) were left up for a week to reach more viewers. This exhibition timeframe was advertised on flyers (Appendix Seven), in a news article (Appendix Eight), and announced at the presentation. The comment book included a short introduction to the research and explanation of the research process, verbatim quotes from participants, and an overview of the symbolism represented in the mural. The significance of this book was that viewers could leave anonymous comments to give feedback on the presentation or the mural to inform my analysis.

\section{Figure 5: The exhibition presentation}
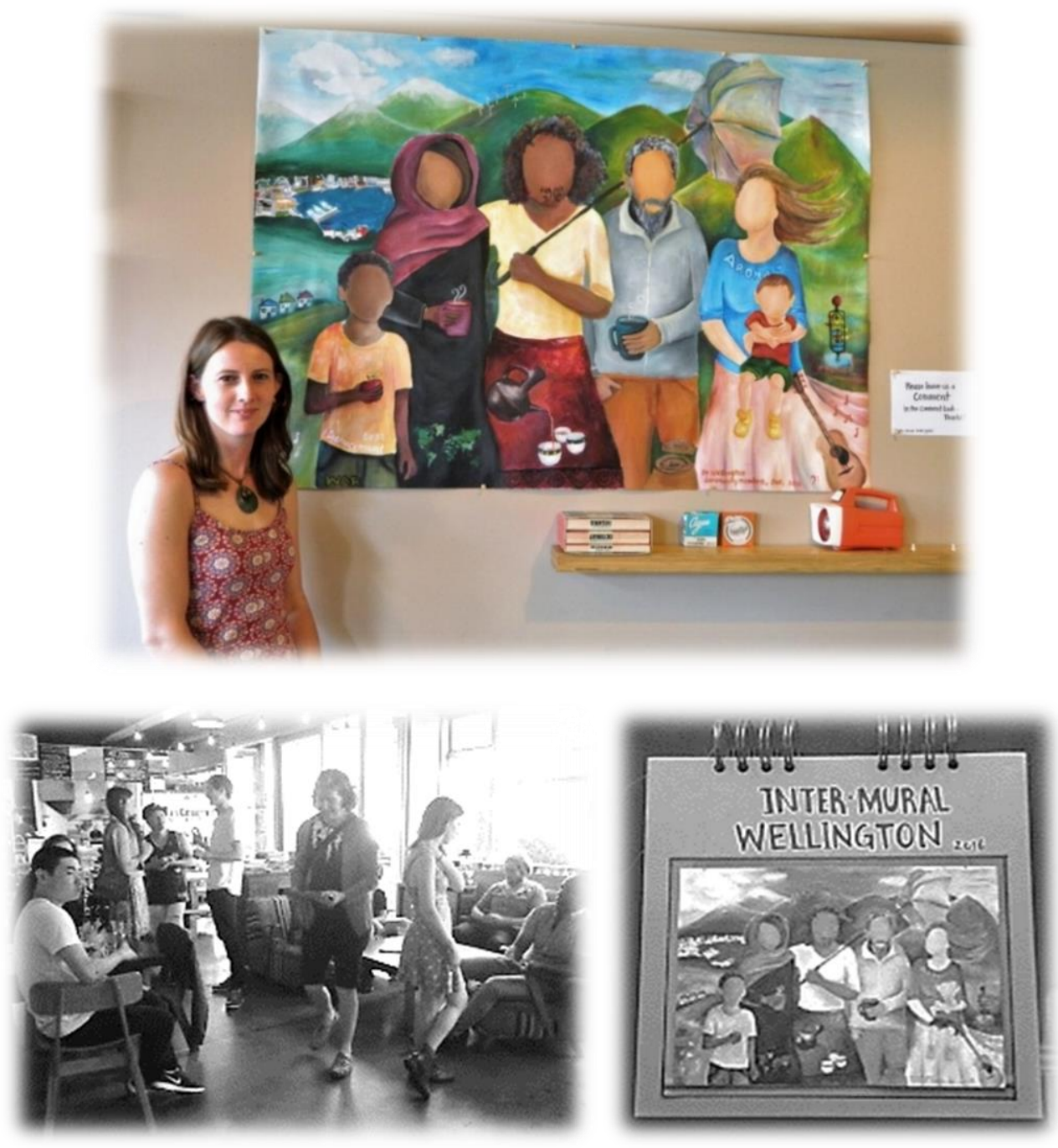

(Source: Jasmin and Karen Kale, 2016) 


\section{Transcription and collation}

Qualitative data from the interviews and painting workshops was transcribed verbatim to capture the flow of dialogue between the researchers and individuals, and within the group. Memos of names (either real or pseudonym), dates, times, locations, observed behaviour, and any other key information noted during the interviews and workshops accompanied each transcription to build a more comprehensive database to contextualise discourse within a broader sociospatial and temporal setting (Cope, 2016; Dunn, 2016). Transcriptions were then collated and inductively coded to highlight conceptual links and inform theory-building. I developed a 'Codebook' (in the form of a matrix) to structure manifest 'in vivo' codes - which identified the terms and expressions commonly referenced by participants; descriptive codes - which expanded on in vivo codes to explore obvious themes and patterns concerning who, what, where, when, and how; and latent analytic codes - which were specifically chosen to link descriptive codes to existing ideas and theories for the purpose of contextualising the data in a wider conceptual framework (Cope, 2016).

Data were then organised into three main categories consisting of concepts, methods, and outcomes. Whilst a conceptually-framed question might not necessarily have elicited a conceptually-based response, these pre-established categories generally provided three consistent groups of data and thus logically informed the coding process. Within the conceptual category, themes pertaining to the key ideas of refugee resettlement, home, belonging, public visibility were coded. The methodological category organised themes relevant to the research methods and processes - for example, the benefits and challenges of representing oneself through painting and symbolism. The outcomes category then consisted of themes concerning social interaction and social impact - looking at how this project influenced social connections, and how it can bring about change within the Wellington community.

\section{Dissemination}

The first stage of research dissemination took place during participant recruitment. I spent around a month e-mailing contacts, flyering around the city, talking to people in shops or at social events, meeting with refugee resettlement practitioners, running ideas by former refugees and fellow academics, and bombarding social network sites with 
ideas for my project. Public engagement was further enhanced during the recruitment stage by local news stories celebrating my achievement of winning the 2016 Kate Sheppard Memorial Award (Newstalk ZB, 2016; Scoop, 2016). Several Wellington community members mentioned that they had heard of the project and the award through the news or the University website, and I also received a letter of support for the project from the mayor of Christchurch, Lianne Dalziel.

The second stage of dissemination followed with the Third Annual Social Movements Conference at Victoria University of Wellington, where I presented the theoretical focus of my research alongside three other panel group members. Prior to the conference our panel group had also organised a trial presentation for the Human Geography Social Theory Spatial Praxis (STSP) research group. The conference was followed by a Refugee Symposium in Palmerston North, and a Refugee Conservatory in Auckland. Each of these events brought together a range of academics, refugee resettlement practitioners, former refugees, and other interested community members to share ideas and pave the way for future academic, policy, and practical resettlement collaboration.

Despite the extra time it took to prepare for and engage in each of these activities, early dissemination of this project was well worth investing in, so that people were aware of the project and could follow its progress and build some sort of social or political rhetoric with it, as opposed to the project outcomes appearing out of the blue and demanding attention from distant strangers. With so much media publicity and public input and support, the project was achieving its objective of bridging the gap between the academy and the community before fieldwork had even begun.

The third stage of dissemination occurred post-workshops and consisted of the advertising of the mural, the public mural presentation and exhibition, and the news stories about the mural on the New Zealand news site 'Stuff' (2016) and in the local paper 'The Wellingtonian' (Appendix Eight). This stage was significant in showcasing the ideas developed throughout the painting workshops, and the collaborative representation of these ideas by the research participants. The exhibition provided a platform to educate the public about diverse individual former refugee and host society experiences, to challenge normative assumptions of home, belonging and public visibility in Wellington, and for the public to provide any feedback. 
Whilst the exhibition comment book did not generate a large amount of feedback, all the messages in it were very supportive of the inclusive nature of the project, and its collaborative approach whereby former refugees and host society members worked together. One comment read, "A very good job Amber, I thought it's creative and insightful way of capturing interaction between former refugees and the host communities. As a former refugee, I can relate to some of the points you made as well as the portrait itself. So well done and congrats". Another comment from a former refugee said, "It's really good research very inclusive researcher: I think refugees need more people like you so well done thank you. Keep it up".

Upon completion of the painting project ChangeMakers Refugee Forum offered to display the mural at their headquarters, and invited me to present my research in March 2017 as part of a new forum to share refugee resettlement research with the local Wellington community. My supervisor Sara Kindon has also asked to incorporate the mural into a celebration of the Victoria University Refugee-Background Students group, and participant Hilary who is part of the Aro Valley Community Council has mentioned exhibiting the mural in the Aro Community Centre. I have also spoken with another refugee resettlement academic working with visual methods in Auckland, to see if it would be possible to present a national exhibition which showcases diverse creative research and refugee narratives. Between March and June 2017, I plan to write two academic articles focusing on the methodological and thematic findings from this research. These will be submitted for publication within appropriate geographical, visual, or refugee journals. This study is intended to inform a $\mathrm{PhD}$, if possible, as well as future art-based integration initiatives.

\section{3:6 Applying a sociospatial relational framework of analysis}

\section{The social construction of place}

To analyse how notions of home, belonging, and visibility within public space were shaping processes of former refugee and host society integration in Wellington, I employed a sociospatial relational analytical framework. In 1974, Lefebvre discussed a sociospatial theory in which there exists a dialectical link between space and social 
relations. This link consists of the perception that space is socially constructed through shared meanings and values within a group. Similar ideas prevail in geographical and urban writing today; however, there has been a shift from space to 'place.' Whilst space is generally perceived as an expansive dimension containing matter, place is more narrowly defined as an identifiable location within space or position within social structures (Agnew, 2011). Due to its specificity, the concept of 'place' is increasingly being used (and is used within this research) to highlight the uniqueness conferred upon diverse territories via context-specific processes of social construction (Castree, 2004).

Recent literature on encounters also acknowledges place as being socially constructed through intersubjective meetings and interactions; however, in contrast to Lefebvre's (1974) focus on shared meaning, Wilson (2016) claims that geographical theories of encounter generally refer to contact between individuals or groups where difference is assumed or preconceived prejudices exist. Thus, encounters play a significant role in the negotiation of diverse or hybridised cultures, worldviews, values, and identities, and can influence the making and unmaking of perceived 'borders' and unique territorial politics of inclusion and exclusion. Such meetings therefore ought to be acknowledged as sites of political and pedagogical importance, and catalysts for social and spatial change (Wilson, 2016).

Acknowledging the transformative potential of social encounters, empirical researchers such as O'Neill and Hubbard (2010) and Tolia-Kelly (2008) have strategically facilitated collaborative, participatory projects involving former refugee and host society members to enhance understanding of places as dynamic and multilayered. By making diverse understandings of place more explicit through sharing individual experiences, people can think more critically about how their actions may include or exclude others. Such relational thinking is evident in Collie, Kindon, Liu, and Podsiadlowski's (2005) research, where refugee background women negotiated their identities depending on who they were associating with, to enhance the likelihood of being included. If host society members were also more mindful of how they exclude people from diverse backgrounds - whether intentionally or unintentionally - then more effort might be made to alter harmful knowledges and behaviours, extend proximate support networks, and enhance social connections. 
Yet, encounters, whether chanced or arranged, can also have the opposite effect: reaffirming and (re)producing prejudice, unbalanced power relations, and conflict (Wilson, 2016). Wilson (2016) claims that there is a risk of scholars labelling such negative encounters as 'meaningless' or omitting them from analysis to present research outcomes in a more positive light. However, whilst a seemingly 'regressive' outcome may pose obstacles to my socially-inclusive research objectives, encounters that fuel conflict may only represent a clash in opinion, not a fundamental inability to cooperate, or simply depict a more 'honest' interaction, as opposed to an encounter where people are acting in a manner they deem to be appropriate, but which belies their true thoughts and feelings (Wilson, 2016).

Negative encounters may also be valuable as social conflict is often acknowledged by social and cognitive theorists for its positive qualities, being instrumental in developing deeper relationships and instigating social change or 'progress' (Baron, 1991; Coser, 2001). In this manner, tension ought not to be disregarded as a sign of failure. Rather, it is a normal and expected aspect of human interaction. Therefore, the complexity and temporality of everyday encounters and diverse social interactions needs to be acknowledged to enable a more insightful analysis of why people act the way that they do in particular circumstances. Such a contextualised analysis can also enhance understanding of how diverse subjective and social circumstances shape experiences of citizenship, home-making and belonging, and the (re)construction of unique places over time.

\section{Applying a multiscalar lens}

To acknowledge the complexity and temporality of everyday encounters, a focus on 'propinquity' is needed. Propinquity is defined as the physical and/or psychological proximity of people within a specific place (Amin \& Thrift, 2002; Darling, 2009; Massey, 2004; Wilson, 2016). This local lens of analysis can enable an exploration of local history, changing social structures, social, political, economic, or cultural circumstances, interpersonal relations, and subjective knowledge or emotional experiences. Such contextual factors are significant as they influence human interactions and shape individual and shared dispositions of trust, acceptance, and responsibility towards others. 
Massey (2004) argues that people tend to trust, accept, and show responsibility towards those who are either physically or psychologically close to us. She claims that,

There is a kind of accepted understanding that we care first for, and have our first responsibilities towards, those nearest in. There are two qualities of this geography which stand out: it is utterly territorial, and it proceeds outwards from the small and near at hand (p. 9).

This defensive territorial behaviour is evident within the current sociopolitical debate on raising the annual New Zealand refugee quota. One of the dominant arguments against accepting more quota refugees in New Zealand, is that we (as a nation) must prioritise the wellbeing of our own citizens and communities before providing assistance to non-nationals (Mojab, 2015). Such a stance reflects domopolitics, as discussed in Chapter Two (Walters, 2004). In this case, a lens of propinquity is needed to analyse the emotional, circumstantial, and contextual processes that shape such domopolitical views, and to consider how the value attributed to close relationships may be extended to enhance a wider sense of social responsibility.

Yet, propinquity alone is inadequate to fully understand former refugee and host society interactions, as there exist a multitude of wider national and global networks and dynamics which shape subjectivities and social structures. Since Lefebvre's (1974) sociospatial theory, there has been a change in perception from place as self-contained - constructed and maintained through internal proximate relations - to a broader, externally interactive view of place. In the highly globalised world we live in today, this 'externally interactive' view is important as it highlights the need to analyse the wider national, regional, and global networks, structures, and ideologies which may shape specific locales. This shift has led to a debate on the extent to which propinquity, and local-global connectivity are each significant and or necessary in theorising encounters and (re)constructions of place (Amin \& Thrift, 2002; Darling, 2009; Massey, 2004; Wilson, 2016).

Massey (2004) claims that, “'A global sense of place' means that any nation, region, city, as well as being internally multiple, is also a product of relations which spread out way beyond it" (p. 6). Through globalisation, networks of migration, trade, and communication, and the transfer of different people, products, and knowledge are 
challenging place-specific boundaries, cultures, practices, and ideologies (Harvey, 1989).

As illustrated by Mortensen (2008) and Sibley and Liu (2007) in Chapter Two, colonial and postcolonial treaty relations have shaped a unique bicultural national identity in New Zealand. Applying a lens of connectivity within this research enables an exploration of how sovereignty struggles between indigenous Māori and the British crown have formed this bicultural sentiment, what tensions still remain within this national identity, and how such a sentiment influences diverse postcolonial understandings and experiences of home, belonging and public visibility in Wellington. As well as colonial and postcolonial relations, Wellington is shaped by other international alliances and obligations, and New Zealand's geopolitical positioning in global trade, migration, security politics and military engagement, and cross-cultural negotiations.

The local effects of global trade, foreign cultures, and migration are publically visible in the streets of Wellington, through foreign products being advertised and sold; unique celebrations, performances, cuisines, and ideas showcasing transplanted or hybridised cultures; and everyday encounters between diverse people challenging local norms. The effects of enhanced international communication networks are also evident, with foreign and social media shaping a local sociopolitical rhetoric of belonging through exposing Wellingtonians to media coverage of the current humanitarian crisis, terrorism, America's war on terror, and anti-immigration sentiments and violence around the world (KhosraviNik, 2010; McKay et al., 2011; O’Doherty \& Lecouteur, 2007).

Darling (2009) claims that,

The grounds of demands, both 'local' and 'distant', should be open to contestation and negotiation in equal measure, for the challenge of a relational account of spatial politics is not to undermine the claims of those strangers 'within' the city, but to cast into question the logics through which some may claim the city as unquestionably 'ours' (p. 1948).

Popke (2007) also says that, 
We might suggest ... that the ethical challenge is to recognize both demands. If there is an unconditional injunction to be responsible for the arrival of the unknown other, it must be tempered by the postcolonial reminder that arrivals and encounters do not take place in a space free from history or power (p. 514).

Thus, a multiscalar lens which interweaves the proximate and distant is used within this research in an effort to produce a more rigorous, holistic understanding of dynamic processes of former refugee and host society integration.

\section{A polymorphic perspective}

Jessop, Brenner, and Jones (2008) claim that social scientists have developed four distinct spatial elements to analyse social constructions of place, consisting of territory, place, scale, and network. However, often only one of these elements is centralised. This centralisation is problematic because the prioritisation of one element over another only provides a partial insight into polyvalent processes of place construction. For example, place centrism "fails to consider how processes of place production are constitutively intertwined with the territorial, scalar, and networked dimensions of sociospatial relations" (p. 391). Therefore, they suggest that "territories (T), places (P), scales (S), and networks (N) must be viewed as mutually constitutive and relationally intertwined dimensions of sociospatial relations" (p. 389). This polymorphic lens is known as the 'TPSN framework'.

However, as Askins (2016) and Wood (2013) claim, there is also a need to explore how intersubjective, emotional encounters and processes of othering shape politics, identities, and social connections and networks, and lead to either inclusive or exclusive integration practices. For the purposes of this thesis I therefore include a fifth element to the TPSN framework consisting of people (see Figure 6). The consideration of people is necessary to challenge public assumptions and media misrepresentations of a twoway integration process between distinct homogeneous groups, and to focus on individual experiences of citizenship as opposed to citizenship as simply an overarching legal framework.

My reason for adopting this framework as an analytical tool to explore former refugee and host society integration is that it centralises the study of social relationships within a specific locale, and provides a range of diverse interactive lenses through which to 
explore these relationships from different perspectives. Through the framework my aim is to carry out a holistic analysis of the complex structures, procesesses, interrelations, power dynamics, and negotiations that shaped processes of former refugee and hostsociety connection within the Inter-Mural Wellington painting project. Such a framework is relevant within this study because the research participants were not simply producing an 'abstract' artwork, but were interweaving narratives from diverse trajectories which are intrinsically linked to various histories, current events, subjective knowledges and embodied emotions and experiences (Oh, 2012; Oldrup \& Carstensen, 2012; Rose, 2012). Thus, it was important to situate the creative interactive processes and content of the group mural in a wider sociospatial relational context.

\section{Figure 6: A sociospatial relational framework}

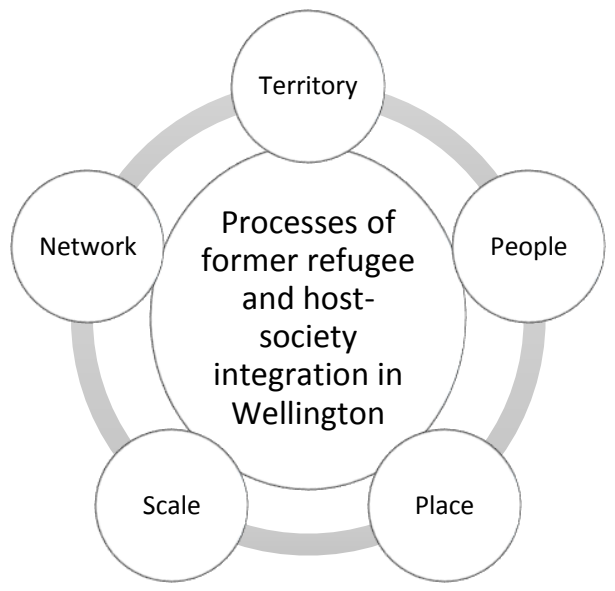

(Source: model adapted from Jessop et al. (2008) by the author, 2016)

\section{3:7 Chapter summary}

Through pre-workshop interviews and a series of weekly painting workshops, research participants invested time, energy, knowledge, and skills to share experiences and work together to produce a collaborative community-based mural. This painting process was democratically guided by an equitable PAR epistemology, which acknowledged the unique contributions each participant could make to the project and provided a space for dynamic interactions and contrary identities and ideas to be negotiated. Postworkshop interviews then offered participants the opportunity to assess the facilitation, 
conduct, and outcomes of the project, and to reflect upon their own role within the workshops, the social connections they formed with one another, and any shifts in their perception of different people, processes, and places. Such assessment and reflection provided the rich, relational data I had initially hoped to generate through the creative and interactive method of painting. In the following two chapters I draw on participants' experiences and reflections, as shared during interviews and workshops, to analyse the research outcomes through a sociospatial relational lens which centralises the study of former refugee and host society relations in Wellington city. 


\section{Chapter 4: Everyday Negotiations of Belonging}

This chapter focuses on some of the ways in which participants felt they were restricted from belonging, were negotiating the 'right' to belong, or were maintaining a sense of belonging to different places within their everyday lives and routines. Drawing on interview and workshop discussions, reflections, and imagery, I explore how the Treaty of Waitangi and other identity tensions include or exclude different groups and individuals in New Zealand, and discuss how the use of symbolism and the creation of multilayered narratives can enhance understanding of the multiple nuanced values and meanings of place to create a more inclusive society. I also explore how the development of people and city systems and structures led to a sense of displacement from or attachment to place for participants, and how their changing perceptions of what it meant to be a 'refugee' or a 'New Zealander' shaped their integration experiences. Following on from these discussions, I aim to highlight how participants' use of humour throughout the workshops enhanced social connections and paved the way for greater cross-cultural understanding.

\section{4:1 National identity and the right to belong}

In the pre-workshop interviews discussing existing understandings and experiences of belonging, all participants claimed that Māori and/or Pākehā had a greater claim to belonging in New Zealand, or were perceived to have a greater claim to belonging, than other ethnic groups. This 'privilege' had historical justifications, based upon either 'being here first' or being recognised through the Treaty of Waitangi. Participants also followed up by saying that, despite our indigenous and colonial history, all residents should have an equal right to belong. Binyam said,

I don't think the Māori got more or the Pākehā got more ... they may be more privileged like they are more 'Kiwi' than the people coming now, the refugees, so any jobs they get first because they have more 'Kiwi' experience. So I think they are privileged but this shouldn't be the way. It should be the same for everybody. 
Sarah* added, "I think Māori people can belong here more than me or other people coming, because first they started this country. But that doesn't mean that they can say you don't have any rights". The participants' views add weight to Mortensen (2008) and Sibley and Liu's (2007) findings that Māori and Pākehā perceived themselves to have a greater claim to belonging in New Zealand over other ethnic groups.

Several host society participants cautiously mentioned that, although they supported the resettlement of refugees in New Zealand, they found it difficult to prioritise resettlement needs when they perceived New Zealand to still have a long way to go with Treaty relations. Ken said,

I prioritise the stability of the society more than I guess helping out individuals, which is unfortunate, but you know, without having a stable society for refugees there won't be anywhere else for them to go. So yeah. Unfortunately that kind of does get muddled up when people make claims that this land is especially for them ...

Hilary presented a similar viewpoint in her interview:

Hilary: Well I suppose I feel like we need to in a way get our Treaty relationship well sorted before we engage in, well not before, it's already too late, but that to me is really important, to have that as well as engaging in that conversation around immigrants. I mean, I think, um, immigrants if they choose to live here and want to be part of this society then they have equal claim to belonging as well ... yeah it's interesting. I probably would still, in a way, in my head put it all in a ... you know ... a category ...

Amber: A hierarchical structure?

Hilary: Yeah, yeah, which is kind of terrible but ... I'm being honest about that in a way

Beyond the focus on the Treaty and racial or ethnic inequalities, discussions on public visibility in Wellington highlighted other identity tensions regarding gender and sexuality. Several people mentioned how leadership positions in New Zealand are maledominated, and in response to the over-representation of men in public life, the three men in the group each tried to downplay the need to represent men in the mural. There was also strong opposition to an image that might represent a nuclear, heterosexual family, as evident in the dialogue below. 
Nick T: I like the idea of it being women and children so it doesn't come off like a nuclear family, you know. You don't want that.

Hilary: No.

Nick T: And women would be really good as well as they have more culturally appropriate symbolic clothing than men do I think.

Amber: Mmmm, but it would be good to represent men as well, because it's Wellington in general ...

Hilary: Yeah.

Nic: Part of it is like posing a question to the audience like what is their identity? I think most people could identify with women ...

Ken: I think six women.

Nick T: I like the idea of women only.

Hilary: That's really interesting, I prefer to have men.

Tayyaba: Me too.

Amber: Me too.

Group: (Laughing at the men wanting to only depict women and the women wanting to depict men as well).

Hilary: Even if it's a boy...

Amber: Yeah a little boy or an old man so it doesn't show a nuclear family if we mix up ages, to avoid that heterosexual normative family.

Hilary: Yeah, an old man, a little boy...

Nick T: I can change my mind.

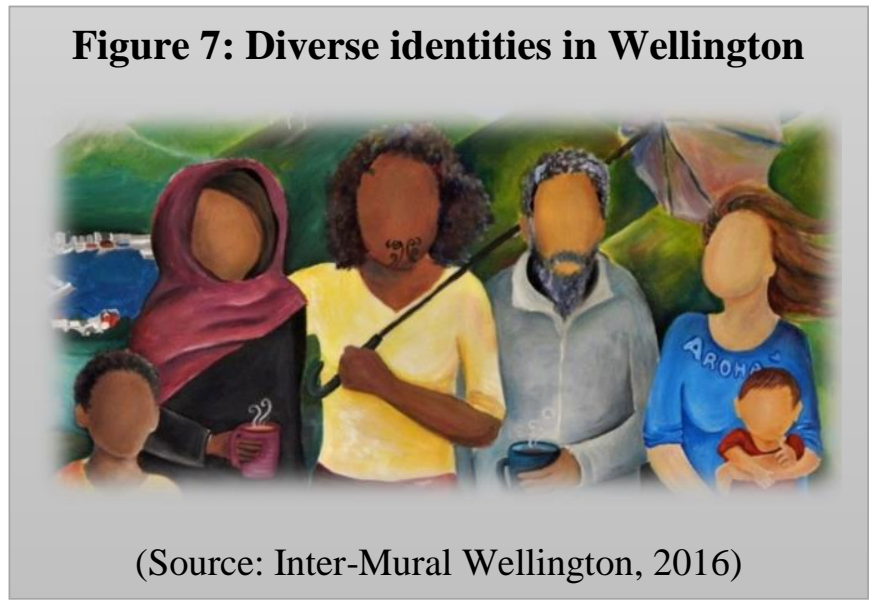

This discussion reflected a perceived need to atone or compensate for gender and sexuality-based inequalities by those who are considered 'privileged' in Western societies - generally white, heterosexual middle-class men. Whilst global feminist and queer movements are important in challenging repressive patriarchal systems 
and negative discrimination, new repressive structures can also emerge which restrict certain interactions and obscure other identities as illustrated in the workshop debate on who best represented Wellington. Nic again highlighted this in his post-workshop interview when he said, "I guess I often feel that my voice as a white male is not that important".

Nick T., Nic, and Ken's emphasis on women being more 'relatable' subtly replicates dominant ideas about women being non-threatening, and may perhaps play into dominant 'fears' of male refugees as posing more of a threat (Rettberg \& Gajjala, 2016). To compromise on the varying stances of who we ought to represent, the group settled on painting a mother with her child to illustrate the value participants placed on family in creating a sense of home and belonging, and a young boy and old man to represent males whilst avoiding excluding alternative sexualities.

We also agreed on painting a Māori woman (identifiable by her facial 'moko' or tattoo) and a woman wearing a hijab - to showcase diversity in cultural and religious identity. The hijab is particularly symbolic in terms of 'negotiations of belonging' within refugee and host society integration around the world, as an increasing number of European nations, including Germany, Austria, France, Belgium, The Netherlands, Italy, Turkey, Denmark, Switzerland, and Russia, have banned, or discussed banning, the wearing of various types of head scarves either nationally or in specific regions or public spaces (BBC News, 2017). Such controversial bans stem from a heightened fear of terrorism often linked to Muslim extremists.

To acknowledge such diverse, complex, and changing identities and politics, we decided to leave the faces in the mural blank so that audiences would not get distracted by specific features captured by a moment in time. We hoped that viewers would see the image as representative - to imagine that that those people depicted could be any one of us at various stages in our lives (Figure 7). In this manner, no particular groups or communities were privileged or excluded from the mural. 


\section{4:2 Symbolism, elicitation, and the creation of multilayered narratives}

\section{The use of symbolism}

Whilst symbolism was significant in terms of how we represented diverse ethnicities, genders, sexualities, ages, cultures, and religions, it was also instrumental in facilitating and enhancing group dialogue within the workshops. Sarah* mentioned that whilst she generally understood what other participants were saying, her limited English vocabulary at times hindered her ability to share her ideas. Yet, when it came to sketching, she was able to communicate some of her experiences and feelings symbolically, as illustrated through her explanation of her sketch below.

Figure 8: A link between home and a new life

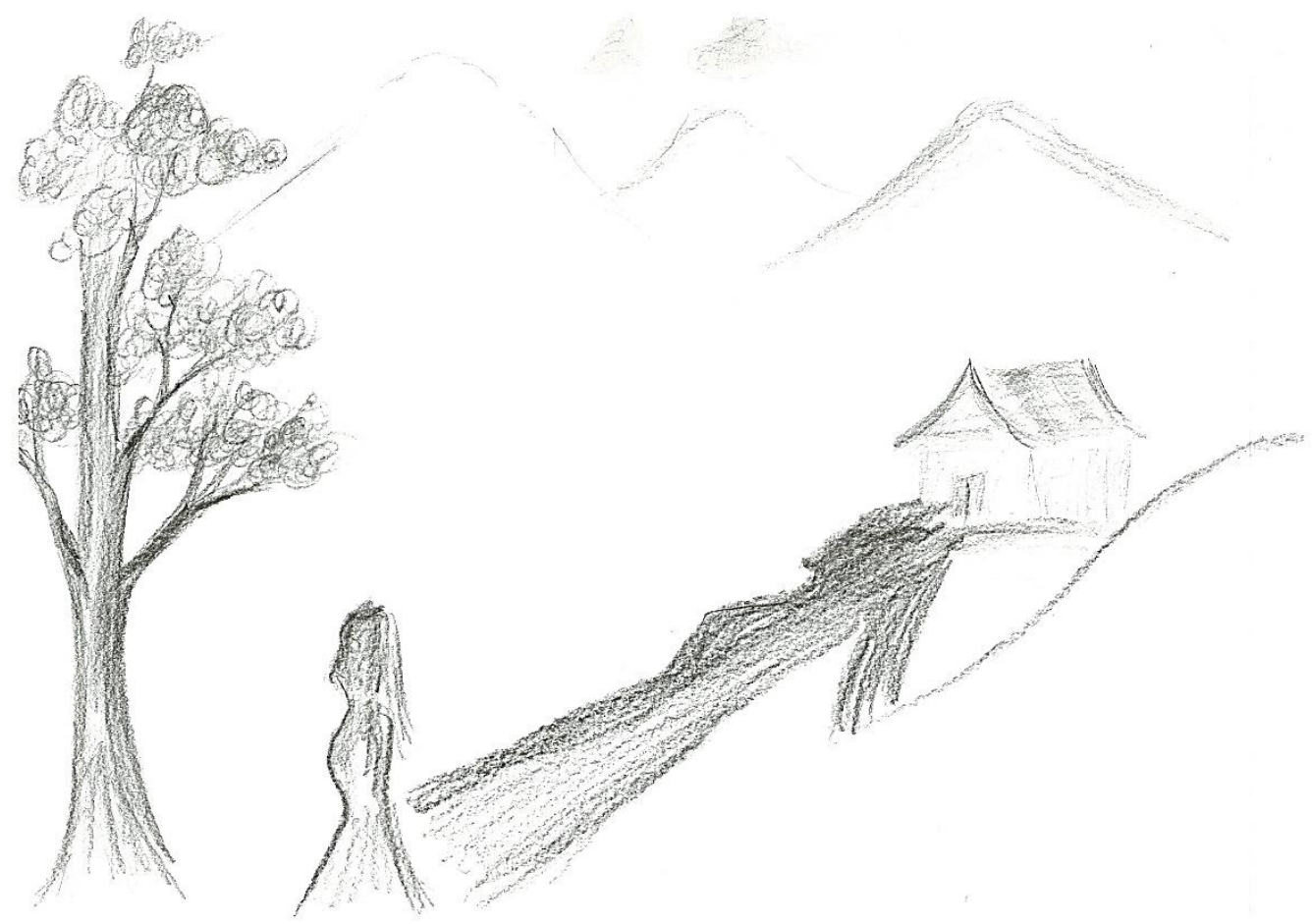

(Source: Sketch by Sarah*, 2016)

Sarah*: It's a home and this is a lady like me, and she has to leave her home and her country. And I just wanted to show, this is her shadow, it still links to her home, her country. And just I wanted to show, she's going to make new life. I draw this tree just because I wanted to show it is life, a new life for her.

Yordanos: That's really cool!

Amber: And what about the mountains and hills in the background? Is that something from your country? 
Sarah*: Just to show, from here to here, it's like, I mean she can make her own life everywhere but just she had to leave her family and her country. But er, how should I say, it's hard to explain in English ...

Yordanos: Like there is still a connection.

Sarah*: Yes! It's like life is very the same but it's different.

Talking through the image helped Sarah* to share more of her story as it prompted questions and suggestions. The symbolism was also a key way to make her experience memorable. After the workshops Yordanos said, "I remember the drawing ... Sarah* drew a woman walking away, and from that I got to know more about her, where she was from, and how her family is still back home”. Sarah* later represented these same experiences in the mural through a person being 'up-rooted' - where his leg is connected to the ground but then severed half way up, showing displacement and the need to put roots down in a new location (Figure 9).

In this manner, sketching and painting became tools for Sarah* to symbolically represent the people, places, times and feelings of disconnection that shaped her understanding of home. A camera could not have captured these particular images, and as acknowledged by Sarah* herself, nor could words always portray her story. Therefore sketching was an effective medium in enabling an alternative, expressive form of crosscultural communication (Afonso \& Ramos, 2004; Canal, 2004; Heusch, 2002; Pugh, 2003; Ramos, 2004).

Figure 9: Feeling uprooted

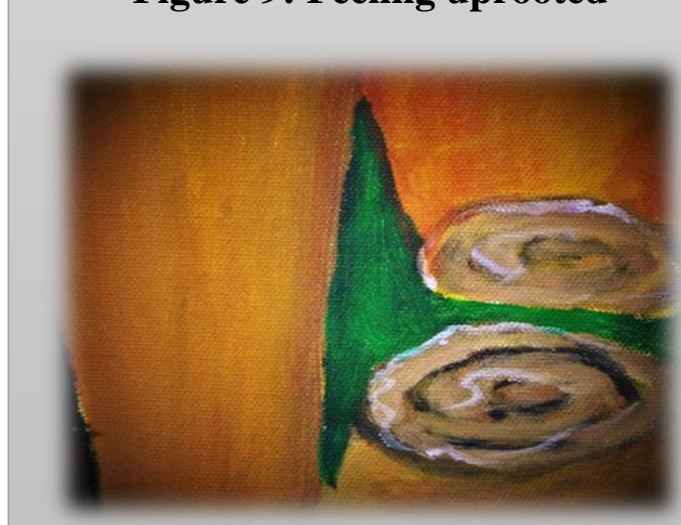

(Source: Painting by Sarah*, 2016)

Symbolism also provided a way for participants to share their unique individual stories without having to publically identify themselves. This was particularly significant for Sarah*, who wished to remain anonymous to protect herself from public scrutiny, yet still perceived it to be important to educate society on the experiences of refugees to deconstruct the negative stereotypes that make public visibility problematic in the first place (Lollar, 2015). 


\section{Elicitation and the creation of multi-layered narratives}

The use of sketching and painting in the workshops not only elicited questions which required the speaker to divulge more information and develop their own ideas further, but prompted other participants to share their experiences as well. For example, in the first workshop when discussing 'apples' Yordanos referred to the inaccessibility of food in Sudan, and how food linked to a feeling of comfort as it was a basic human necessity. Ken revisited this idea again later, adding how the availability of food contributes to peoples' health and safety. Nick T. again mentioned food in our discussions of how to make Wellington feel more homely, saying that the weekly night markets were a good way to showcase different cultures and cuisines and bring different people together.

Discussions of coffee followed a similar trajectory, beginning with one participant saying that coffee made them think of home, then extending to the sharing of multiple diverse ways coffee is made and used around the world. Yordanos explained Ethiopian coffee, saying,

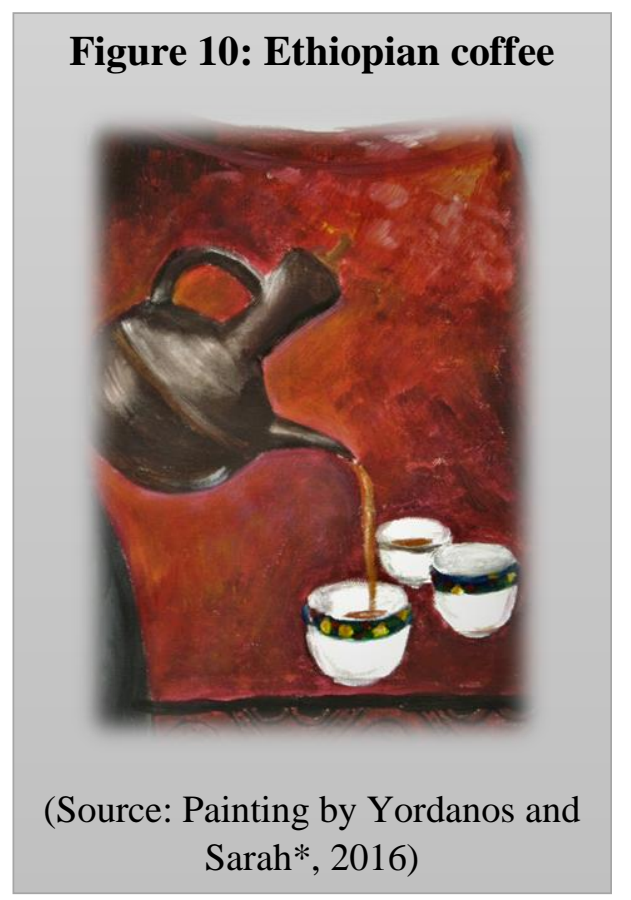

It takes about three hours and you have three breaks so it's like little tiny teacups. So you have one then they prepare the coffee all over again. So they roast it then it's crushed and everything then put in like a little kettle kind of thing made out of clay. And then it goes through the whole process three times. You have popcorn on the side ... it's all about getting people together and just talking and laughing and drinking coffee.

Thus, the symbols of an apple and coffee on our mural came to represent a range of unique experiences and nuanced meanings for different people (See figures 10 and 14).

The process of uniting all these unique experiences and symbols within a cohesive artwork reflected the challenges and benefits of wider processes of social integration, whereby unity must be achieved in a manner that does not 'over-ride' diversity. Whilst this type of unity required negotiation and some flexibility from participants, as evident 
in the discussion on identity representation, the finished mural portrayed more than just an eclectic juxtaposition of individuals and cultures; it told a story of encounter and interaction, of shared geographic and social landmarks, and a vibrant, welcoming multicultural home and city. It also depicted a collaborative journey to portray the complexity of this city through a shared creative process.

In this manner, the finished mural epitomised Aristotle's well quoted philosophy that 'the whole is greater than the sum of its parts', as a multilayered narrative was produced which challenged viewers to reconsider shared localities as having multiple meanings, uses, and value to diverse people (Cresswell, 2004). The depth of meaning achieved through symbolism showed that drawing and painting have great potential for challenging normative perceptions of people and places, and for addressing Putnam's (2007) challenge for diverse societies to create a more capacious sense of 'we'.

\section{4:3 Change and displacement}

\section{The making and un-making of home}

Throughout the painting project, former refugee participants mentioned feeling like 'aliens' in New Zealand, feeling torn between two different places, and missing family members. Having been forced from their homes, I had predicted that these participants might feel displaced. However, I had not anticipated the extent to which host society participants also reported feeling, or having previously felt, displaced. Host

Figure 11: The 'family home'

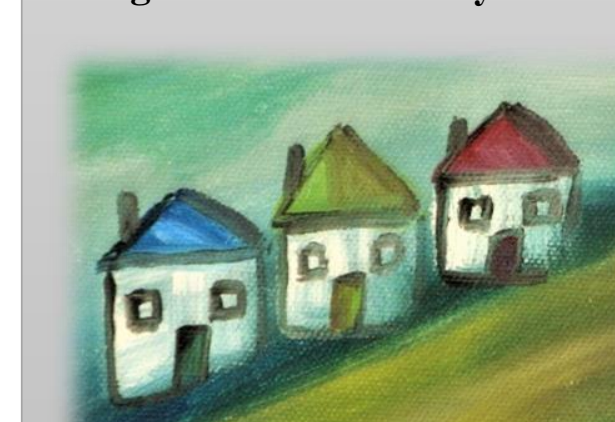
society participants discussed how individual perspectives of home and belonging change over time, saying how when they were young they loved the family home, as they grew older they couldn't wait to leave it, and then how they have created new homes with their partners and children and perhaps they might go back to visit the old 
family home and feel nostalgia (Figure 11). In sharing her experience of home Jamie claimed that,

My home as I got older ... some aspects became negative living there and I had to get out and so for awhile I thought, you know, I was so attached when I was growing up and it was always going to be my home. Then as I got older and yeah, I became a little detached ... but then uh, that's getting better so it's a bit more positive, so now like it's really nice coming home and seeing my mum and it was just so awesome to see my house and stuff like that.

Participants also discussed how individuals may view a place in one way, but it can develop and change - old pony clubs torn down to make motorways as one participant described, or recognisable icons demolished - there one day and gone the next. For example, in a discussion regarding the iconic Wellington landmark of the Cuba Street bucket fountain (Figure 12) Nic said,

It's interesting with the bucket fountain what it is and what it represented at the time, but then what that area is transitioning into at the moment and does it still feel like home anymore? Like how corporate that area is and Vodafone moving in ... it [the fountain]got put in in the 60's and had that warmth and gentrification and now that process has happened and creative people are slowly getting pushed out of that area.

\section{Figure 12: Our representation} of the bucket fountain

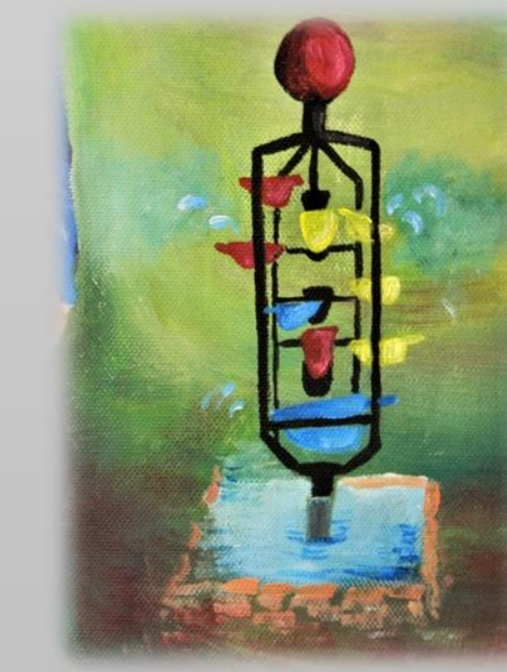

(Source: The author, 2016)
The bucket fountain was installed on Cuba Street in 1969 by architects and town planning consultants Burren and Keen to attract residents to a dwindling retail area. Whilst it is often viewed as 'embarrassing' by locals, it has also attracted its own fan-base due to its unique quirks, and is perceived as a Wellington icon (Harper \& Lister, 2007). Through our discussions of what the bucket fountain symbolised to us, as current local residents, we came to see it as a site of resistance to homogenisation; a way to reclaim the city as a place that reflects the creative and diverse 
people living there. This understanding highlighted the dynamic role of structure and agency in narratives of displacement, where changing landscapes can be forced upon people or force people out, but also where such changes may be negotiated or resisted (O’Neill \& Hubbard, 2010; Tolia-Kelly, 2008).

Whilst the experiences of displacement that participants chose to share were each very unique to the time, place, and circumstances in which they occurred, they resulted in participants dealing with common emotions of sadness and grief from a sense of loss. Recognising these emotions in one another enabled individuals from different backgrounds to connect through an empathic embodied understanding which transcended language and cultural barriers (Ferguson, 2011; Ramos, 2004). Thus, host society participants could begin to comprehend the challenges that asylum seekers, refugees, and former refugees may go through in having to leave their homes and resettle someplace foreign.

\section{Connecting to Wellington}

Despite the interviews mainly taking place in cafés, homes, and studios, and the workshops taking place at the university, many participants mentioned feeling more connected to Wellington city or specific sites within the city after the workshops. Nic claimed that he felt more connected to the city through "just knowing more people", whilst Ken felt more connected to the city due to "doing something voluntary, which I don't do much in my own time, it was kinda good having other commitments".

As well as interacting with others and contributing to a local project, this renewed sense of place-attachment emerged through the process of talking about places during the workshops, then remembering these conversations when confronted with the place itself, and considering it from a new perspective. For instance, Yordanos claimed that,

I've realised that I actually do belong more. Because just talking about trying to think what it was in Wellington that we can relate to, it made it more concrete for me in a way, my idea of belonging in Wellington. Like you know when we were talking about the little bucket thing, usually I think that's just a bucket, but it's part of Wellington and it shows the connection I have with the city. 
The iconic bucket fountain which previously had little personal meaning to many of the participants now symbolised a shared identity and a familiar landmark. Nic, Tayyaba, and Hilary also mentioned the bucket fountain as an interesting point of discussion which shaped how they see the city. Thus, it became a key symbol of home in our painting. Tayyaba claimed that,

I think when you guys were talking about the bucket fountain - that symbolism stuff, and I was like yeah it's interesting. Cause we don't consciously think about the symbolic sort of stuff but it makes such an impact on what you define as home. And that's what has changed for me about Auckland, because it is changing so much structurally that those symbols I used to connect to no longer exist and that has really displaced me.

The windiness of Wellington was another shared aspect of local identity that emerged as significant, as participants each had stories of the windmills that are visible on the surrounding hills, umbrellas blowing insideout and being found in rubbish bins, and hair blowing across

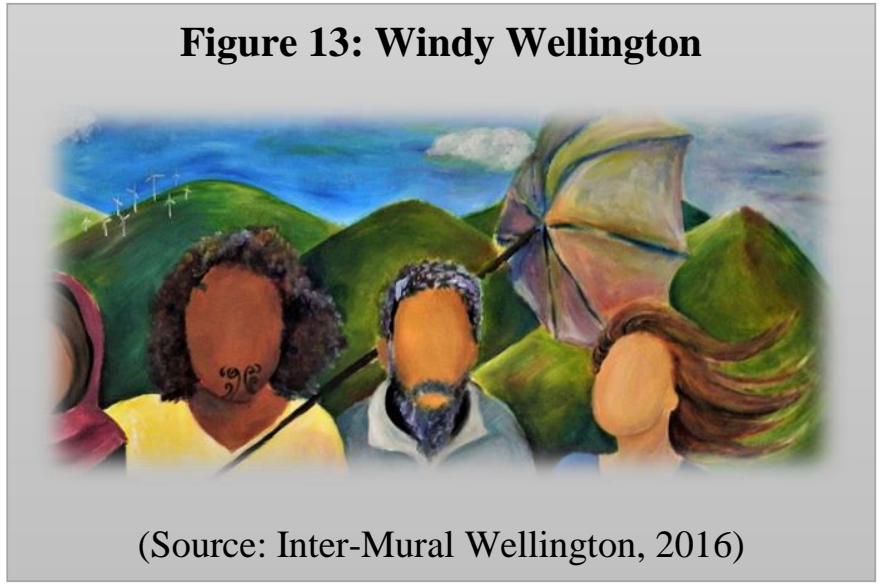
faces. Thus, 'Windy Wellington' became the background for our mural (Figure 13). As with the bucket fountain, participants perceived the windmills as a familiar landmark to orientate themselves around. Yordanos said, "Flying into Wellington on Monday I saw the windmills and was like yeah, I'm back. I'm back home. It's little things like that". In this manner, geographic landmarks and symbols were identified as important aspects of displacement and place-attachment which shaped individual perceptions of home and belonging. 


\section{4:4 Challenging hegemonic discourse}

\section{Deconstructing refugee stereotypes}

When I asked former refugee participants if they identified themselves as refugees in their pre-workshop interviews, Binyam said, "I was a refugee at one stage of my life, but that is over now". Yordanos also referred to being a refugee as a transitional period in her life, claiming that, "I consider myself a former refugee”. Sarah* agreed, saying,

Before I became a refugee I didn't think good about refugee, I just think homeless person and feel pity for them. But after I leave my country I see it's about different situations. Now I have my own experience, I meet lots of people with different experiences, so now when I hear this word I don't know about them. I used to only hear about it from the media and it's not always right ... I don't like this word [refugee]. In New Zealand I don't think so, I have this background, but now I'm allowed to work and study ... I'm Iranian who lives in New Zealand. When you hear this word [refugee], just not judge people because there are a lot of people with different cultures and attitudes. Don't judge them, try to know them. If you know just four people you can't judge all the people the same. They come from different culture for different reason.

Sarah's* story depicted her experience as a non-refugee, a refugee, and a former refugee. Her understanding of the term refugee changed throughout this journey, shifting from pity to empathy and an acknowledgment that refugees are not a homogeneous group but individual people each with their own unique lives. Yet, despite each of the former refugee participants claiming to no longer be a refugee, they still felt the stigma that comes from having such a background. Yordanos discussed how the term 'refugee' carries with it a strong image of a certain 'type' of person, with whom many people fleeing war or persecution are unlikely to identify.

From my experience, people don't know that, a lot of them don't know you're a former refugee. Because they have this idea of what a refugee is from what they see on TV, especially with what's going on right now in Syria and stuff. So a lot of my friends at first didn't know that I was a former refugee, but once they do find out they're like 'oh my god, like really, what happened to you? Like what sort of trauma did you go through?' ... Once they found out it was like, yeah, they were interested, they wanted to know. And that's something I've noticed - that people like a story. It sounds bad, but they like to hear a story. Once they find out you're a former refugee they want to know 
more ... which is good because it brings awareness to what's going on in the world ... but there is also that pressure. Well not pressure, I don't have to say anything, but it's just people want to know and there's that judgement and assumption of what I've been through. Because the number of refugees in the world has grown, there's so many different issues now arising and people have an idea of what a refugee should be ... Sorry, on a side note, I met this lady yesterday and she works for the consulate in Denmark and she was telling me about the refugees, um, from Syria to Denmark. She was talking about how a lot of them are men and it makes you question, 'Are they really refugees or are they just migrants?' And I was so frustrated because she thinks just because they are men they can't be refugees fleeing, like yeah. It's people like that that need to be educated to understand what it really means to be a refugee. Like there's so many, it's not just one specific definition. There are so many reasons why someone can be a refugee. We didn't have any choice. My dad was being sent back to Ethiopia to be prosecuted and it wasn't safe for him in Sudan and so he went through the whole UNHCR process and without any choice we had to leave and come here. We left my mum behind then she moved 5 years ago and went to Sweden which is great ... I saw her 3 years ago and that was the first time in 11 years. That was amazing. I haven't seen her since I've been at uni, but I'm hoping to see her soon or she can come here. Resettling here was probably the most difficult time of my life. And I was so young as well. I didn't know about New Zealand before I came here and couldn't speak English as well. I could only speak Arabic and I didn't know anyone else here. It was just me, my dad, my step-sister and my step-mum. It was just us. So yeah, I struggled to fit in and make friends at first. Because I couldn't communicate with them. So that was like my first struggle at first, but once I learnt English I could fit in. I started to belong.

In particular the assumption of an experience of trauma by Yordanos' friends in her story was problematic, as such assumptions overlook the strength and resilience many former refugees express, and can lead to further (often unfounded) assumptions of former refugees being 'burdens' on healthcare and welfare systems (Collie et al., 2010; Lenette et al., 2013; Munt, 2012). Far from being dependent on others, the three former refugee participants in this research were highly qualified, volunteered within their communities, and were proactive in starting their own businesses or finding work. 


\section{Shifting perceptions}

As discussed in Chapter Two, the media has been heavily critiqued by academics for perpetuating negative refugee stereotypes and misinformation, and for the suppression of alternative discourses, although it is acknowledged that more 'counter-narratives' are now emerging as well (KhosraviNik, 2010; McKay et al., 2011; O’Doherty \& Lecouteur, 2007). Some of the host society participants in this project claimed not to follow the news or expressed a strong distrust for news stories in general. Tayyaba said,

I'm actually really not happy with the New Zealand media, and I'll tell you why, it is because we don't have a New Zealand media identity. We rely on global news and make it a domestic issue. And I think that is really a problem because it just takes away from what is really happening here. And I've seen that happen often. The other reason why I don't rely on the media is because of my work overseas where I found media adds fuel to the fire. If you really want to know what is happening with an issue, don't get your primary knowledge from the media. The third thing I think to add to that is that our media here is rather limited. So they won't diversify the content, which means that you get a really narrow confined view of something. You have very few alternative perspectives represented there.

Ken also expressed distrust in mainstream media due to the extreme polarised views expressed which overlook the complexity of a situation and fail to represent alternative viewpoints. When I asked where he got most of his information from he said, "Mostly social media like Youtube. Youtube is a very good place to find information. I generally don't trust mainstream media as much because they ... one media firm will be like right leaning, the other will be left leaning”. Nic and Jamie also both mentioned getting information from social media or through individuals such as "the guy who started doing 'humans of New York'”. Whilst social media can also be misleading, it can often provide the alternative viewpoints which mainstream media lacks and which the research participants were searching for (Fozdar \& Pedersen, 2013).

Providing a space to share individuals' lived experiences through discussions in our workshops addressed this need for alternative discourse. It also encouraged participants to consider how different labels and stereotypes were being used, and challenged them to be more open and mindful of what it means to be a 'refugee', and what it means to 
be a 'New Zealander'. In post-workshop interviews, many of the participants reported having learnt something new about what it means to be a refugee, about the resettlement process in New Zealand, or about one another's lives.

Through discussing resettlement with Yordanos, Nic had the opportunity to hear a firsthand account of the stigma associated with refugee status and the challenges former refugees face in dissociating themselves from harmful refugee stereotypes. He said, "I guess it was all about when you change from being a refugee into just a citizen and yeah, just the misunderstanding or not having knowledge about what that meant." Yordanos said, "I feel like we educated each other. Like I talked about my refugee experience and stuff and, what's his name, Nic, how he does art. And I learnt about his organisation."

In this manner, education was not something that participants attributed to the researchers, or to any specific institution, knowledge was something we all had, all shared, and all acquired (Choudry, 2014; Kindon et al., 2007; mrs kinpaisby, 2008). When discussing what she had learnt from the painting process in her post-workshop interview, Hilary claimed that,

I think just sort of recognising that there are a lot of different people walking around in this environment who have different experiences. And I suppose especially with my, the work that I do voluntarily with the Aro Valley Community Council, and working out how we can try to connect with refugees in our community. We're not particularly good at doing that so it was good to realise that we've got to work a bit harder. Well not harder, smarter. To think about what would work in terms of connecting.

Thus, the opportunity to talk with people who have actually experienced being a refugee can augment, ground, and shift media constructed representations, particularly regarding migration, asylum, gender, and trauma. Social encounters and an analytical focus on propinquity are thus valuable political processes for sharing alternative discourses and counteracting those global media stories which perpetuate negative refugee stereotypes and misinformation (Amin \& Thrift, 2002; Darling, 2009; Massey, 2004; Wilson, 2016).

Yet, encounter alone is not necessarily enough to facilitate discussion. Simply being in a shared space or close proximity does not mean that language, cultural, social, 
economic, political, physical, or psychological barriers have been removed. Different resources are needed to engage diverse individuals and enable them to find common ground and begin to build connections. Such resources may be physical objects which can be acknowledged, shared, and negotiated, or they may be cognitive or emotional resources such as starting a conversation or sharing a laugh. The painting project provided such resources through both physical tools and relationship-building techniques that prompted participants to interact and transform an initial encounter into something more meaningful and sustainable.

\section{4:5 The role of humour in social interaction}

\section{'Letting go of some of the angst'}

When discussing the concept of home in the first workshop, the following dialogue ensued:

Yordanos: When living in Sudan we used to have apples, like you know apples. They were these big red juicy apples and I wasn't allowed to have them because they were so expensive. And one day my mum bought it for me and it was like the most amazing, like the happiest day of my life, and I couldn't, I've only had it once in Sudan. And I came here and I saw how many apples there were in New Zealand and we were at the Mangere resettlement centre - all I ate for the first couple of days was apples and I got so sick of it that I actually hate apples now.

Group: (Giggling)

Ken: (Holds up the apple juice)

Amber: Oops sorry about that ...

Ken: (Joking) ... You've ruined her safe space now

Group: (Laughing)

The laughter from this interaction had two immediate effects. It set the scene of the workshop as a relaxed, fun space, and it established a sense of connection within the group, as, despite their different cultural backgrounds, participants could relate to Yordanos' story and see the humor in it. This particular exchange acted as an 'icebreaker', enabling participants to feel more at ease with one another as they were all in on the joke. Martineau (1972) claimed that ongoing 'in-jokes' between group members 
can create a 'common language', whereby meaning is derived from reference to the joke, but only to those who understand the wider context in which the joke was first shared or conceived. Such a common language became more evident throughout the workshops, as the subtle apple references continued, even within the mural (Figure 14). Thus, in a similar manner as to how familiar landmarks created a common geographical reference point for participants to bond over, the use of humour created a common social reference point.

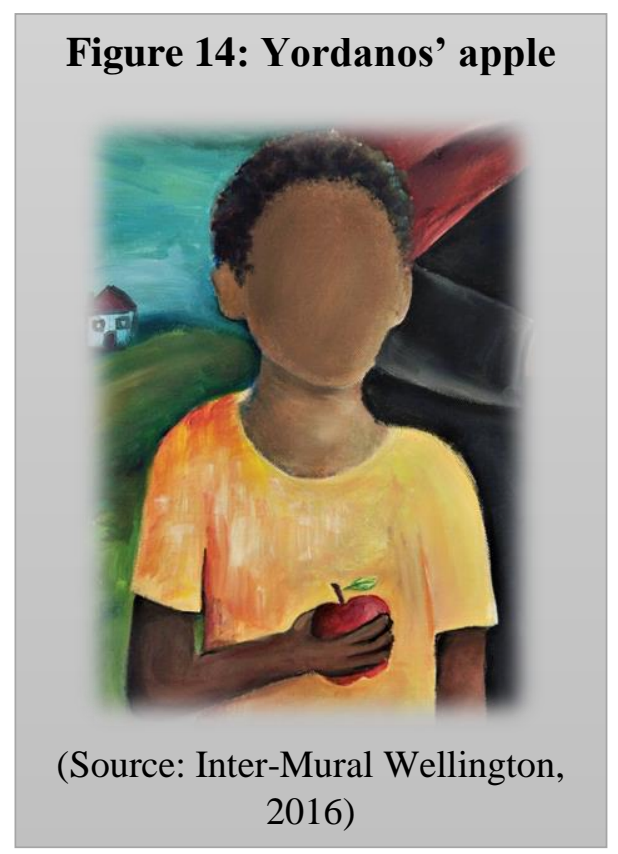

Whilst the significance of humour appears to have been overlooked within geographic research on social integration, anthropologists and psychologists have focused on the use of humour to navigate social standpoints, ease conflict, and strengthen social cohesion, as well as its use as a social corrective (to punish those who deviate from the status quo) and political ventilation (to satirically challenge controversial policies and government actions) (Ziv, 2009). Ziv (2009) claims that humour can be used to investigate the 'standpoint' or 'spectrum of opinion' of an individual or group, without the person using humour feeling pressured to meet social expectations. Depending on whether the story or joke elicits laughter or shock, the speaker gains insight as to whether others might understand or agree with their experiences, views, and perceptions. If the story is ill-received, it can be brushed off with the speaker claiming that they were 'just joking', and their reputation remains intact.

When discussing the use of humour with research participant Tayyaba in a postworkshop interview, she claimed that, "If the team dynamics are not so great I use tools of humour to defuse those tensions and gel the team back together. And I think that's a great tool for people, it helps to get them to loosen up and let go of some of the angst, because laugher helps with that". Thus, humour can also lessen tensions and conflict within a group, and work to build trust and strengthen community relations (Radcliffe- 
Brown, 1940; Ziv, 2009). Many of the workshop participants further highlighted the significance of humour in making social events fun. Hilary said that, "In that sort of space where you are doing something in your free time, it's important that it feels relaxed and fun as opposed to this is really serious work, you wanna be enjoying it". Yordanos also claimed that,

Coming to the workshop was fun because it wasn't like you have to be here, you have to draw or sketch or something, it wasn't like that. It was, you know, come and hang out for a bit, do some drawing, have a chat. Like me personally, I'm not a good artist, but the fact that I could make a joke about that, saying oh look, I can't even draw an apple! It makes everyone more comfortable and I dunno, if you were shy about your skills or anything ... I was terrible at it, but it's not like anyone judged me or anything, there was no judgement.

\section{Mindful negotiations of humour}

Whilst humour lessened negative judgement in this context, which was important in creating a safe and trusting environment, it is also important to consider how humour may have encouraged more subtle processes of assimilation. Bergson (1914) and Ziv (2009) claimed that laughter may be used as a corrective behavioral tool to challenge an individual who acts outside of 'normal' group etiquette. By making this individual the butt of the joke, by laughing at them not with them, the group can bully the individual out of the group or reform them to 'fit in'. Whilst this did not occur during the painting workshops, there is the possibility that individuals may have chosen not to share specific stories or jokes which they assumed may be misunderstood or unappreciated by others, to avoid this sort of response. In this manner, individuals may be suppressing their own sense of humour to 'fit in' with normative assumptions of what is amusing.

Therefore, it is also important to acknowledge what may not be said in a group context. Post-workshop individual interviews provided an opportunity to explore the withholding of information, as participants could reflect on how they interacted with others without the fear of causing offense or feeling embarrassed. In Nic's interview he claimed that he felt his voice as a white man was unimportant. The idea that his race and gender made him feel as though his contribution would be less valuable in a project 
that focused on social justice for marginalised groups, restricted what he chose to share with the group. This 'withholding' is an example of Ting-Toomey's (2005) theory of Mindful Identity Negotiation, as Nic acted strategically to enhance his likelihood of being accepted within the group, or to meet perceived research expectations. Such negotiations could be empowering in terms of choosing when to speak up or remain invisible (Lollar, 2015), though may also be restricting due to perceived social boundaries, and the risk of exclusion or disapproval should these boundaries be crossed.

Anthropologist Radcliffe-Brown acknowledged the way different identities are positioned and negotiated within humorous interactions in 1940, when he discussed the humorous relationship as one of "permitted disrespect". He claimed that, "Any complete theory of it must be part of, or consistent with, a theory of the place of respect in social relations and in social life generally" (p.196). Participant Ken highlighted this concept of 'permitted disrespect' by claiming that, "One of the things I really enjoy about comedy is that it puts things into a different light. Puts things into a different perspective, into quite a silly humorous way that people might not have thought of. So it's good. But obviously some people have zero tolerance so ... it's how you word it really". Ken illustrates how humour could easily evolve into perceived cruelty if the joke crosses personal or social boundaries of appropriateness, and acknowledges the thoughtful consideration that is needed in deciding whether to share a joke or how to deliver it in a way that minimises offense.

Whilst the delivery and specific content of humour may require diplomacy, both on the part of those individuals who are interacting and any facilitators who may intervene, the overall benefits of humour in the painting workshops led participants and myself to conclude that humour played a key role in enhancing social connections, whilst also providing a space to express alternative viewpoints and unique experiences. In particular, the use of humour relieved the pressure of participants having to perform to a particular standard, which enabled more open and honest dialogue. 


\section{4:6 Chapter summary}

The themes discussed in this chapter highlight complex challenges to developing and maintaining a sense of belonging in Wellington. These challenges shaped participants' everyday lives in subtle and unique ways, requiring ongoing identity negotiations which constantly repositioned individuals in relation to one another, and in relation to various places and politics (Collie et al., 2010; Ting-Toomey, 2005). However, the use of symbolism and humour during the workshops highlighted two key relationship-building techniques which can be utilised to enhance social connections and a sense of belonging for former refugees and host society members.

Through the use of symbolism, multilayered narratives of home, belonging, and visibility within public space were developed, which enhanced understanding of both the diversity and commonalities between individual participants and different cultures (Afonso \& Ramos, 2004; Cresswell, 2004). Humour also enhanced cross-cultural understanding through creating a relaxed atmosphere within the group which enabled participants to feel comfortable talking about their experiences and discussing sensitive topics (Martineau, 1972). These relationship-building techniques are important in deconstructing perceived social and cultural barriers and enabling greater social collaboration for a more accepting and equitable society. 


\section{Chapter 5: A More Inclusive Citizenship}

This chapter explores how we, as diverse New Zealanders, might work together to begin to bridge the incongruence between New Zealand's non-discriminatory citizenship rights in law, and exclusionary practices within processes of social integration. I build on Askins (2016) and Wood's (2013) theories of emotional citizenship, and Marshall's (2006) theory of social citizenship, to argue that a more inclusive form of citizenship is needed which focuses on diverse emotional experiences of everyday life in New Zealand, and which aims to enhance social connections, build social capital, and enable a greater sense of belonging for former refugees and other marginalised groups.

\section{5:1 Hospitality and welcome}

\section{Performing a 'good' welcome}

Despite participants perceiving New Zealand to have a hierarchy of belonging that privileges Māori and Pākehā, almost all participants claimed that New Zealanders are generally friendly and hospitable towards former refugees. However, there were several stories of discrimination which also emerged. Yordanos claimed that,

I have come across people who do feel like only a certain group or race should belong in New Zealand. Um, like, I've been told to go back to my country before ... I am a New Zealand citizen now - this is my home. I just sorta want to whip out my passport when that sorta stuff comes out, like really?!

These overt tones of racism are problematic in making individuals feel unwelcome and unsafe, yet equally as troubling to participants were the less visible, and perhaps less intentional, forms of social exclusion. Several participants discussed the idea that being friendly does not necessarily equate to being welcoming. Binyam said, "Kiwis are nice people, but it's hard to integrate. They're really welcoming, but it's a matter of like ... not getting involved”. Tayyaba agreed, saying,

Generally people are really nice you know, but that's just New Zealanders, they are not the kind of people who are going to be awful to you. But being nice actually doesn't 
equate to being welcoming, and I think that's the difference. So being nice and saying hi or hello, that doesn't mean that we don't have barriers and take precautions, we aren't breaking the ice.

Hilary added, "I suppose even in my own situation where I know that those people are there, some of them live down the road from us and go to our school, but I guess there's a certain ... I guess I haven't gone out of my way to get to know them". These experiences highlight a key flaw in New Zealand's refugee resettlement system and wider society - a lack of social bridging.

Through her empirical PhD research, Woodrow (2016) highlights this same flaw in Australian resettlement. She argues that, "As hosts and cultural agents we need to do significantly more than erect a sign, or write policies about social inclusion, to genuinely welcome people from refugee and asylum seeking backgrounds to urban centers in Australia. A good welcome needs to be performed" (p. 163). By 'performed', Woodrow refers to a good welcome being practised or lived through everyday actions - similar to the way citizenship is described as being lived in Chapter Two.

I agree with Woodrow, and argue that a focus on emotional and social citizenship and investment in building social capital in New Zealand is key to encouraging such an embodied and sincere welcome. As participant Tayyaba said, "It's really important that we understand the nuances. It's not just as simple as rescuing people and bringing them here and the job is done. Actually now is when the job starts, cause these people need to be reintegrated; learning a whole new system from the beginning”. Binyam reiterated this point when I asked him what the most difficult part of moving to New Zealand was:

Just the whole resettlement process, different culture, different people, different environment. Like the first time people take us to Pak n' Save, for shopping, and it's just a different world. It's totally different. We live in ... the place that we came from, it's totally different. Everything is different. It's just huge. Like, with the children, we had to teach the children how to go toilet, even that was different. And other things, the money, and some people are asking to give us food. They think we just need food, clothing, shelter, and we don't want the benefit, but yeah. It's just totally different. Like an alien person from another planet ... and the signs are all in English, so imagine someone can't speak English like you can't even find the toilets. Everything is different 
so you need someone to look after you for awhile to help. Even the shopping is really hard for people.

\section{Changing roles of 'hosts' and 'guests'}

The question of who ought to perform such a welcome was also raised by participants. As residents who were familiar with Wellington, host society participants generally perceived themselves to have a responsibility to welcome newcomers. In Ken's postworkshop interview the following discussion took place:

Amber: So you're kind of like a host because you've got that familiarity ...

Ken: Yep.

Amber: So do you reckon that refugees could become hosts as well?

Ken: I believe so. 'Cause I've only been living in Wellington for like eight years now so ... it just takes time to get used to the city. And then in the future they can help other refugees as well, so that's one of the benefits.

This excerpt highlights how knowing one's way around the city and how to navigate local systems, as well as having familiar contacts and networks, can enhance a sense of belonging. For Ken this sense of familiarity with Wellington made the city itself feel like home, hence his choice to depict it on our mural (Figure 15). However, a sense of familiarity could also be developed by

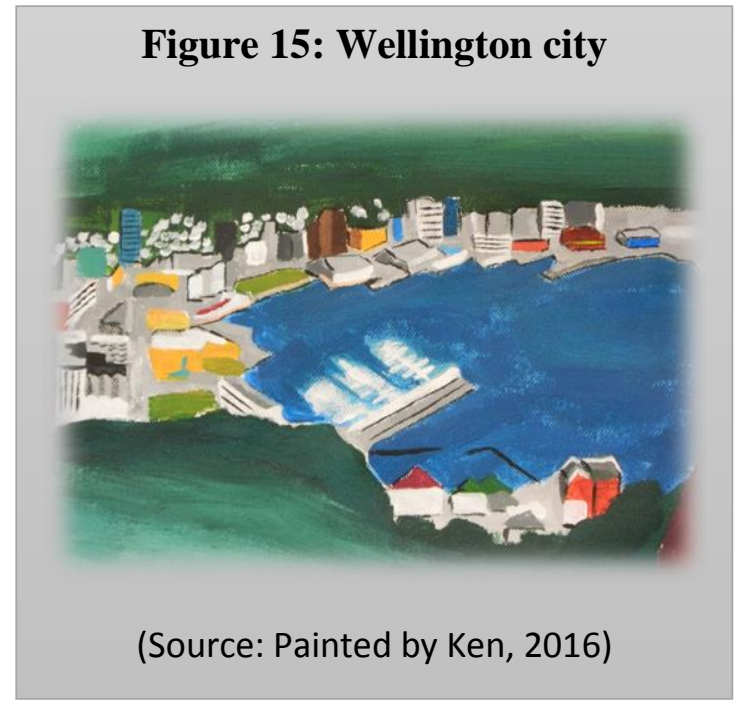
newcomers over time, enabling immigrants to feel 'at home' and to act as 'hosts' and welcome others.

This link between familiarity and hospitality was visible within the painting workshops. The workshop space was new to many of the participants, but familiar to myself, and may have contributed to hierarchical power relations as Nick T. and I set up the room, provided food, and invited the participants in. Research participant Nic acknowledged this role of 'hosting' in his post-workshop interview, saying, 
I guess the manaakitanga [hospitality] ... like the hosting and the food kinda stuff was quite interesting like whether you make food or buy it in packages and how it is a different sense of hosting. But yeah, it was awesome that you did that and um, also like do you have tea, coffee, and how much of that becomes part of the process?

Nic was referring to the different ways power dynamics might be shaped through the creation and presentation of food, and how that may impact upon the art-making process. His comments were significant as, over time, when participants become more familiar with the painting space, they stopped waiting for me to offer the food and drink I always had on the table and started to offer it to one another. Participants also began to take it upon themselves to find the nearest rest-room to change the painting water, or let other participants into the building. They moved around to work in different areas or to make use of the computer and projector to search for images and to play music, shifting the seminar space into a creative interactive environment which better suited different needs.

In this manner, the 'guests' became 'hosts' over time through the way they distributed, shared, and negotiated space and resources (Askins \& Pain, 2011; Wilson, 2010). Such a shift in power enabled a once hierarchical space to become more open and participatory, and helped participants to feel more confident in sharing ideas and contributing to the painting. This emphasis on the significance of place within participatory power relations supports Kesby's (2007) claim that empowerment needs reconceptualising in spatial terms as well as temporal.

However, Wilson (2010) points out that, "A person is host not only within a fixed geographic space but can also be host to ideas or experiences, which they then invite others to participate in as their guests" (p. 113). Even in the early stages of resettlement when former refugees' abilities to participate in and contribute to society may be limited due to physical and social barriers, as discussed in Chapter Two, individuals possess a wealth of knowledge, skills, ideas, and networks which can be shared. Yet, for such interactions to take place, both former refugees and host society members must be willing to accommodate one another to some degree; hence the need to enhance understanding of the unique spatial, temporal, and epistemological ways in which people can act as hosts. 


\section{5:2 Emotional citizenship}

Participants also acknowledged the concept of familiarity to extend far beyond the recognition of geographic and social landscapes. Research assistant Nick T. mentioned that familiarity was, "Just certain smells, like walking past someone wearing your grandma's perfume and you think oh that reminds me of home. Smells or hearing an old song or something, you know, reminds you of time with the family". Thus, familiarity did not necessarily mean knowing a place as Fitzpatrick (2002) describes, or even being present in a familiar place, it was also about the emotions and associations that certain locations, people, and senses evoked. In this sense, feeling 'at home', or as though one belonged, was a fluid emotional reaction to changing circumstances and stimuli and multiple sensory experiences (Cresswell, 2004; Munt, 2016; Trnka, Dureau, \& Park; Wilson \& Milne, 2012).

Ken then noted how familiarity was linked to identity - how we recognise those things that are important to us and which have shaped our lives in some way. He said,

I used to live in Mount Cook and there is a street called Bidwell Street that forks off and there are all these houses bunched up, and when I walk down it kinda reminds me of where my grandparents live cause all the streets in Japan are quite narrow and bunched up. So walking down that street reminded me of my relatives overseas. Those subtle links that bring together your subtle identities even though I guess they may not be your home. In a way, it's part of who you are, your origin.

Through her painting of the 'ajrak' (Figure 16), Tayyaba also illustrated how subtle identities can connect different times and places through the development and expression of personal values and philosophies.

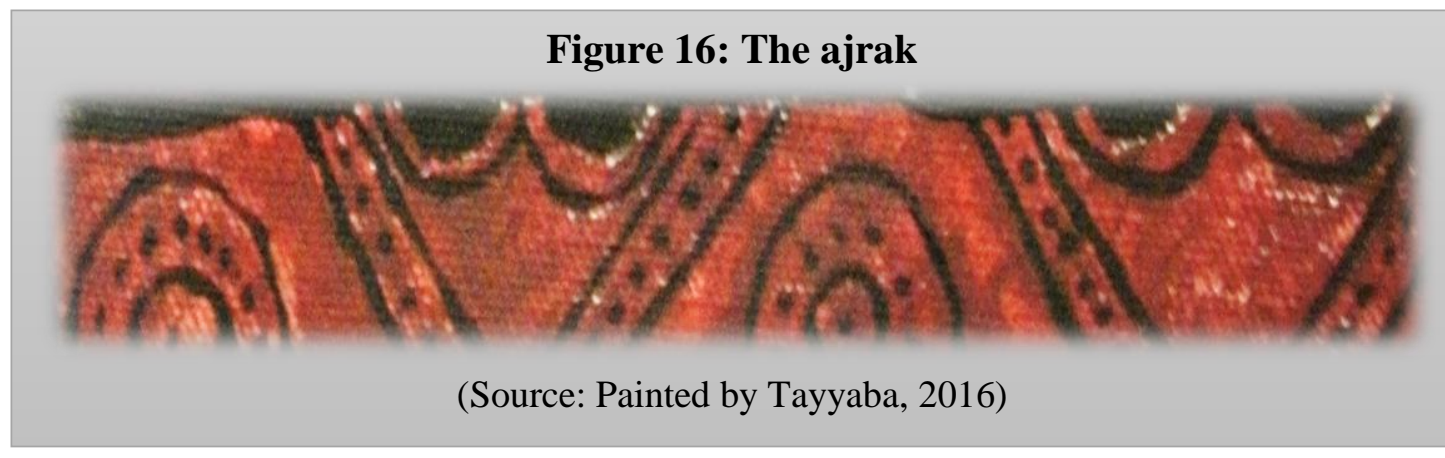


Where I was born in Pakistan it is a really impoverished small town in the province of Sindh. And they have a particular pattern. Um, it's a shawl which you give to someone in honour of respecting them, valuing them. And kind of, whether I give that to you because I think that you are an amazing person or you are wise or I respect you, and it's called the ajrak. So I guess for me, I use those values quite a bit wherever I go and however I operate.

Whilst these experiences of familiarity were important in reaffirming certain identities and making people feel comfortable within certain spaces, they also prompted negative feelings. Tayyaba said, "Because my background is one of displacement and war, it's kind of a huge part of what I carry wherever I go". Thus,

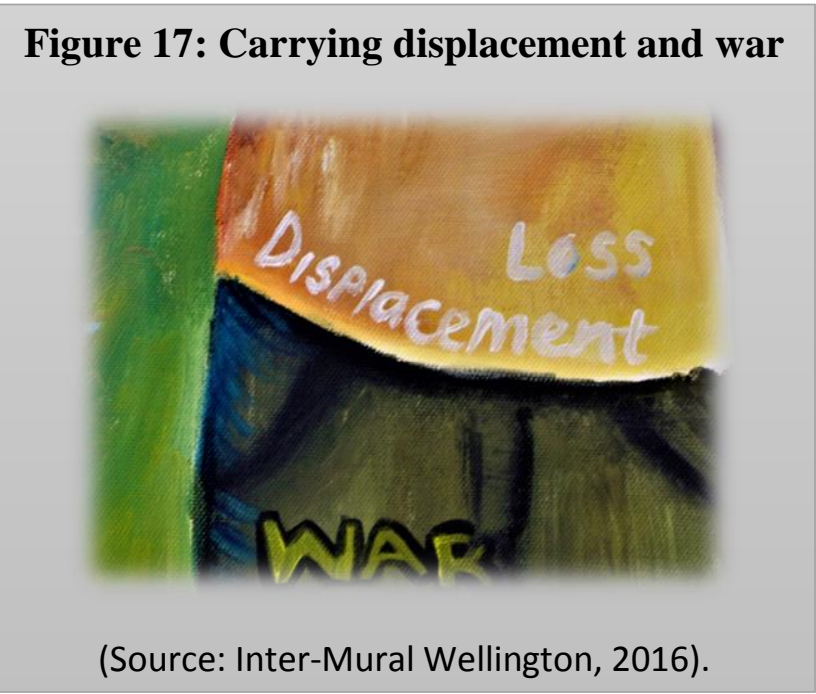
familiar senses from her past made her feel worried for her family who still live in areas of conflict - supporting Blunt and Dowling's (2006) claim that home may also be a place of insecurity, violence, and terror, and therefore ought to be recognised as subjective, contextual, and complex. The words 'war', 'displacement', and 'loss' were written onto one of the people in our mural to represent these diverse identities and feelings that people carry with them and which shape understandings of new places (Figure 17).

The significance of acknowledging these subjective, contextual, and complex emotional understandings of home is that emotions and feelings shape the extent to which individuals participate in and contribute to society (Wood, 2013). If people are struggling to deal with loss or feelings of guilt or fear from leaving their homes, if they do not feel welcome or appreciated in their new homes, if they feel isolated and unappreciated, all of these potentially compounding issues can cause social and psychological barriers to integration. As Yordanos said,

I obviously don't fit in with everyone, I am different, so I feel that I belong in Wellington because it's such a diverse little city. And a lot of people do appreciate the different 
cultures. When I talk to someone they are like, oh, where are you from? I say I'm Ethiopian and they say I've never tried Ethiopian food or what's that like? And I can be like, there is an Ethiopian restaurant in Wellington - go and check it out. I feel like I belong when my culture and who I am is appreciated.

Through sharing their unique experiences in the painting project, host society and former refugee participants recognised common feelings in one another and bonded over these shared sentiments. The creation of such emotional bonds enabled participants to extend a more embodied and sincere welcome to others in the group. Thus, emotions are a common human language which can be recognised even when strong cultural differences and unique circumstances exist. They provide a way for people to see themselves reflected in one another - to connect as humans (Askins, 2016).

\section{5:3 Social citizenship}

\section{Generating dialogue}

Whilst this project was small scale and the information we created and shared may not have any great societal impact, it was enough to generate further discussions beyond the research spaces (Kesby, 2007). When I asked Nic if he thought it had been beneficial to learn more about what it means to be a refugee, the following discussion took place:

Nic: Definitely, but I'm not sure how that will apply to everyday life ... Yeah it was quite interesting, I went to the festival of place at Aro Valley and that was quite interesting talking to the ladies there. Just realising that they had funding ... I guess this is outside of the process so I shouldn't really talk about this ...

Amber: Na, its cool, so if it ...

Nic: Yeah I guess it [the painting process] triggered that inquest and inquiry. Just talking to them about ESOL and how it was funded for an amount of time then it ran out in August. And then that community that had helped to support and develop wasn't able to stay at the community centre anymore because they didn't have the funding, but then it transitioned to individuals' homes. Yeah but then that was even interesting, realising how much of Aro Valley's population is mixed like that ...

Amber: So like refugees living in Aro Valley?

Nic: Yeah, I think someone said council housing takes up sixty percent of housing in Aro. 
Whilst Nic at first struggled to understand how what he has learnt in the painting process can enhance everyday praxis, he quickly realised that the painting process had triggered further interest and interactions and enabled him to learn about other aspects of refugee integration. The exhibition comment book also highlighted the potential for creative dissemination of research to capture public interest and generate further dialogue on key integration issues. One person said, "I think the painting is really good and after looking at it I was really interested to learn more and find out what all the symbols meant". This curiosity is the first step in creating a more equitable society, as it can enhance cross-cultural understanding and social connections and act as a catalyst for social and spatial change (Wilson, 2016).

\section{Enhancing social networks}

Social connections that had developed throughout the painting project were discussed by several participants in the post-workshop interviews:

Hilary: Yeah it's funny, one of the guys I bumped into in the city center and we talked about our shared experience so ...

Amber: So it's just like another familiar face to say hi to?

Hilary: Yeah, and you've got something to talk about.

Hilary and Nic encountered one another outside of the usual research space and took the time to stop and talk. This interaction was not facilitated or prompted, and was not done for the sake of research, but evolved from a common experience that prompted recognition and mutual understanding and interest.

As well as the workshops creating a shared experience for people to reflect upon together, they provided a space for networking where individuals could share information and services. Sarah* mentioned that, "The Japanese guy, Ken. I'm interested in Archeticture and that is what he studied. So I can get some ideas from him and help me to decide what subject to choose to study. He could help me". This interaction was particularly signicant, as Sarah* had only been in New Zealand for four months and was still learning how to navigate diverse New Zealand systems and discover what opportunities exist for her future here. Through offereing to share the knowledge he had from his own experience applying for and studying these courses, 
Ken was practising social citizenship as he was enabling Sarah* to access her right to education here in Wellington.

Through workshop discussions and sketches, participants also began to think of other

Figure 18: Sharing music

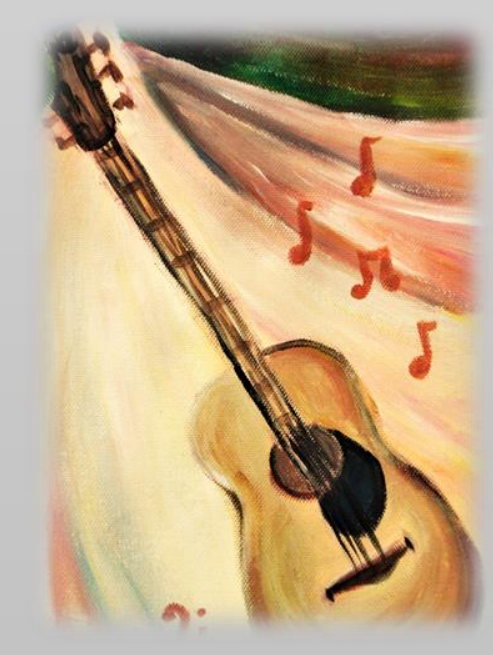

(Source: Inter-Mural Wellington, 2016) creative ways in which to create a more welcoming and inclusive city. Nick T. said, "I know there are good food markets that have a lot of cultural foods, but if they put more of the emphasis into multiculturalism and diversity in music and stuff like that. I guess music is a big part of identity as well" (Figure 18). The subsequent discussion on music led to the group considering how we could incorporate more diversity into existing shared urban spaces and areas of common interest to enable more Wellingtonians to develop a greater sense of belonging and to feel more 'at home'. Whilst these ideas have the potential to make Wellington a more

welcoming city, further action is now needed to benefit from and enhance such potential.

\section{5:4 Chapter summary}

To encourage New Zealanders to extend a more sincere welcome to newcomers, a shift in thinking is needed to prioritise emotional and social citizenship discourse. This shift in focus is important in conversations concerning former refugee and host society integration, as explorations of the multiple realities and experiences of everyday citizenship can inform how we, as a nation, value and support our diverse residents and citizens in policy and through everyday actions. Particular attention needs to be paid to the notion of hospitality within such dialogue, to highlight the various ways that time, place, and resources shape power dynamics between individuals and different social groups, and contributes to practices of social inclusion or exclusion and individual sentiments of belonging. 


\section{Chapter 6: The Art of Social Connection}

In the first section of this concluding chapter I evaluate my qualitative multi-method research methodology and make recommendations for future participatory painting projects. Participants' reflections and feedback are interwoven with my own to enable a more comprehensive and critical project analysis. I then revisit the research question to distil key learnings from the project and re-engage with the wider disciplinary and political context. The final section shifts beyond the painting project to a discussion of how this research might inform a more inclusive multicultural social policy in New Zealand to shape future integration praxis and political debate.

\section{6:1 Methodological evaluation and recommendations}

\section{Participant recruitment}

As mentioned in Chapter Three, I experienced challenges in recruiting research participants. To enhance recruitment processes in refugee integration research, more research is needed on why people choose not to engage with participatory research, and how engagement may be encouraged. Such explorations are not only significant for academics involved in PAR, but also for refugee resettlement practitioners to be able to provide more accommodating services, and for former refugees (and other community members) to benefit from the projects, resources, knowledge, and support on offer.

Ongoing attendance was also a challenge in the painting workshops due to the complexity of trying to juggle the everyday demands of multiple lives. As participant Ken mentioned, "The discussions and connecting with people were pretty good. So I enjoyed that. It was just a shame that not everyone was able to come as often as we hoped". One potential method Hilary and I discussed in regards to recruiting participants and enhancing attendance, is for researchers to collaborate with existing community groups. For example, a workplace might team up with an English-language class. In this manner, painting workshops could provide an activity to stimulate English 
conversation classes, or the painting could be a collaborative way of promoting or creating designs for a local business.

The benefits of this would be that existing relationships of trust and familiarity could lend support to those willing to engage, and pre-established resources and meeting times or agendas could be utilised. One challenge of this, however, is that not everyone may enjoy painting. Other challenges could occur in negotiating power relations, avoiding marketisation or the prioritisation of business needs over individuals, and juggling vested interests. Having the researcher as a third party may help to reduce potential conflict as they could mediate between these groups, yet these methods require further research.

\section{Participants}

The criteria of residency or citizenship ruled out the participation of asylum seekers in this research, as mentioned in Chapter One. However, it is crucial that future studies do take asylum seeker voices into account to inform immigration and social policies, address asylum seeker needs in our communities, and ensure that New Zealand is upholding its international humanitarian obligations (Human Rights Commission, 2016a; UNHCR, 1996). Tayyaba said, “We don't include in that process [New Zealand refugee resettlement] people who come under family reunification, or those who seek asylum. And that's a pretty huge flaw in the resettlement process".

Thus, I recommend more empirical creative research be done which includes asylum seekers, to acknowledge the challenges of liminal home-making and how such transient lives and uncertain citizenship status can shape a sense of belonging. Reproducing the painting project with children may also be valuable to understand its cross-generational value. To recruit child participants, researchers could collaborate with schools, youth foundations, or existing organisations such as Make Foundation (2016), which works with local primary school students to depict former refugees' stories through art, music and theatre.

\section{The trade-off between time and 'output'}

Time was restricting when creating the mural, due in part to the project being delayed as recruitment took longer than expected. Nic claimed that the project "felt like a little 
bit rushed". However, he also acknowledged the challenge in trying to get people to invest in such projects when production is slow. "Like the process is generally more important than the outcome, but you need that output to have the people to buy into it, to do it". Such 'output' was commonly requested for the media coverage of the project where journalists wanted to depict the visual work to engage more readers. Whilst public engagement was important to find participants, build on local knowledge, and widely disseminate the research - producing ideas and imagery that could inspire people required time. This trade-off between time and output could be of particular concern in research where external funders require obvious progress and social benefits to invest in research, yet if outcomes are forced or rushed this could compromise research integrity and hinder the development of social relationships (Ferguson, 2011; O'Neill \& Hubbard, 2010). In such 'forced' circumstances, creative expression may also be stifled.

To enable greater social value through participatory research, I recommend that more longitudinal studies are undertaken to enable relationships to be strengthened. I also recommend that more follow-up evaluation studies take place, to understand the impact PAR can have beyond participatory research spaces (Kesby, 2003). Such evaluations will require careful consideration of the specific indicators to be used in assessing research impact (Spoonley, Peace, Butcher, \& O’Neill, 2004).

\section{Research scope and the unpredictable nature of impact}

This research predominantly focused on the interrelations between participants, aiming to analyse the effectiveness of a participatory painting project in enhancing social connections. Whilst social connections were enhanced through the project, participatory research often juggles multiple diverse perspectives, needs, and interests, and therefore requires researchers to cede complete control over the project. In this manner, there may be limitations in obtaining certain goals as the research design, methods, and dissemination will need to be negotiated.

Due to dynamic social interactions and shifting power relations, research impact is unpredictable and difficult to calculate (Rogers et al., 2014). This unpredictability can be limiting in that unexpected or negative results may hinder progress; however, it may also open new avenues of inquiry and opportunities which enable research boundaries 
to be challenged. Whilst it is difficult to calculate impact, activities which have proven to be useful bonding techniques in other contexts can be explored within PAR to increase the likelihood of social change. For example, to enable participants to learn more about one another and strengthen social connections, Nic recommended more "break-out one-on-one sessions". When I questioned what he meant by this he explained:

Nic: I guess just like trying to do that whole actually getting to know someone properly, like if there is something you are willing to tell someone in confidence, in individual ... Amber: So like breaking up into pairs to get to know someone better?

Nic: Yeah.

Amber: Yeah, that's a good idea.

Nic: Like sometimes when we are devising stuff we'll break out into smaller groups, I guess we'd usually have more people to work with, but then sharing the other person's ideas instead of yours. So trying to tell their story not your story which re-enforces your kinda taking on what they're about.

Nic's idea is one commonly used in ice-breakers in educational contexts (or in Nic's experience as a teamwork exercise in a theatre group) but would also be well suited to PAR. The idea that people may feel more comfortable initially confiding in one person rather than to a group is worth trialing to meet different participant's needs. Asking participants to then share one another's stories could also be a beneficial way to enable people to connect and to prompt further interaction and understanding.

Yet, whilst pairing up may work well at times, participants generally agreed that a collaborative mural was a better approach to explore integration than individuals or pairs painting separate canvases. As Yordanos claimed, "We were all working together. We weren't off in a corner trying to come up with ideas or anything, we all were working together, we were talking. I think that worked well”. When I asked what the most challenging part of collaborative painting was, Ken said, "I guess committing to ideas, especially with everyone else there ... because you kind of don't want to sit back, but you also don't want to intrude on other people's ideas or whatever. But we got there in the end". Thus, encouraging people to work 
together increases the need for participants to negotiate diverse identities and find a way to connect and cooperate.

To acknowledge different levels of confidence within participation and to enhance both personal and social development, I recommend a mix of workshop activities that provide space and time for individual reflection, bonding in pairs, and collaboration as a group. Having the opportunity to work with different people at different stages of the painting process may also serve to keep the workshops interesting and inspiring as different social dynamics can change the atmosphere of the workshop space.

\section{Tactile sensory stimulation}

Throughout the workshops participants discussed how familiar sights, sounds, tastes, smells and tactile stimuli contributed to a sense of being 'at home' or belonging somewhere. Painting was a key method in enabling such sensory embodied experiences to be shared, due to both the tactile and visual ways that painting can engage individuals, and because participants could use symbolism to represent sensory experiences, such as the wind in Wellington being depicted through windmills and an inside-out umbrella (Figure 13). The recognition of common sensory experiences, and the common emotions such stimuli can elicit, helped participants to transcend language and cultural barriers and connect with one another.

Whilst sensory geographies are already being theorised by researchers such as Munt (2016), and Trnka, Dureau, and Park (2013), theories remain under-explored in refugee resettlement praxis in New Zealand. Therefore, I recommend that more empirical

participatory research on sensory perceptions of place should be facilitated within New Zealand resettlement regions to inform processes and practices of home-making, integration, and citizenship. Such research would benefit from an interdisciplinary approach, for example, involving experts in visual and verbal signal processing, or researchers who explore the effect that climate or physical touch may have on an individual's wellbeing and ability to adapt to changing conditions. 


\section{Location and inspiration}

Whilst workshop discussions prompted a wide scope of ideas and memories, participants did at times struggle to think how these ideas might be represented through painting. The seminar room that we used as a work space may have contributed to this translation barrier, due to a lack of visual stimuli. Making use of the computer and projector in the room, participants often found inspiration through online searches where they could draw upon existing shapes, colours, and styles of imagery. Yet, for Sarah* who had only recently arrived in New Zealand and was not so familiar with Wellington, unique city symbols and icons remained somewhat difficult to represent.

To enhance the sense of familiarity that we discussed as being so important to homemaking, and to inspire more creative thinking, Sarah* suggested venturing out into the city more throughout the research process. In this manner, participants could take sketchpads or cameras and capture different images around the city to later represent in the mural. Similar ideas have been explored in O'Neill and Hubbard's (2010), and Tolia-Kelly's (2008) participatory arts projects which involved walking, mapping, and sketching in different locations in the UK.

Another idea we discussed is the creation of a city mural on a wall, which would not only enable participants to directly interact with the city and work together on a collaborative art-work, but would visibly alter a public space and engage people as they went about their everyday lives and routines. This altering of space is significant, as, in the workshop discussions of the iconic Wellington bucket fountain, participants' perceived art and sculpture to be a way to resist homogenising development and to reclaim the city in a manner that reflects the diverse people living there.

\section{Empowerment}

Having the choice of where to meet for the individual interviews made participants feel more relaxed and it balanced power relations, as whilst I chose the interview questions, participants invited me as a guest into spaces which had certain meanings or advantages to them. They chose whether we removed our shoes, where we sat, and whether we had food or drink. Participants could also shape the flow of the interview - stopping to speak with a child, show me a project they were working on, or to put the kettle on if 
they needed a break. Hilary claimed that, "You've [the researcher] gotta recognise that people are giving up their time and the more that it fits in with their own schedule the better”. Thus, place needs to be carefully considered when aiming to enhance agency and challenge power imbalances in participatory research (Kesby, 2007; Thomas et al., 2015).

Whilst the choice of location was significant in making people feel more confident and that their time was appreciated, there were mixed reactions regarding empowerment in terms of the skill-based aspect of painting. Hilary claimed that,

I think it's more than writing which is great, it engages people in a different way. But I suppose what comes in with the painting a little bit is judgement and concern about not being good enough to do that. I know that's what I felt a little bit. Which I guess isn't that helpful necessarily, it's quite a fear. I guess it's about feeling ok to express in that form. It's something that I love to do but I struggle to do it well enough to be public about it.

Tayyaba said, "As I was doing it I just thought oh man, I'm so bad at drawing. But as you let go of that and just have fun and you know, play around with the colours, it's a good experience, just letting go of those confined barriers in your life." The majority of participants claimed that, despite doubting their own artistic skills, the emphasis on 'just having fun' and there being 'no wrong way' to paint helped them to overcome some of their initial hesitations. Yordanos said,

It was fun. Like I'm not really a social person, I don't go out of my way to join clubs or anything like that because I feel like there's a pressure, I dunno, I feel like there is pressure if I did that. But with a workshop like this where everyone is different and we share our own stories, it makes it easier for me to participate.

As the participants in my 2015 honours pilot painting workshop mentioned, painting will not always be suitable for everyone. Individuals will need to each explore their own levels of comfort and set their own personal challenges. Yet, those participants who attended more workshops were also those who reported feeling less pressured and less concerned about the judgement of others, which supports the idea that as well as considering place, time is significant in establishing trust and empowering individuals within participatory research (Ferguson, 2011; O’Neill \& Hubbard, 2010). 


\section{6:2 Key learnings}

The painting project aimed to address the research question: How can collaborative, participatory painting processes enhance social connections between former refugees and Wellington host society members; advocate social justice for former refugees; and begin to bridge the incongruence between New Zealand's non-discriminatory citizenship rights and exclusionary practices within processes of social integration? The key learnings from these empirical explorations are distilled in the following discussion.

\section{Enhancing social connections}

As predicted, the painting workshops enhanced social connections between former refugee and Wellington host society participants, though not always in ways that I had anticipated. The use of humour was particularly significant in building trust and a sense of familiarity within the group, as joking and having fun relieved the pressure of participants feeling as though they had to perform to a particular standard or agree with dominant views. This lack of pressure, or a lack of negative 'judgement' as several participants described, enabled more open, honest, and critical dialogue and debate.

Humour also contributed to the development of a 'common language' whereby ongoing jokes, such as that regarding Yordanos' apple, became a shared social reference point. Familiar symbols on our mural such as the iconic Wellington bucket fountain and the windmills also became shared reference points, which the group could orientate themselves around and connect through. Whilst the diverse experiences associated with these symbols depicted the uniqueness of each individual participant and the complexity of their interwoven histories, identities, affiliations, and beliefs, there were also striking similarities in the feelings and emotions that these experiences evoked. Recognising these emotions in one another enabled individuals from different backgrounds to connect through an empathic embodied understanding which transcended language and cultural barriers (Ferguson, 2011; Ramos, 2004).

Such emotional connections are significant as they enable individuals to recognise themselves in one another and close the percieved distance between 'us' and 'them'. It is these empathic, human connections which inspire people to reach out and support one another as equal and valued citizens and enhance a sense of belonging for those 
who feel 'out-of-place' (Askins, 2016; Wood, 2013). Participants also felt more connected to one another through participating in a shared experience which they could talk about outside of the research spaces, through finding common interests, or through making future plans together.

In this manner, social citizenship was being practised as participants were performing a sincere welcome that extended beyond a pretence of acceptance to actually reaching out and supporting one another and enjoying one another's company (Woodrow, 2016). Research shows that individuals who are more socially connected are happier, and that happier people are more trusting of others and more likely to volunteer and contribute to society (Bruni et al., 2008; Waldinger, 2016). Thus, participatory painting processes that centralise social connections have potential to enhance individual wellbeing and social capital, and social collaboration and development.

\section{Advocating social justice}

The scholar activist orientation driving this research prioritised collaborative pedagogical and community development methods which, based on existing theories, empirical research, and experience, were likely to enhance social justice for former refugees. PAR offered a framework where participants were included in key decision making processes, where hegemonic discourse and normative social assumptions could be challenged, and where unique stories could be shared and new relationships built.

This participatory process was significant as Lefebvre (1968) and Harvey (2003) argue that enhancing access to rights not only requires the provision of resources, but also involves increasing agency to enable individuals to change the city and society. An enhanced capacity for individual action and a growing sense of confidence was observed within the painting workshops, as when participants became more familiar and comfortable with one another and the workshop venue, they took it upon themselves to change the space into a more creative interactive environment which better suited their needs. In this manner, 'guests' become 'hosts' over time, challenging existing power imbalances through the way they distributed, shared, and negotiated space and resources. 
Collaborative, participatory methods also enabled greater social connections and support networks to be developed which, as discussed above, were significant steps in enhancing social capital and access to rights for marginalised individuals. Thus, more equitable social outcomes were being developed through both the 'empowering' research methods themselves, and through the social connections and community support networks these methods fostered. The production of our collaborative mural also provided an innovative platform to express political agency and advocate social justice for former refugees, as the mural provided a way to reclaim the city from homogenising or assimilating processes to reflect the diverse multicultural population living in Wellington, and to encourage inclusivity.

\section{Bridging the incongruence between New Zealand's non-discriminatory citizenship rights and exclusionary practices}

As discussed throughout this thesis, New Zealand's legal citizenship framework is ethically reputable and the majority of former refugees are happy to make New Zealand home (Kibreab, 2003; Searle et al., 2012). However, many former refugees in both this study and prior research reported feeling isolated or disconnected from the wider New Zealand host society. They also claimed that a 'hierarchy of belonging' persists which privileges Māori and Pākehā over other ethnic groups (Beaglehole, 2013; Ford, 2012; Sibley \& Liu, 2007). Thus, there exists an incongruence between New Zealand's nondiscriminatory citizenship rights and exclusionary practices.

Through a broad sociopolitical objective to improve access to rights for former refugees, the painting project aimed to explore how New Zealanders might begin to bridge this incongruence. Whilst this project was too small to create wide social change in regards to the way in which Wellingtonians and other New Zealanders welcome former refugees, I argue that the new knowledge and social connections participants developed throughout the painting process did help them to feel more appreciated, welcome, and confident in accessing their rights and reaching out to assist others. Thus, participatory painting processes have potential for enabling more equitable citizenship discourses, practices and outcomes.

However, in pursuing social justice for former refugees and other marginalised groups, it is also important for New Zealand scholars, policy-makers, resettlement practitioners, 
activists, and local communities to acknowledge that newcomers are not entering a space free from history and power. Rather, they are entering a postcolonial nation with existing cultures, traditions, agreements and inequalities (Darling, 2009; Popke, 2007). Therefore, acknowledging the injustice of British imperialism and indigenous struggles for sovereignty rights is vital if we are to understand our post-colonial relations, continue righting past wrongs, and retain a relatively stable and peaceful country (Waitangi Tribunal, 2016).

A couple of the participants mentioned the need to sort the Treaty before extending our welcome to others. Yet, this is not a viable solution when the global humanitarian crisis continues to escalate. As I type, the battle of Aleppo is in the midst of a new wave of fear and violence and people are posting their goodbyes on social media, a final desperate plea for the world to remember them, to send help, to act now (BBC, 2016). In matters of international crisis, when urgent assistance is needed, Treaty discussions should not prevent New Zealand from welcoming refugees and directing resources towards resettlement and integration. Our internal ethnic relations ought not to obscure the fact that New Zealand is also a global constitute with international obligations, and that New Zealanders also have a role to play as global citizens (Figure 19).

Figure 19: Global citizens

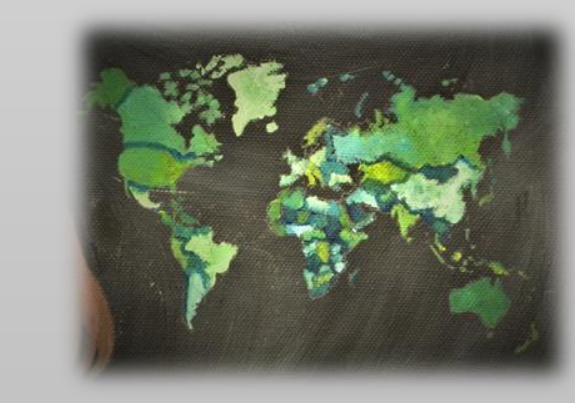

(Source: Inter-Mural Wellington, 2016)
Therefore, due to the need to juggle both internal and external commitments, postcolonial and current immigration conversations should be happening simultaneously. The interweaving of these discussions could ensure that all New Zealand residents and citizens are being represented in our national identity and future development, and that diverse individuals and communities have the opportunity to collaborate - to work together for mutually beneficial integration and social development.

To once again quote Putnam (2007), "The challenge is best met not by making 'them' like 'us', but rather by creating a new, more capacious sense of 'we' (pp. 163-164). The onus should not be on former refugees to prove themselves as worthy of being New 
Zealanders, but for New Zealanders to work together to inspire, enable, and support all those willing to live here to be the best versions of themselves that they can be. It is up to all of us, as hosts and newcomers, to collaborate to create a nation that we are proud to be a part of and contribute our unique knowledge, skills, and passions to.

Therefore, I argue that a shift in focus is needed within integration research, policy, and praxis, to prioritise the understanding and practice of emotional and social citizenship and to enhance social capital. In encouraging a focus on social capital, I am not arguing that economic capital, employability, and market citizenship are unimportant in processes of integration. Rather, I am arguing that emotional wellbeing and social networks are essential precursors to a productive economy and peaceful society. Enhancing social capital and emotional wellbeing can assist former refugees in participating in society, confidently applying for work, and engaging in politics in a society which is welcoming, confident employing people with diverse ethnic and cultural identities, and not adverse to diversity, innovation, and change. This shift in focus is necessary to provide the support and funding needed to enable more projects like the painting project, which could benefit more individuals and subtly challenge negative stereotypes and discriminatory practices.

\section{6:3 Informing social policy}

As New Zealand prepares to raise our annual refugee quota and shape our nation's role within the global humanitarian crisis, more democratic, inclusive explorations and representations of place (such as those exhibited in the painting project) are crucial in informing social policy to enhance integration praxis. Mortensen (2008), Singham (2006), Spoonley, Peace, Butcher, and O’Neill (2004) argued that New Zealand is lacking the multicultural social policy framework needed to guide equitable integration praxis and critical political debate, and enhance a sense of belonging for former refugees.

Multicultural policies can include measures to increase social, political, and economic participation for marginalised groups; enhance recognition of diverse cultural and religious beliefs and practices; enable greater access to education and work; decrease 
racism; and provide sufficient funding for effective integration praxis (Bromell, 2008; Kymlicka, 1998). In 1971 Canada was the first country to implement a national multicultural policy, followed by Sweden in 1975, Australia in 1978, and the UK in 1997 (Bromell, 2008).

However, despite the potential benefits, there is also strong opposition to multiculturalism. Opponents claim that multiculturalism may oppress the dominant culture, undermine indigenous rights, erode national unity, and promote segregation or reinforce discriminatory practices. Such views have led to a rising sense of nationalism in Australia, the Netherlands, Denmark, France, Germany, the UK and the United States of America (USA) (Bromell, 2008). Nationalist sentiment has been particularly visible in recent months through widespread media coverage on the UK exiting the European Union (popularly referred to by the campaign slogan 'Brexit'), and the anti-immigration rhetoric and actions of controversial American president Donald Trump. These political shifts are concerning as they encourage domopolitics whereby perceived 'outsiders' are excluded, assimilated, marginalised, and often targeted through xenophobic attacks (Walters, 2004).

Despite a rise in nationalist sentiment, this does not signify a fundamental flaw in multicultural ideology. Rather, the elite way in which multicultural policy has been designed, implemented, practised, and evaluated in countries such as Australia, has likely contributed to its declining popularity. Brown (2006) claimed that, despite youth being the main instigators of ethnic tensions and violence in Australia, they were excluded from policy-making processes and had little opportunity for inter-cultural dialogue. Due to this lack of community consultation and engagement, the problems continued. This case highlights how the way in which multicultural policy is practically addressed can impact the effectiveness of social integration.

In contrast to Australia, 'Multicultural New Zealand', a collective voice for ethnic, migrant and refugee communities, has recently explored a more collaborative, participatory approach to social policy design in New Zealand. In 2014 this NGO initiated a project called Our Multicultural Future, where diverse New Zealanders shared their visions for a multicultural New Zealand and identified the barriers to achieving these visions. The report on this project claimed that, 
The development of a successful multicultural society is seen as a journey, building on the unique but unfinished New Zealand narrative of Māori and Pākehā working out a fair and just bicultural relationship and taking into account the ever changing demographics of communities. Strong positive relationships are forged between Māori and Pākehā, Pacific, Asian and other ethnic groups and new migrants settling in New Zealand (Multicultural New Zealand, 2015, p. 9).

Thus, 'Multicultural New Zealand' acknowledges New Zealand's postcolonial history, as well as the country's growing multicultural demographics. They make an effort to engage the diverse people of New Zealand in conversations regarding citizenship and integration, and they offer a platform to work together for mutually beneficial social development. The painting project can add to this evolving multicultural narrative through its exploration of unique everyday citizenship experiences, and through the unique way it enabled diverse citizens to build social connections and co-construct shared places and identities. 


\section{Reference List}

Afonso, A., \& Ramos, M. (2004). New graphics for old stories: Representation of local memories through drawings. In S. Pink, L. Kurti, \& A. Afonso (Eds.), Working Images: Visual Research and Representation in Ethnography (pp. 72-89). London: Routledge.

Agnew, J. (2011). Space and Place. In J. Agnew, \& D. Livingstone (Eds.), Handbook of Geographical Knowledge (pp. 316-330). London: Sage.

Al-Ali, N. \& Koser, K. (2002). Transnationalism, International Migration and Home. In N. Al-Ali \& K. Koser (Eds.), New Approaches to Migration: Transnational Communities and the Transformation of Home (pp. 1-14). London: Taylor and Francis Books.

Alexander, J., \& Jarratt, S. (2014). Rhetorical Education and Student Activism. College English, 76(6), 525-544.

Aljazeera. (2017). News: Refugees. Retrieved from http://www.aljazeera.com/topics/subjects/refugees.html

Amin, A., \& Thrift, N. (2002). Cities: reimagining the urban. Cambridge: Polity.

Anderson, B. (2006). Imagined Communities: Reflections on the Origin and Spread of Nationalism. UK: Verso.

Askins, K. (2016). Emotional citizenry: everyday geographies of befriending, belonging and intercultural encounter. Transactions of the Institute of British Geographers, 41, 515-527.

Askins, K., \& Pain, R. (2011). Contact Zones: participation, materiality, and the messiness of interaction. Environment and Planning D: Society and Space, 29, 803821.

Baldwin, M. (2012). Participatory Action Research. In M. Gray, J. Midgley, \& S. A. Webb (Eds.), The Sage Handbook of Social Work (pp. 467-481). UK: Sage.

Baron, R. (1991). Positive Effects of Conflict: A Cognitive Perspective. Employee Responsibility and Rights Journal, 4(1), 25-36.

BBC News. (2016). Aleppo: Trapped Syrians say goodbye on social media. Retrieved from http://www.bbc.com/news/world-middle-east-38309852 
BBC News. (2017). Europe Migrant Crisis. Retrieved from

http://www.bbc.com/news/world-europe-32395181

Beaglehole, A. (2013). Refuge New Zealand: A Nation's Response to Refugees and Asylum Seekers. New Zealand: Otago University Press.

Berg, B. (2008). Visual Ethnography. In L. Given (Ed.), The SAGE Encyclopedia of Qualitative Research Methods (pp. 935-939). Thousand Oaks, CA: SAGE Publications, Inc.

Bergson, H. (1914). Laughter: An Essay on the Meaning of the Comic. New York: The Macmillan Company.

Bifulco, L. (2013). Citizen participation, agency and voice. European Journal of Social Theory, 16(2), 174-187.

Blunt, A., \& Dowling, R. (2006). Home. London: Routledge.

Bose, P. S. (2014). Refugees in Vermont: Mobility and Acculturation in a New Immigrant Destination. Journal of Transport Geography, 36, 151-159.

Bromell, D. (2008). Ethnicity, Identity and Public Policy: Critical Perspectives on Multiculturalism. Wellington: Victoria University.

Brown, G. (2006). Growing Pains: Australia's Adolescent Multicultural Policy. Georgetown Journal of International Affairs, 7(2), 75-82.

Bruni, L., Comim, F., \& Pugno, M. (2008). Capabilities and Happiness. UK: Oxford University Press.

Burn, S. M. (2011). Women across Cultures: A Global Perspective, Third Edition. New York: McGraw-Hill.

Cahill, C., Sultana, F., \& Pain, R. (2007). Participatory Ethics: Politics, Practices, Institutions. ACME: An International E-Journal for Critical Geographies, 6(3), 304318.

Canal, G. (2004). Photography in the Field. In S. Pink, L. Kurti, \& A. Afonso (Eds.), Working Images: Visual Research and Representation in Ethnography (pp. 31-46). London: Routledge.

Castree, N. (2004). Differential geographies: place, indigenous rights and 'local' resources. Political Geography, 23, 133-167.

ChangeMakers Refugee Forum, The New Zealand National Refugee Network, ESOL Assessment and Access Specialist Service (MCLaSS), Joe, A., Kindon, S., O'Rourke, 
D., \& The Empowering Study For Refugee Background Students Research Team. (2011). An equitable education: Achieving equity status and measures to ensure equality for refugee-background tertiary students in Aotearoa New Zealand. NZ: Victoria University.

Chappell, D., Chappell, S., \& Margolis, E. (2011). "School as ceremony and ritual: How photography illuminates performances of ideological transfer", Qualitative Inquiry, 17(1), 56-73.

Choudry, A. (2014). (Almost) Everything you always wanted to know about activist research but were afraid to ask: what activist researchers say about theory and methodology. Contention: The Multidisciplinary Journal of Social Protest, 1(2), 7588.

Collie, P., Kindon, S., Liu, J., \& Podsiadlowski, A. (2010). Mindful identity negotiations: The acculturation of young Assyrian women in New Zealand. International Journal of Intercultural Relations, 34, 208-220.

Colson, E. (2003). Forced Migration and the Anthropological Response. Journal of Refugee Studies, 16(1), 1-18.

Community Law. (2016). Legal Ages: When You Can Do What. Retrieved from http://communitylaw.org.nz/community-law-manual/chapter-9-youth-rights/legalages-when-you-can-do-what-chapter-9/

Coser, L. (2001). The Functions of Social Conflict. New York: Routledge.

Cope, M. (2016). Organizing and Analyzing Qualitative Data. In I. Hay (Ed.), Qualitative Research methods in Human Geography (4 ${ }^{\text {th }}$ ed., pp. 373-392). UK: Oxford University Press.

Costantino, T., Guyotte, K., Kellam, N., \& Walther, J. (2014). Seeing Experiences of Interdisciplinarity through Student Artwork. International Review of Qualitative Research, 7(2), 217-235.

Crang, M. (2010). Visual Methods and Methodologies. In D. Delyser, S. Herbert, S. Aitken, M. Crang, \& L. McDowell (Eds.), The Handbook of Qualitative Geography (pp. 208-225). London: Sage.

Cresswell, T. (2004). Place: A Short Introduction. UK: Blackwell Publishing.

Darling, J. (2009). Thinking beyond place: The responsibilities of a relational spatial politics. Geography Compass, 3(5), 1938-1954. 
DeSouza, R. (2011). Doing it for ourselves and our children: Refugee women on their own in New Zealand. Report. New Zealand: Refugee Services Aotearoa.

Dictionary.com. (2016). Intermural. Retrieved from http://www.dictionary.com/browse/intermural

DoingOurBit. (2017). The Issue. Retrieved from http://www.doingourbit.co.nz/p/theissue.html

Dowling, R. (2016). Power, Subjectivity, and Ethics in Qualitative Research. In I. Hay (Ed.), Qualitative Research methods in Human Geography (4 ${ }^{\text {th }}$ ed., pp. 29-44). UK: Oxford University Press.

Dunn, K. (2016). Interviewing. In I. Hay (Ed.), Qualitative Research methods in Human Geography (4th ed., pp. 149-188). UK: Oxford University Press.

Durkheim, E. (1951). Suicide: A Study in Sociology. USA: The University of California. Elliot, S. \& Yusuf, I. (2014). 'Yes, we can; but together': social capital and refugee resettlement. Kōtuitui: New Zealand Journal of Social Sciences Online, 9(2), 101110.

Evans, M. (2004). Ethics, anonymity and censorship in community centered research of the Island Cache. Pimatisiwin: A Journal of Aboriginal and Indigenous Community Health, 2(1), 59-76.

Evans, N. (2005). 'Size Matters'. International Journal of Cultural Studies, 8(2), 131149.

Evolve \& Victoria University of Wellington. (2005). African Youth Health and Wellbeing: Participatory Action Research Project. Report. New Zealand: Victoria University of Wellington.

Ferguson, J. (2011). Weaving a New Tartan in Scotland: The Role of Arts and Culture in Refugee Integration. West Coast Line, 44(4), 24-33.

Fitzpatrick, F. (2002). A Search for Home: The Role of Art Therapy in Understanding the Experiences of Bosnian Refugees in Western Australia. Art Therapy, 19(4), 151158.

Ford, K. (2012). Contesting Representations of Refugee-Background Women (and Men) as 'Needy' and 'Problematic' in Healthcare Literature in Aotearoa New Zealand: Advancing the Case for a Capability-Driven Model. (Masters' Thesis, Victoria University of Wellington, New Zealand). Retrieved from 
http://researcharchive.vuw.ac.nz/xmlui/bitstream/handle/10063/2525/thesis.pdf?seq uence $=2$

Fozdar, F., \& Pedersen, A. (2013). Diablogging about asylum seekers: Building a counter-hegemonic discourse. Discourse \& Communication, 7(4), 371-388.

Frideres, J. (1992). A World of Communities: Participatory Research Perspectives. Canada: Captus Press.

Gellner, E. (1983). Nations and Nationalism. USA: Cornell University Press.

George, R. M. (1996). The Politics of Home: Postcolonial Relocations and TwentiethCentury Fiction. Cambridge: Cambridge University Press.

Happer, C., \& Philo, G. (2013). The Role of the Media in the Construction of Public Belief and Social Change. Journal of Social and Political Psychology, 1(1), 321-336.

Harper, J., \& Lister, A. (2007). Wellington: A City for Sculpture. NZ: Victoria University Press.

Harvey, D. (2003). The Right to the City. International Journal of Urban and Regional Research, 27(4), 939-941.

Heusch, N. (2002). Art Therapist's Countertransference: Working with Refugees who had Survived Organized Violence. In A. R. Hiscox, \& A. C. Calisch (Eds.), Tapestry of Cultural Issues in Art Therapy (pp. 154-198). UK: Jessica Kingsley Publishers.

Howitt, R., \& Stevens, S. (2016). Cross-Cultural Research: Ethics, Methods, and Relationships. In I. Hay (Ed.), Qualitative Research methods in Human Geography ( $4^{\text {th }}$ ed., pp. 29-44). UK: Oxford University Press.

Human Rights Commission. (2016a). New Zealand's International Obligations. Retrieved from https://www.hrc.co.nz/your-rights/human-rights/internationalhuman-rights-legislation/international-obligations/

Human Rights Commission. (2016b). Tracking Equality at Work. Retrieved from http://tracking-equality.hrc.co.nz/\#/issue/pay

Humpage, L. (2008). Talking about citizenship in New Zealand. Kōtuitui: New Zealand Journal of Social Sciences, 3(2), 121-134.

Immigration New Zealand. (2016). Becoming a Citizen. Retrieved from http://www.immigration.govt.nz/migrant/stream/alreadyinnz/residents/becomingacit izen/ 
Javidi, H. \& Yadollahie, M. (2012). Post-traumatic stress disorder. The International Journal of Occupational and Environmental Medicine, 3(1), 2-9.

Jessop, B., Brenner, N., \& Jones, M. (2008). Theorizing sociospatial relations. Environment and Planning D: Society and Space, 26, 389-401.

Kale, A., \& Kindon, S. (2016). Turning the Curve 2012-15: Refugee Women Drive. Evaluation Report. New Zealand: Victoria University of Wellington.

Kesby, M. (2007). Spatialising participatory approaches: the contribution of geography to a mature debate. Environment and Planning, 39, 2813-2831.

Kibreab, G. (2003). Citizenship Rights and Repatriation of Refugees. The International Migration Review, 37(1), 24-73.

Kindon, S. (2010). Participation. In S. Smith, R. Pain, S. Marston, \& J. Jones III (Eds.), The SAGE Handbook of Social Geographies (pp. 517-545). London, UK: Sage.

Kindon, S. (2012). 'Thinking-through-Complicity' with Te Iwi o Ngāti Hauiti: Towards a Critical Use of Participatory Video for Research. (PhD Thesis, University of Waikato, New Zealand). $\quad$ Retrieved from http://researchcommons.waikato.ac.nz/handle/10289/6286

Kindon, S. (2016). Empowering Approaches: Participatory Action Research. In I. Hay (Ed.), Qualitative Research methods in Human Geography ( $4^{\text {th }}$ ed., pp. 350-370). UK: Oxford University Press.

Kindon, S., Pain, R., \& Kesby, M. (2007). Participatory Action Research Approaches and Methods: Connecting people, participation and place. London: Routledge.

Kirkwood, S., Mckinlay, A., \& McVittie, C. (2013). The Mutually Constitutive Relationship between Place and Identity: The Role of Place-Identity in Discourse on Asylum Seekers and Refugees. Journal of Community \& Applied Social Psychology, $23,453-465$.

KhosraviNik, M. (2010). The representation of refugees, asylum seekers and immigrants in British newspapers: A critical discourse analysis. Journal of Language and Politics, 9(1), 1-28.

Kymlicka, W. (1998). Finding Our Way: Rethinking ethnocultural relations in Canada. Toronto: Oxford University Press. 
Lefebvre, H. (1974). The production of space. (Donald Nicholson-Smith, Trans, 1991). Cambridge: Blackwell.

Lenette, C., Brough, M. K., \& Cox, L. (2013). Everyday resilience: narratives of single refugee women with children. Qualitative Social Work, 12(5), 637-653.

Lollar, K. (2015). Strategic Invisibility: Resisting the Inhospitable Dwelling Place. Review of Communication, 15(4), 298-315.

Lyubomirsky, S. (2008). The How of Happiness: A New Approach to Getting the Life You Want. New York: The Penguin Press.

Make Foundation. (2016). What is Home? - Art Project. Retrieved from http://www.makefoundation.org/2016/03/home-art-project/

Marriott, L., \& Sim, D. (2015). Indicators of Inequality for Māori and Pacific People. Journal of New Zealand Studies, NS20, 24-50.

Marshall, T. H. (2006). Citizenship and Social Class. In C. Pierson, \& F. G. Castles, (Eds.), The Welfare State Reader (pp. 30-39). UK: Polity.

Martin, S. (2008). Justice, Women's Rights and Forced Migration. USA: Georgetown University Press.

Martineau, W. H. (1972). A model of the social functions of humor. In J. H. Goldstein, \& P. E. McGhee (Eds.), The Psychology of Humor (pp. 101-125). New York: Academic Press.

Massey, D. (2004). Geographies of responsibility. Geografiska Annaler, 86(B), 5-18.

McKay, F., Thomas, S., \& Blood, R. W. (2011). Any one of these boat people could be a terrorist for all we know! Media representations and public perceptions of 'boat people' arrivals in Australia. Journalism: theory, practice \& criticism, 12(5), 607626.

McLeod, A. \& Reeve, M. (2005). The health status of quota refugees screened by New Zealand's Auckland Public Health Service between 1995 and 2000. The New Zealand Medical Journal, 118(1224), 1-17.

McNeill, W. (1994). "Reasserting the Polyethnic Norm." In J. Hutchinson, \& A. D. Smith (Eds.), Nationalism (pp. 300-305). Oxford: Oxford University Press.

Ministry for Women. (2016). New Zealand Women. Retrieved from http://women.govt.nz/about/new-zealand-women 
Mojab, D. (2015). Refugee Fear Mongering Must Stop. Retrieved from http://www.stuff.co.nz/national/71828612/Refugee-fear-mongering-must-stop Morris, P. (2009). Religion in New Zealand Schools: Questions and Concerns. New Zealand: Human Rights Commission.

Mortensen, A. (2008). Refugees as 'Others': Social and Cultural Citizenship Rights for Refugees in New Zealand Health Services. (PhD Thesis, Massey University, New Zealand). Retrieved from http://muir.massey.ac.nz/handle/10179/631?show=full mrs kinpaisby. (2008). Taking Stock of Participatory Geographies: Envisioning the Communiversity. Transactions of the Institute of British Geographers, 33(3), 292299.

Munt, S. (2012). Journeys of resilience: the emotional geographies of refugee women. Gender, Place \& Culture: A Journal of Feminist Geography, 19(5), 555-577.

Munt, S. (2016). Sensory geographies and defamiliarisation: migrant women encounter Brighton Beach. Gender, Place \& Culture, 23(8), 1093-1106.

Nawyn, S. J. (2011). 'I have so many successful stories': Framing social citizenship for refugees. Citizenship Studies, 15(6-7), 679-693.

Newstalk ZB. (2016). Kate Sheppard Memorial Trust Winner Announced. Retrieved from http://www.newstalkzb.co.nz/news/national/kate-sheppard-memorial-trustaward-winner-announced/

New Zealand Immigration. (2016). Settlement Strategy. Retrieved from https://www.immigration.govt.nz/about-us/what-we-do/our-strategies-andprojects/settlement-strategy

New Zealand Immigration. (2017). Refugee and Protection unit. Retrieved from https://www.immigration.govt.nz/about-us/what-we-do/our-strategies-andprojects/supporting-refugees-and-asylum-seekers/refugee-and-protection-unit

New Zealand Red Cross. (2017). Pathways to Settlement. Retrieved from https://www.redcross.org.nz/what-we-do/in-new-zealand/refugeeprogrammes/pathways-settlement/

O’Doherty, K., \& Lecouteur, A. (2007). "Asylum seekers”, “boat people”, and "illegal immigrants": Social categorisation in the media. Australian Journal of Psychology, 59(1), 1-12. 
Oh, S. (2012). Photofriend: creating visual ethnography with refugee children. Area, 44(3), 282-288.

Oldrup, H. H., \& Carstensen T. A. (2012). Producing Geographical Knowledge through Visual Methods. Geografiska Annaler: Series B, Human Geography, 94(3), 223-237.

O’Neill, M., \& Hubbard, P. (2010). Walking, sensing, belonging: ethno-mimesis as performative praxis. Visual Studies, 25(1), 46-58.

Pain, R., \& Francis, P. (2003). Reflections on Participatory Research. Area, 35(1), 4654.

Pain, R. \& Kindon, S. (2007). Participatory Geographies. Special Issue of Environment and Planning A, 39, 2807-2865.

Pink, S. (2007). Doing Visual Ethnography, Second Edition. London: Sage Publications.

Popke, E. J. (2007). Geography and ethics: Spaces of cosmopolitan responsibility. Progress in Human Geography, 31, 509-518.

Pugh, A. (2003). Painting a path to well-being: art therapy helps children of war mend the wounds. CrossCurrents, 6, 14-16.

Pulitano, E. (2012). In liberty's shadow: the discourse of refugees and asylum seekers in critical race theory and immigration law/politics. Identities: Global Studies in Culture and Power, 20(2), 172-189.

Pussetti, C. (2013). 'Woundscapes': suffering, creativity and bare life - practices and processes of an ethnography-based art exhibition. Critical Arts: South-North Cultural and Media Studies, 27(5), 569-586.

Putnam, R. (2007). E Pluribus Unum: Diversity and Community in the Twenty-first Century. The 2006 Johan Skytte Prize Lecture. Scandinavian Political Studies, 30(2), 137-174.

Radcliffe-Brown, A. (1940). On Joking Relationships. Africa: Journal of the International African Institute, 13(3), 195-210.

Ramos, M. (2004). Drawing the lines: The limitations of intercultural ekphrasis. In S. Pink, L. Kurti, \& A. Afonso (Eds.), Working Images: Visual Research and Representation in Ethnography (pp. 147-156). London: Routledge.

Rettberg, J. W. \& Gajjala, R. (2016). Terrorists or cowards: negative portrayals of male Syrian refugees in social media. Feminist Media Studies, 16(1), 178-181. 
Rogers, A., Bear, C., Hunt, M., Mills, S., \& Sandover, R. (2014). Intervention: The Impact Agenda and Human Geography in UK Higher Education. ACME: An International E-Journal for Critical Geographies, 13(1), 1-9.

Rose, G. (2012). Visual Methodologies: An Introduction to Researching with Visual Materials, Third Edition. London: Sage Publications.

Saanich News. (2016). Auction takes wing to find homes for refugees. Retrieved from http://www.saanichnews.com/news/373287751.html

Scoop. (2016). Kate Sheppard Memorial Trust Announces Successful Applicant. Retrieved from http://www.scoop.co.nz/stories/CU1609/S00296/kate-sheppardmemorial-trust-announces-successful-applicant.htm

Searle, W., Prouse, E., L’Ami, E., Gray, A., \& Grunner, A. (2012). New land, new life: long-term settlement of refugees in New Zealand. Main report. Wellington: Ministry of Business, Innovation and Employment.

Sibley, C., \& Liu, J. (2007). New Zealand = bicultural? Implicit and explicit associations between ethnicity and nationhood in the New Zealand context. European Journal of Social Psychology, 37, 1222-1243.

Singham, M. (2006). Multiculturalism in New Zealand - the need for a new paradigm. Aotearoa Ethnic Network Journal, 1(1), 33-37.

Smyth, G., Stewart, E., \& Da Lomba, S. (2010). Introduction: Critical Reflections on Refugee Integration: Lessons from International Perspectives. Journal of Refugee Studies, 23(4), 411-414).

Spoonley, P., Peace, R., Butcher, A., \& O’Neill, D. (2004). The Social and Economic Inclusion of Immigrants in a Socially Cohesive Society: Challenges for New Zealand. The Social Policy, Research and Evaluation Conference 2004, What Works? Retrieved from https://www.msd.govt.nz/documents/...work/.../socialpolicy.../24-pages85-110.doc

Stafford, A. (2010). Photo-texts: contemporary French writing of the photographic image. UK: Liverpool University Press.

Strang, A., \& Ager, A. (2010). Refugee Integration: Emerging Trends and Remaining Agendas. Journal of Refugee Studies, 23(4), 589-607.

Stuff. (2016). Refugee-inspired mural by Wellington masters student bringing community together. Retrieved from 
http://www.stuff.co.nz/entertainment/arts/87204594/refugeeinspired-mural-bywellington-masters-student-bringing-community-together

Sultana, F. (2007). Reflexivity, Positionality, and Participatory Ethics: Negotiating Fieldwork Dilemmas in International Research. ACME: An International E-Journal for Critical Geographies, 6(3), 374-385.

Swe, Y. Y. (2013). Mobility Encounter: The Narratives of Burmese Refugees in Norway. Norsk Geografisk Tidsskrift - Norwegian Journal of Geography, 67(4), 229-238.

Taylor, H. (2013). Refugees, the state and the concept of home. Refugee Survey Quarterly, 32(2), 130-152.

Te Ara. (2016). Story: Ethnic Inequalities. Retrieved from http://www.teara.govt.nz/en/ethnic-inequalities

The Autonomous Geographies Collective. (2010). Beyond Scholar Activism: Making Strategic Interventions Inside and Outside the Neoliberal University. ACME: An International E-Journal for Critical Geographies, 9 (2), 245-275.

The Dominion Post. (2016). Refugee campaign wants Kiwis to get to know the truth behind the stereotypes. Retrieved from http://www.stuff.co.nz/dominionpost/news/78641835/refugee-campaign-wants-kiwis-to-get-to-know-the-truthbehind-the-stereotypes

The Press. (2016). Why we left: Refugees tell the stories of their journeys to New Zealand. Retrieved from http://www.stuff.co.nz/the-press/news/71954641/Whywe-left-Refugees-tell-the-stories-of-their-journeys-to-New-Zealand

The Refugee Art Project. (2016). Memories of Home / Dreams of Escape. Retrieved from http://therefugeeartproject.com/home/memories-of-home/

Thomas, R., Chiarelli-Helminiak, C., Ferraj, B., \& Barrette, K. (2015). Building relationships and facilitating immigrant community integration: An evaluation of a Cultural Navigator Program. Evaluation and Program Planning, 55, 77-84.

Ting-Toomey, S. (2005). Identity negotiation theory: Cross cultural boundaries. In W. B. Gudykunst (Ed.), Theorizing about intercultural communication (pp. 211-233). Thousand Oaks, CA: Sage Publications.

Tolia-Kelly, D. (2008). Motion/Emotion: Picturing Translocal Landscapes in the Nurturing Ecologies Research Project. Mobilities, 3(1), 117-140. 
Trnka, S., Dureau, C., \& Park, J. (2013). Senses and citizenships: Embodying political life. New York: Routledge.

Tsoukala, A. (2016). Turning Immigrants into Security Threats: A Multifaceted Process. In G. Lazaridis (Ed.), Security, Insecurity and Migration in Europe. UK: Routledge.

United Nations. (2017). Social Integration - Social Policy and Development Division. Retrieved from https://www.un.org/development/desa/dspd/social-integrationsocial-policy-and-development-division.html

UNHCR. (1996). Convention and Protocol Relating to the Status of Refugees. Report. Geneva: Author.

UNHCR. (2014). World Refugee Day: Global forced displacement tops 50 million for first time in post-World War II era. Retrieved from http://www.unhcr.org/53a155bc6.html

UNHCR. (2016). UNHCR viewpoint: 'Refugee' or 'migrant' - Which is right? Retrieved from http://www.unhcr.org/news/latest/2016/7/55df0e556/unhcrviewpoint-refugee-migrant-right.html

UNHCR. (2017). Asylum-Seekers. Retrieved from http://www.unhcr.org/asylumseekers.html

Urry, J. (2012). Social Networks, Mobile Lives and Social Inequalities. Journal of Transport Geography, 21, 24-30.

Waitangi Tribunal. (2016). Waitangi Tribunal. Retrieved from http://waitangitribunal.govt.nz/

Waldinger, R. (2016). The Good Life. Retrieved from https://www.youtube.com/watch?v=q-7zAkwAOYg

Walters, W. (2004). 'Secure borders, safe haven, domopolitics'. Citizenship Studies, 8, 237-260.

Warner, D. (1996). Voluntary Repatriation and the Meaning of Return to Home: A Critique of Liberal Mathematics, Journal of Refugee Studies, 7(2/3), 160-174.

Wilson, E. K. (2010). Hospitality: Protecting the Unprotected - Reconceptualising Refugee Protection through the Notion of Hospitality. Local-Global: Identity, Security, Community, 8, 100-122. 
Wilson, H. F. (2016). On Geography and Encounter: Bodies, Borders, and difference. Progress in Human Geography, 1-21.

Wilson, S., \& Milne, E.J. (2012). Young People Creating Belonging: spaces, sounds and sights. Stirling: University of Stirling.

Wilson, S., \& Milne, E.J. (2015). 'Social justice, visual activism: young people creating 'home' across public and domestic spaces'. Current Sociology, 64(1), 140-156.

Wood, B. (2013). Young people's emotional geographies of citizenship participation: Spatial and relational insights. Emotion, Space and Society, 9, 50-58.

Woodrow, N. (2016). The Geography of Welcome: Refugee Storytelling, Cultural Translation and Co-Performing Activism. (PhD Thesis, Queensland University of Technology, Australia). Retrieved from https://eprints.qut.edu.au/98493/

Wynne-Jones, S., North, P., \& Routledge, P. (Eds.). (2015). Practising participatory geographies: potentials, problems and politics [Special Issue]. Area, 47(3)1-4.

Ziv, A. (2009). The Social function of Humor in Interpersonal Relationships. Society, 47(1), 11-18. 


\section{Appendices}

\section{APPENDIX ONE: PILOT PAINTING WORKSHOP}

The pilot painting workshop was developed in 2015 as an independent course of study for my honours degree at Victoria University of Wellington. The aim of this project was to evaluate whether painting was a suitable method of data collection and production for conducting refugee resettlement research. Five refugee-background volunteers from Ethiopia and Eritrea participated in a trial workshop, painting and discussing images of what health and wellbeing meant to them. At the time this theme was chosen to support a wider research project on mobilities, empowerment, and wellbeing for refugeebackground women involved in a local driving programme. Painting was effective in prompting memories, inspiring narratives, depicting experiences that were difficult or traumatic to verbalise, and representing abstract emotions, world views, and ideas. In this manner, painting expanded understanding of complex experiences and provided opportunities for participants to reflect on their experiences and chose how they wanted to represent themselves. Due to these benefits, I decided to build upon this method within my Masters. 


\section{WELCOME TO THE COMMUNITY PAINTING PROJECT:}

\section{Inter-mural Wellington}

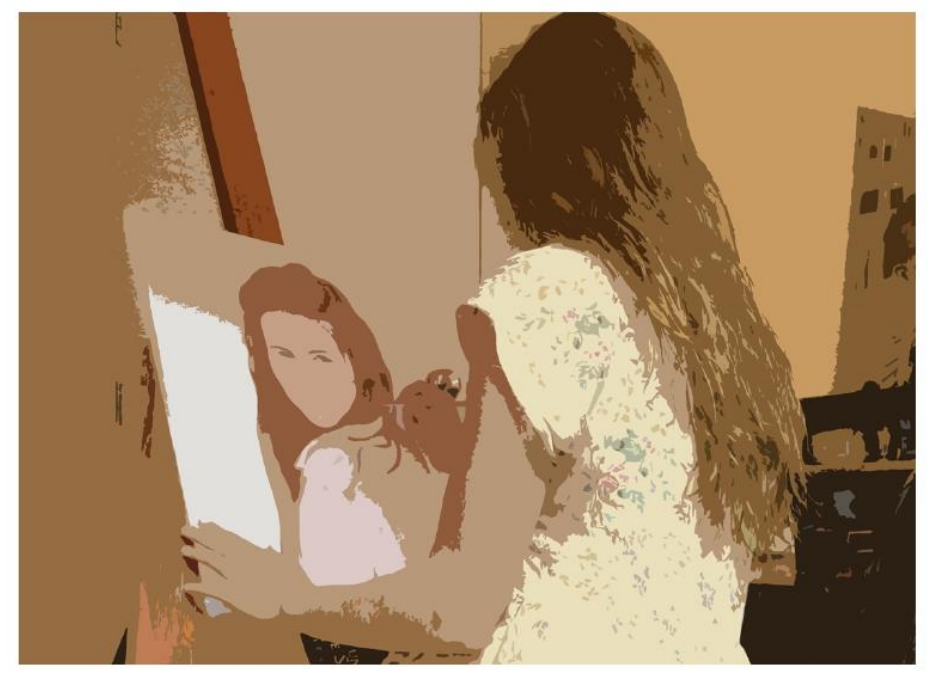

\section{OCTOBER - NOVEMBER 2016}

My name is Amber Kale and I am a Masters student at Victoria University doing research on refugee resettlement.

The aim of my research is to explore how a community painting project can strengthen social connections between former refugees and Wellington host-society members.

I am looking for 5 participants from a refugee background, and 5 participants who are NZ citizens from a non-refugee background. Participation will require approximately twelve hours involvement over two months, attending 2 meetings, 2 face-to-face interviews, 4 painting workshops, and a painting exhibition. Please contact me for further information.

This research has been approved by the Victoria University Ethics Committee.

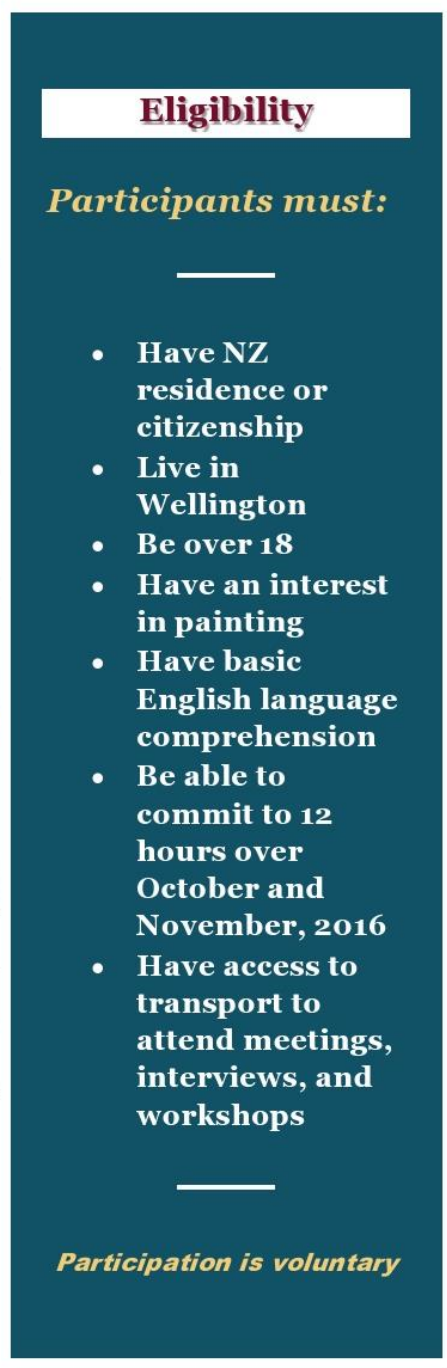

\section{RESEARCHER: AMBER KALE \\ E-mail:}

kaleambe@myvuw.ac.nz

5 


\section{APPENDIX THREE: INFORMATION, CONSENT, AND CONFIDENTIALITY FORMS}

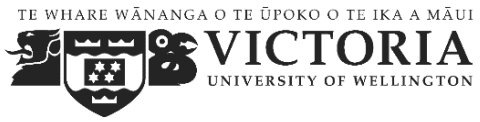

The Art of Social Connection: Exploring Former Refugee and Host Society Integration via a Collaborative, Participatory Painting Project in Wellington City

\section{Participant Information Sheet}

My name is Amber Kale and I am a Masters student at Victoria University, studying refugee integration within the discipline of Human Geography. Welcome to my research project. Please read this information before deciding whether or not to take part. If you decide to participate, thank you. If you decide not to take part, thank you for considering my request.

\section{Research Aim}

Despite being granted permanent residency in New Zealand, many former refugees who have resettled here have reported feeling isolated and being discriminated against. Isolation and discrimination are problematic because they can lead to social inequalities and prevent former refugees from accessing the rights that they are entitled to as New Zealanders. As New Zealand raises its annual refugee quota, there is an increasing need for cooperation and understanding between different cultural groups. Therefore, the aim of this research is to explore how a community painting project can strengthen relationships between former refugees and Wellington host society members, and how exhibiting these paintings can educate the wider Wellington society about refugee integration, and challenge negative refugee stereotypes. This research project has been approved by Victoria University's Human Ethics Committee.

\section{How can you help?}

I invite you to participate in my research via meetings, individual interviews, painting workshops, and a painting exhibition. This will require approximately twelve hours involvement over two months. Your participation is voluntary. Your names will not be 
used and you will not be able to be identified in any publications, unless you specifically request that your real name be used. You may withdraw from the interviews or workshops altogether without having to give reasons. If you decide you would like to withdraw your information, you have up until $1^{\text {st }}$ December 2016 to let me know. Upon your withdrawal, the group artwork will still be exhibited and analysed.

\section{Meetings}

Two group meetings will be held in central Wellington, each lasting approximately one hour. These meetings are to ensure that participants have an opportunity to contribute to the research process and raise any concerns or ideas they may have. The first meeting will be prior to the research and will involve discussing and signing confidentiality forms. This meeting will not be recorded. The second meeting will be after the exhibition to gather feedback and discuss research dissemination and the future of the group artwork. This meeting will be recorded unless the group requests that the taperecorder be turned off.

\section{Individual Interviews}

There will be two individual interviews. Each interview will be approximately half an hour long. We will agree on an appropriate place to meet. Questions will be asked regarding your experiences of home, belonging, and visibility within public space, as well as your understanding and views of refugee integration processes in New Zealand. With your permission, your responses will be audio-recorded and written up at a later date. If at any point you do not want to answer a question that is fine. You may also request that the tape-recorder be turned off.

\section{Group Painting Workshops}

There will be four painting workshops with ten participants. Each workshop will be approximately two hours long and take place in central Wellington. You will have the opportunity to discuss your experiences of home, belonging, and visibility within public space with the group, and to paint these experiences to share them with the wider Wellington community. With the groups' permission, discussions will be audiorecorded and written up at a later date. The group may also request that the tape-recorder be turned off. 


\section{Exhibition}

The exhibition will take place in central Wellington. It will remain set up for the public to view for several days. You will be invited to attend a small opening ceremony and if you wish to identify yourself as one of the artists you may be introduced or have the opportunity to speak to the public. You are under no obligation to attend, or to speak, if you wish your identity to remain confidential.

\section{What will happen to the information you give?}

A copy of the interview and workshop discussion notes will be returned to you, and you will be involved in deciding what to do with the group artwork. I will store a copy of your information and a copy of the artwork electronically and securely for five years under the University guidelines. This storage is so that I can produce my Master's thesis, papers for academic conferences, and publications for academic journals and the media. All information will be deleted at the end of five years.

Should you have any questions about the project, please do not hesitate to contact me.

\section{Contact Details:}

Researcher:

Name: Amber Kale

Email: kaleambe@myvuw.ac.nz

\section{Supervisor:}

Name: Sara Kindon

Email: $\underline{\text { Sara.kindon@ vuw.ac.nz }}$

Address: School of Geography Environment and Earth Sciences

Cotton Building, Kelburn Parade

Victoria University of Wellington

PO Box 600, Wellington

Human Ethics Committee information: If you have any concerns about the ethical conduct of the research you may contact the Victoria University HEC Convener: Associate Professor Susan Corbett. Email susan.corbett@vuw.ac.nz or telephone +644-463 5480. 


\begin{abstract}
IE WHARE WÃNANGA TE UPOKG O TE IKA MALUI
The Art of Social Connection: Exploring Former Refugee and Host Society

Integration via a Collaborative, Participatory Painting Project in Wellington City
\end{abstract}

\title{
Participant Consent to Participate
}

I have had the opportunity to consider all the information presented to me in the information sheet and to have any questions answered to my satisfaction.

I understand that my participation is completely voluntary and that I may withdraw my participation at any time up to December $1^{\text {st }} 2016$. I may not withdraw after this date.

I give my consent to take part in the interviews and workshops and for the information and images I share to be publically exhibited and published. Specifically:

- I agree to answer interview questions, participate in group meetings and discussions, and contribute to a group artwork regarding my experiences of refugee integration, home, belonging and visibility within public space.

- I agree to the meetings, interviews, and workshop discussions being recorded, either by tape recorder or handwritten notes, to be written up later.

- I understand that a copy of the interview and workshop discussion notes will be returned to me, and that the researchers copy will be kept for five years to inform future publications arising from the research (listed below). Besides myself and the researcher, no-one else will have access to my interview without my permission.

- I agree that the group artwork can be exhibited and that after the exhibition I will have a say in how the artwork is to be used in the future.

- I agree that the information shared, and copies of the artwork, can be used for a Masters' thesis submitted to Victoria University, for conference papers, and for publication in academic journals and the media. 
This consent is given on the understanding that all information will be confidential and will not be able to be traced back to an individual source, unless I specifically request that my real identity be used.

\section{Real Name:}

(First name)

(Last name)

Do you want your REAL name to be used in the published research? Please circle yes, no, or first name only:

\section{YES / NO / First Name Only}

Do you want to be identified at the exhibition? Please circle yes or no:

\section{YES / NO}

If you don't want your real name to be used, what name would you like me to use instead? Only a first name is required:

\section{E-mail:}

(If you do not have e-mail access please write your address so a hardcopy of the interview notes can be sent)

Address:

\section{Signature}

Date

1




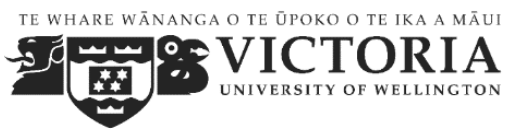

The Art of Social Connection: Exploring Former Refugee and Host Society Integration via a Collaborative, Participatory Painting Project in Wellington City

\section{Group Confidentiality Agreement}

I have read the Participant Information Sheet and understand the nature of this research and its requirements for confidentiality.

I agree to maintain full confidentiality in regards to the workshops that I participate in. Thus, I agree to hold in strictest confidence the identification of any individual that may be revealed during the research.

Name:

Signature:

Date: 


\section{APPENDIX FOUR: PRE-WORKSHOP INTERVIEW QUESTIONS}

\section{Demographics}

1. Where were you born?

2. For how many generations has your family lived in your birth country?

3. Where else have you lived?

4. Where do you consider to be 'home'?

5. Do you have New Zealand residency or citizenship?

6. How long have you lived in Wellington?

7. Do you have family living in Wellington?

8. What is your marital status?

9. Do you have children?

10. What is your ethnicity?

11. What is your gender?

12. How old are you?

13. What qualifications or skills do you have?

14. Do you work, volunteer, or belong to any other social groups?

\section{Former refugee participants}

1. What does the term 'refugee' mean to you?

2. Do you think of yourself as a 'refugee'?

3. Why did you move to New Zealand?

4. Tell me about your experience resettling in New Zealand ...

5. How do you think New Zealanders treat former refugees?

6. Do you spend much time with New Zealanders living in Wellington?

7. Do you think it would be beneficial for New Zealanders to learn more about what it means to be a refugee? Why / why not?

8. What does 'home' mean to you?

9. Do you think that there are certain groups of people who have a greater claim to 'belonging' in New Zealand than others? Why / why not? 
10. Do you have a sense of 'belonging' in Wellington or in other places? Describe this sense of belonging.

11. Who do you think is represented in Wellington's identity and city structures? Why do you think this? Who is underrepresented or excluded?

\section{Host society participants}

1. What does the term 'refugee' mean to you?

2. Why do you think refugees come to New Zealand?

3. What do you know about the refugee resettlement process in New Zealand?

4. How do you think New Zealanders treat former refugees?

5. What, or who, has influenced your views about refugee resettlement?

6. Do you spend much time with former refugees living in Wellington?

7. Do you think it would be beneficial for New Zealanders to learn more about what it means to be a refugee? Why / why not?

8. What does 'home' mean to you?

9. Do you think that there are certain groups of people who have a greater claim to 'belonging' in New Zealand than others? Why / why not?

10. Do you have a sense of 'belonging' in Wellington or in other places? Describe this sense of belonging.

11. Who do you think is represented in Wellington's identity and city structures? Why do you think this? Who is underrepresented or excluded? 


\section{APPENDIX FIVE: WORKSHOP DISCUSSION QUESTIONS}

\section{Former refugee and host society participants}

1. What does 'home' mean to you?

2. What makes you feel 'at home' in Wellington?

3. How could Wellington feel more homely?

4. What does 'belonging' mean to you?

5. Describe a place where you feel like you belong.

6. What could change to help you feel like you 'belong' in Wellington?

7. Do you feel like your identity and values are represented in Wellington's collective identity and city structrues and facilities?

8. How would you like to be represented and percieved in Wellington? How might we achieve this? 


\section{APPENDIX SIX: POST-WORKSHOP INTERVIEW QUESTIONS}

\section{Former refugee participants}

1. How has your understanding of 'home' changed?

2. How has your understanding of 'belonging' in Wellington changed?

3. How has your understanding of 'visibility' in Wellington changed?

4. Is painting a suitable method for sharing your experiences with other people?

5. What worked well with painting?

6. What was challenging about painting?

7. What changes would you make to the painting workshops?

8. Is there anything else you want to say about the workshops?

9. Do you have any comments about the interviews, meetings, or exhibition?

10. Do you feel like you had the opportunity to share your ideas in this research?

\section{Host society participants}

1. From the painting process, what have you learnt about what it means to be a 'refugee'?

2. What have you learnt about refugee resettlement in New Zealand?

3. Do you think it has been beneficial for you to learn more about what it means to be a refugee? Why / why not?

4. How has your understanding of 'home' changed?

5. How has your understanding of 'belonging' in Wellington changed?

6. How has your understanding of 'visibility' in Wellington changed?

7. Is painting a suitable method for sharing your experiences with other people?

8. What worked well with painting?

9. What was challenging about painting?

10. What changes would you make to the painting workshops?

11. Is there anything else you want to say about the workshops?

12. Do you have any comments about the interviews, meetings, or exhibition?

13. Do you feel like you had the opportunity to share your ideas in this research? 


\section{MURAL

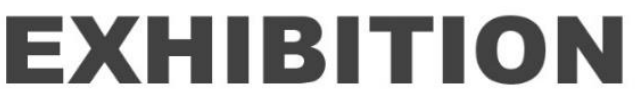

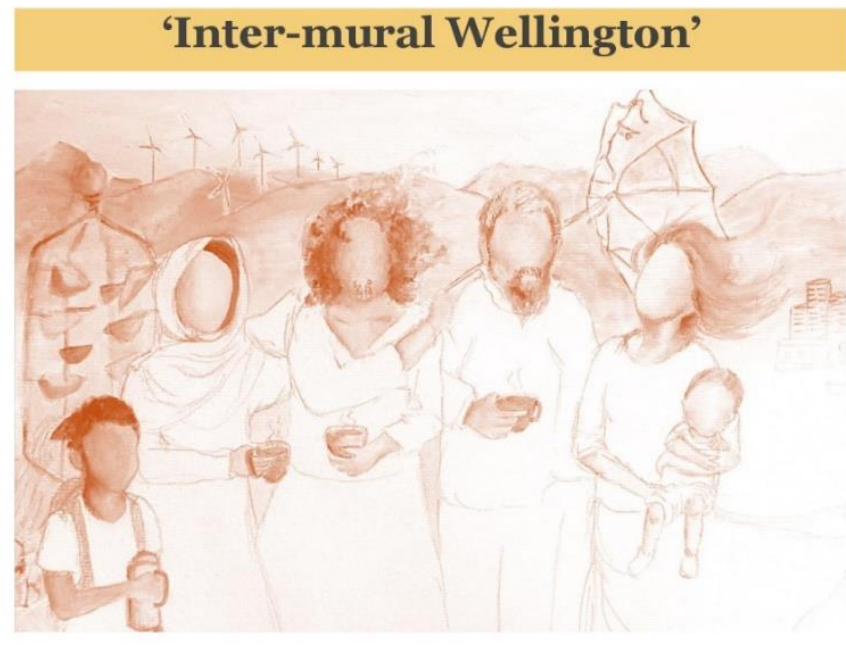

\section{Opening presentation 3rd December 2016, 4-6pm}

This exhibition showcases a collaborative mural on canvas, painted by Wellington residents from diverse refugee and non-refugee backgrounds. The mural explores ideas of home, belonging, and public visibility, highlighting multiculturalism in Wellington. It is part of a wider research project which focuses on building crosscultural connections between former refugees and resettlement societies, and enhancing social justice for refugee background New Zealanders. The opening presentation is free to the public, and the mural will be on display at the Preservatorium Café until the $12^{\text {th }}$ December.

\section{E9}

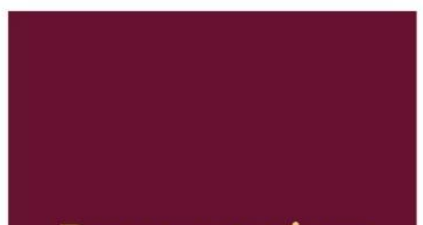

\section{Preservatorium Cafe \& Cannery 39 Webb Street}

The mural will be on display instore from the $3^{\text {rd }}-12^{\text {th }}$ December

The opening presentation is free to the public, or you can come in to view the mural and leave comments throughout the week

For more information on this research e-mail Amber :

kaleambe@myvuw.ac.nz 


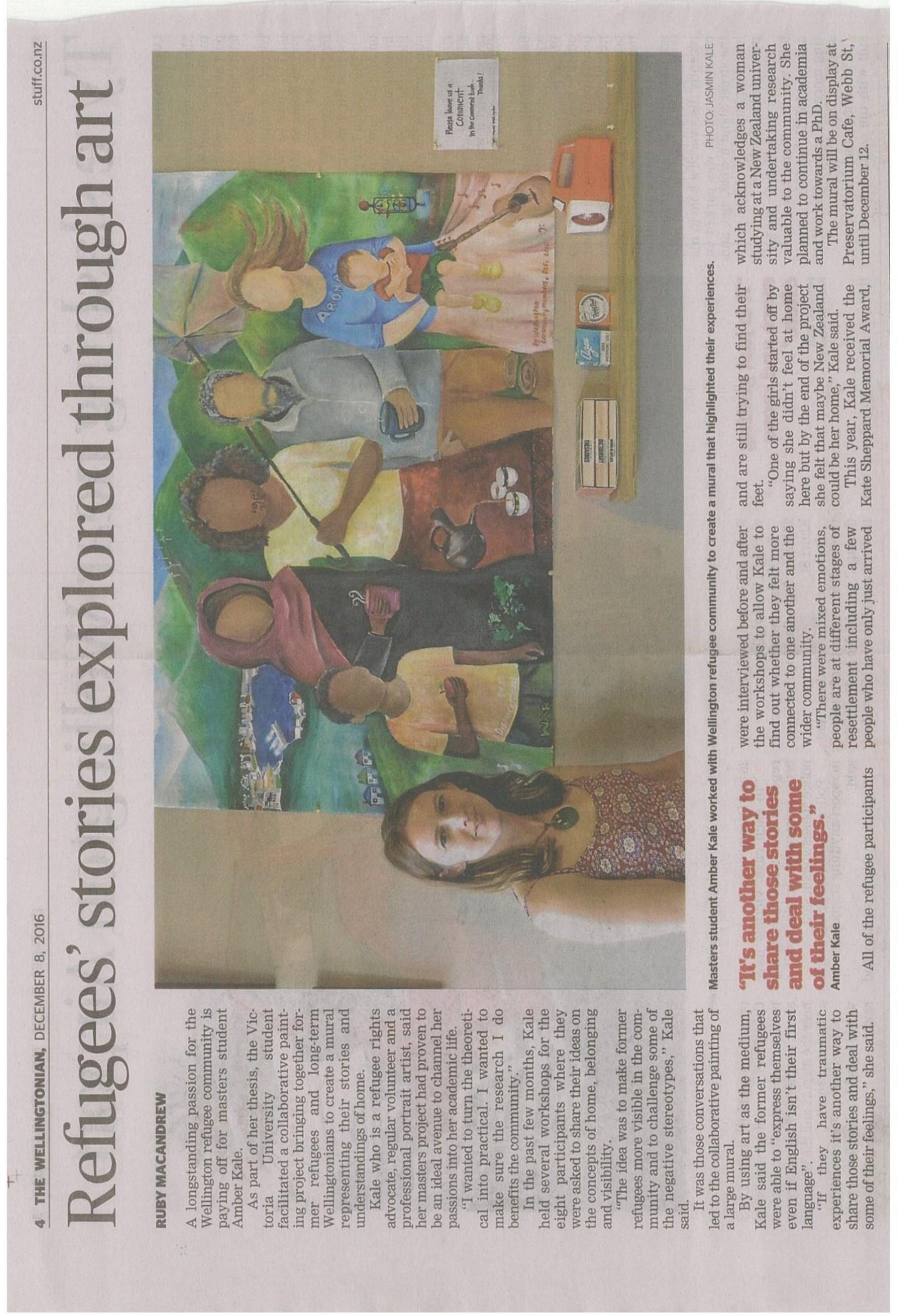

